Portland State University

PDXScholar

11-8-1996

\title{
Effects of the Cardioprotective Drugs Dexrazoxane and ADR-925 on Doxorubicin Induced Ca2+ Release from the Sarcoplasmic Reticulum
}

Thomas Andreas Herzinger

Portland State University

Follow this and additional works at: https://pdxscholar.library.pdx.edu/open_access_etds

Part of the Physics Commons

Let us know how access to this document benefits you.

\section{Recommended Citation}

Herzinger, Thomas Andreas, "Effects of the Cardioprotective Drugs Dexrazoxane and ADR-925 on Doxorubicin Induced Ca2+ Release from the Sarcoplasmic Reticulum" (1996). Dissertations and Theses. Paper 5069.

https://doi.org/10.15760/etd.6945

This Thesis is brought to you for free and open access. It has been accepted for inclusion in Dissertations and Theses by an authorized administrator of PDXScholar. Please contact us if we can make this document more accessible: pdxscholar@pdx.edu. 


\section{Thesis Approval}

The abstract and thesis of Thomas Andreas Herzinger for the Master of Science in Physics were presented November 8, 1996, and accepted by the thesis committee and the department.

Committee Approvals:

Jionathan J. Abrámson, Chair
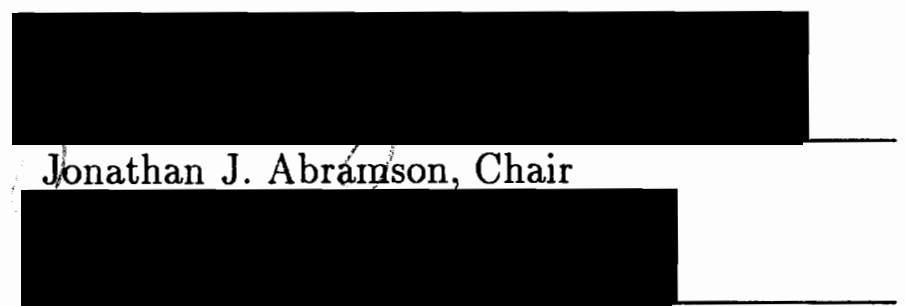

Terry G. Favero

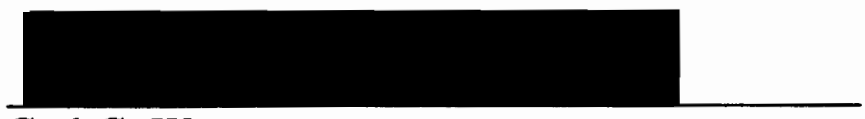

Carl C. Wamser

Representative of the Office of Graduate Studies

Department ApProval:

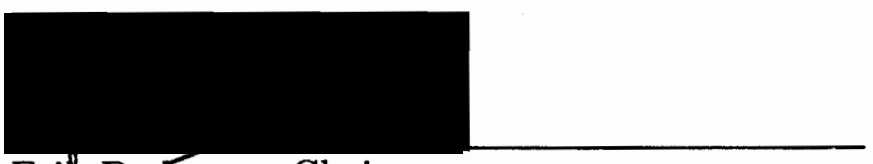

Erik Bodegom, Chair

Department of Physics

$* * * * * * * * * * * * * * * * * * * * * * * * * * * * * * * * * * * * * * * * * * * * * * * * * * * * * * * * * * * * * * * * * *$

ACCepted for Portland State University by the LibraRy

by

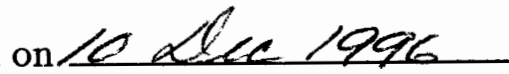




\begin{abstract}
The abstract of the thesis of Thomas Andreas Herzinger for the Master of Science in Physics presented November 8, 1996.

Title: Effects of the Cardioprotective Drugs Dexrazoxane and ADR-925 on Doxorubicin Induced $\mathrm{Ca}^{2+}$-Release from the Sarcoplasmic Reticulum
\end{abstract}

The sarcoplasmic reticulum is the intramuscular organelle responsible for the regulation of cytoplasmic calcium levels in muscle. This thesis investigates the effects of the cardioprotective drug, dexrazoxane, and its metabolite ADR-925 on doxorubicin induced calcium release from skeletal sarcoplasmic reticulum. Doxorubicin is a widely used antineoplastic agent. One of the major side effects of doxorubicin usage is chronic cardiotoxicity. Doxorubicin is a potent activator of the calcium release mechanism from the SR. The interaction between doxorubicin and the calcium release channel has been proposed as the possible underlying mechanism behind cardiotoxicity. A short overview of different hypotheses describing doxorubicin induced cardiotoxicity and proposed mechanisms of cardioprotection by dexrazoxane are presented. While dexrazoxane did not appear to affect the calcium permeability of the SR, its metabolite, ADR-925, modulates the ryanodine 
receptor complex. ADR-925 inhibits high affinity ryanodine binding to the ryanodine receptor/calcium release channel complex by decreasing the sensitivity of the receptor for stimulation by calcium. ADR-925's ability to inhibit doxorubicin stimulated ryanodine binding is independent of the doxorubicin concentration. These results demonstrate that ADR-925 directly affects the ryanodine receptor complex of the SR by desensitizing the receptor to activation by calcium. Furthermore, ADR-925 reduces the inhibitory effect of hydrogen peroxide on the ryanodine receptor/calcium release channel. This suggests that ADR-925 may protect the SR from oxidative effects of free radicals. It has been somewhat controversial whether doxorubicin induced cardiotoxicity is due to a specific interaction with the calcium release mechanism of SR. The findings presented in this thesis which demonstrate that the cardioprotectant ADR-925 interacts directly with the ryanodine receptor from SR, further support the hypothesis that the ryanodine receptor is a primary target of doxorubicin's action. 


\title{
EFFECTS OF THE CARDIOPROTECTIVE DRUGS DEXRAZOXANE AND ADR-925 ON DOXORUBICIN INDUCED $\mathrm{Ca}^{2+}$-RELEASE FROM THE SARCOPLASMIC RETICULUM
}

\author{
By \\ THOMAS ANDREAS HERZINGER \\ A thesis submitted in partial fulfillment of the \\ requirements for the degree of
}

MASTER OF SCIENCE

in

PHYSICS

Portland State University

1996 


\section{Acknowledgments}

First and foremost I would like to thank my advisor Jon Abramson. He provided outstanding effort and patience in introducing me to the physics of membranes and channels, and great guidance throughout the project. I strongly appreciate his help in overcoming the obstacles of English as a foreign language. In this matter I am also grateful to $D r$. Tony Zable and his wife for their incredible help during the final write-up of this thesis and the fruitful discussions throughout the 15 months that helped me understand many of the mysteries of biophysics and -chemistry. I am indebted to the entire "Abramson Lab," Shawn, Lisa, and all the others that created an unforgettable working atmosphere. I enjoyed the time in the computer lab, working with great people like Armin, Sven, Tony, Lynn, Shawn and all the others who provided so much help with the bits and pieces, and were always there for laughs and plenty of distraction. I also want to thank Erik Bodegom and the Physics Department for the encouraging help and unbureaucratical way of solving administrative problems. I am grateful for the financial support from 
the Oregon-Baden-Württemberg exchange program and the Universität Ulm. I especially want to thank my family, and all my friends for their support, love, and friendship. Without them I would not have been able to be at Portland State and would have missed this extraordinary experience. I have spend a wonderful time here in Portland. Thank you! 


\section{Contents}

$\begin{array}{lll}\text { Acknowledgments } & \text { ii }\end{array}$

1 The $\mathrm{Ca}^{2+}$ Release Channel 1

1.1 Introduction $\ldots \ldots \ldots \ldots \ldots \ldots \ldots \ldots \ldots \ldots$

1.2 Muscle . . . . . . . . . . . . . . . . 2

1.3 Overview: Ion Channels $\ldots \ldots \ldots \ldots \ldots$

1.4 T-Tubule . . . . . . . . . . . . . . . . 13

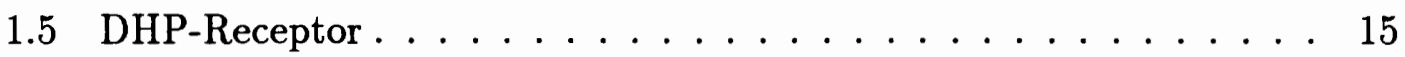

1.6 Sarcoplasmic Reticulum . . . . . . . . . . . . . 17

1.7 Ryanodine Receptor $\ldots \ldots \ldots \ldots \ldots \ldots \ldots$

1.8 EC Coupling $\ldots \ldots \ldots \ldots \ldots \ldots \ldots \ldots \ldots \ldots \ldots$

1.8.1 Mechanical Coupling . . . . . . . . . . . . 26

1.8.2 Electrical Coupling . . . . . . . . . . . . 27

1.8.3 Chemical Coupling $\ldots \ldots \ldots \ldots \ldots$ 
1.9 Mechanisms of $\mathrm{Ca}^{2+}$ Release from Sarcoplasmic Reticulum . . . . . 33

1.9.1 Modulators of the SR $\mathrm{Ca}^{2+}$ Release Channel . . . . . . 33

2 Doxorubicin, Dexrazoxane and ADR-925 37

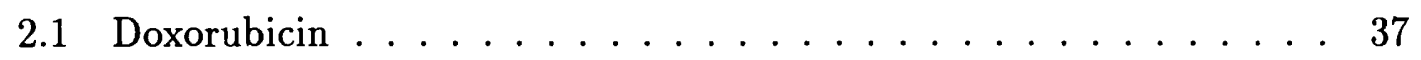

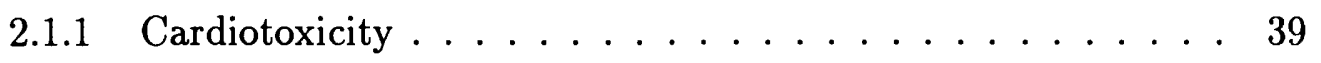

2.2 Effects on the Sarcoplasmic Reticulum . . . . . . . . . . . . 49

2.2.1 Effects on Skeletal Muscle SR ............. 49

2.2.2 Effects on Cardiac Muscle SR ............ 51

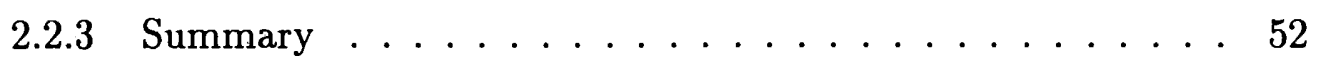

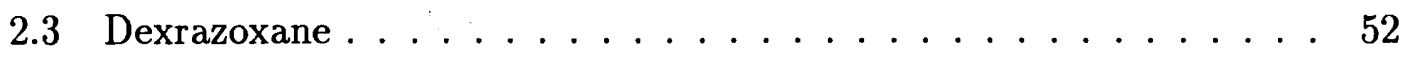

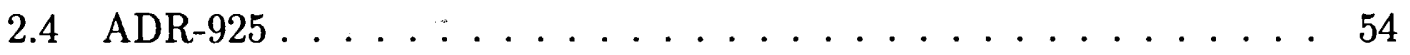

2.5 Proposed Mechanisms of Cardioprotection . . . . . . . . . . 55

2.5.1 Cardioprotection by Ion Chelation ......... 57

2.5.2 Cardioprotection by Increased Glutathione Levels . . . . . . 58

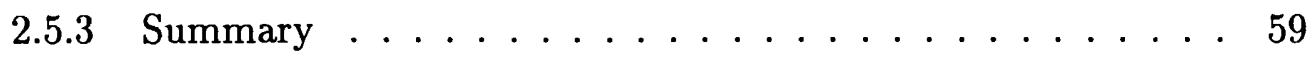

2.6 Medical Application as a Cardioprotective . . . . . . . . . . 59

3 Materials and Methods $\quad 61$

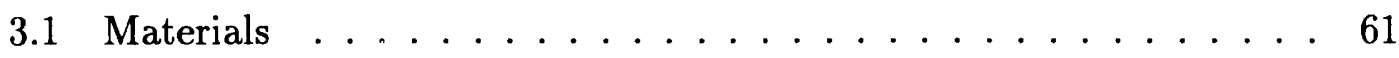

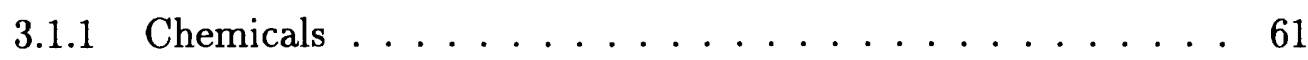


3.1.2 SR-Preparation .................... 62

3.2 Methods ...................... 63

3.2.1 Determination of Free Calcium Concentration . . . . . . . 63

3.2.2 Ryanodine Binding Assays . . . . . . . . . . . . . 64

3.2.3 $\mathrm{Ca}^{2+}$ selective Potentiometry ............ 69

4 Results $\quad \mathbf{7 4}$

$4.1 \mathrm{Ca}^{2+}$ Efflux Assays ..................... 74

4.1.1 Effects of Dexrazoxane on Doxorubicin Induced $\mathrm{Ca}^{2+}$ Release 74

4.1.2 Limitations of Transport Assays in Experiments Involving Strong $\mathrm{Ca}^{2+}$ Chelators ............. 77

4.2 Effects of ADR-925 and Dexrazoxane on Ryanodine Binding . . . . 78

4.3 Doxorubicin Dependence of Ryanodine Binding: Effect of ADR-925 79

4.4 Effect of ADR-925 on the Calcium Activation of Ryanodine Binding 81

4.5 Ryanodine Association Experiments . . . . . . . . . . . 87

4.6 Effects of ADR-925 on the $\left[\mathrm{H}_{2} \mathrm{O}_{2}\right]$ Dependence of Ryanodine Binding 90 


\section{List of Tables}

1 Modulators of the $\mathrm{Ca}^{2+}$ release channel of the SR . . . . . . 36

2 Formation constants for EGTA and ADR-925 at $37^{\circ} \mathrm{C} \ldots \ldots 56$

3 Hill parameters for $\mathrm{Ca}^{2+}$ activation assay in the presence of $1 \mathrm{mM}$ $\mathrm{Mg}^{2+} \ldots \ldots \ldots \ldots \ldots \ldots \ldots \ldots \ldots \ldots$ 


\section{List of Figures}

1 Anatomy of human skeletal muscle $\ldots \ldots \ldots \ldots$

2 Schematic drawing of a muscle fiber . . . . . . . . . . 4

3 Micrograph and corresponding schematic diagram of a longitudinal section of a striated muscle from the leg of a frog $\ldots \ldots \ldots 6$

4 Schematic representation of the structure of the DHP receptor . . . 16

5 Computer generated image of the junctional channel complex . . . . 24

6 Model of the $\mathrm{Ca}^{2+}$ release protein gated by SH oxidation and reduction of three endogenous $\mathrm{SH}$ groups $\ldots \ldots \ldots \ldots$. . . . . 30

7 Structure of the antitumor anthraquinones . . . . . . . 38

8 Proposed free radical hypothesis for doxorubicin-induced myocardial

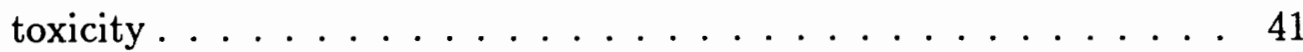

9 Enzymatic reactions in which reduction of doxorubicin leads to the formation of oxygen free radicals $\ldots \ldots \ldots \ldots \ldots 4$

10 Nonenzymatic mechanism for free radical generation by doxorubicin 43 
11 Illustration suggesting that doxorubicin, by oxidizing sulfhydryl groups on calcium release channels of sarcoplasmic reticulum, promotes release of calcium into the cytoplasm . . . . . . . . . . 44

12 Doxorubicin dependence of Ryanodine Binding and $\mathrm{Ca}^{2+}$ dependence of Ryanodine Binding. . . . . . . . . . . . . . . . 50

13 Structures of dexrazoxane (ICRF-187), its one-ring open hydrolysis intermediates, and its two-ring open strongly metal ion binding product ADR-925 ....................... 54

14 Sample recorder reading of $\mathrm{Ca}^{2+}$ efflux assay . . . . . . . . 73

15 Doxorubicin induced $\mathrm{Ca}^{2+}$ efflux rate as a function of dexrazoxane

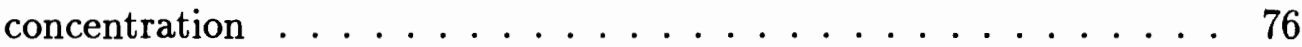

16 Effect of ADR-925 and dexrazoxane on ryanodine binding . . . 80

17 Effects of $300 \mu \mathrm{M}$ ADR-925 on the doxorubicin dependence of ryanodine binding ..................... 82

18 Effects of doxorubicin and ADR-925 on $\mathrm{Ca}^{2+}$ activation of ryanodine

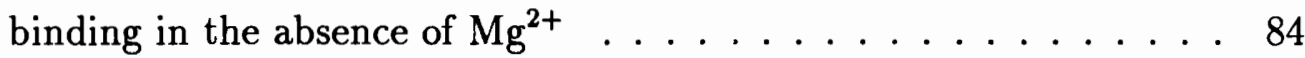

19 Effects of doxorubicin and ADR-925 on $\mathrm{Ca}^{2+}$ activation of ryanodine binding in the presence of $1 \mathrm{mM} \mathrm{Mg}^{2+} \ldots \ldots . \ldots 66$

20 Double reciprocal analysis of ryanodine binding assay carried out in

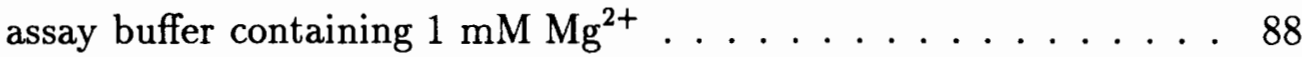


21 Time dependence of ryanodine binding . . . . . . . . . . 89

22 The effect of ADR-925 on the peroxide dependence of ryanodine

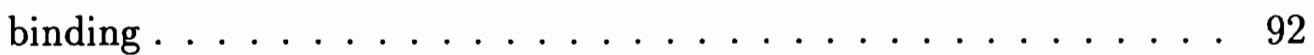

23 Example of the effect of different rate constant in a first order ligand receptor interaction ................ 96

24 WORSE Flowchart ..................... 101

25 Flowchart of the algorithm used to determine the concentration of free metals and ligands ................. . . 102

26 Flowchart of the algorithm that calculates the total concentration needed to yield a desired free concentration for one of the substances 104

27 WORSE main screen .................... 105

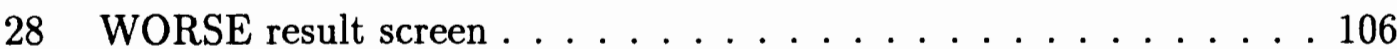




\section{Chapter 1}

\section{The $\mathrm{Ca}^{2+}$ Release Channel}

\section{$1.1 \quad$ Introduction}

"The muscle is the instrument of voluntary motion" is the introductory sentence of the description of human muscles by the surgeon Ambroise Paré in the 16th century. The topic of how this "initial will" (i.e., an electrical signal), is translated into the final mechanical action, the shortening of the muscle, still is not completely understood. The process is referred to as "EC Coupling." It is the subject of many recent research projects. 


\subsection{Muscle}

There are three different types of muscles. Skeletal muscle is connected to the skeletal system and is responsible for its movement. Cardiac muscle, the muscle of the heart, is mainly characterized by a slower response time to the electrical stimulation and a broader response to hormonal effectors. The third type of muscle is called smooth muscle. It is defined by smaller fibers and a poorly defined sarcoplasmic reticulum. The response time of smooth muscle is slower than either skeletal or cardiac muscle. In spite of some obvious differences in many respects, the mechanism involved in smooth muscle contraction is similar to skeletal and cardiac muscle. The following descriptions and the entire thesis will focus strictly on skeletal muscle.

Figure 1 shows the anatomy of human skeletal muscle starting with the entire muscle, going down to the molecular level.

Each muscle contains bundles of fibers a few millimeters in diameter. Each of these fascicles are composed of 20 to 40 muscle fibers or myofibers (C). A detailed drawing of a muscle fiber is shown in figure 2. Each myofiber is enclosed by a plasma membrane, the sarcolemma (S). The myofiber, or muscle cell is multinucleated. It has up to 100 nuclei. 


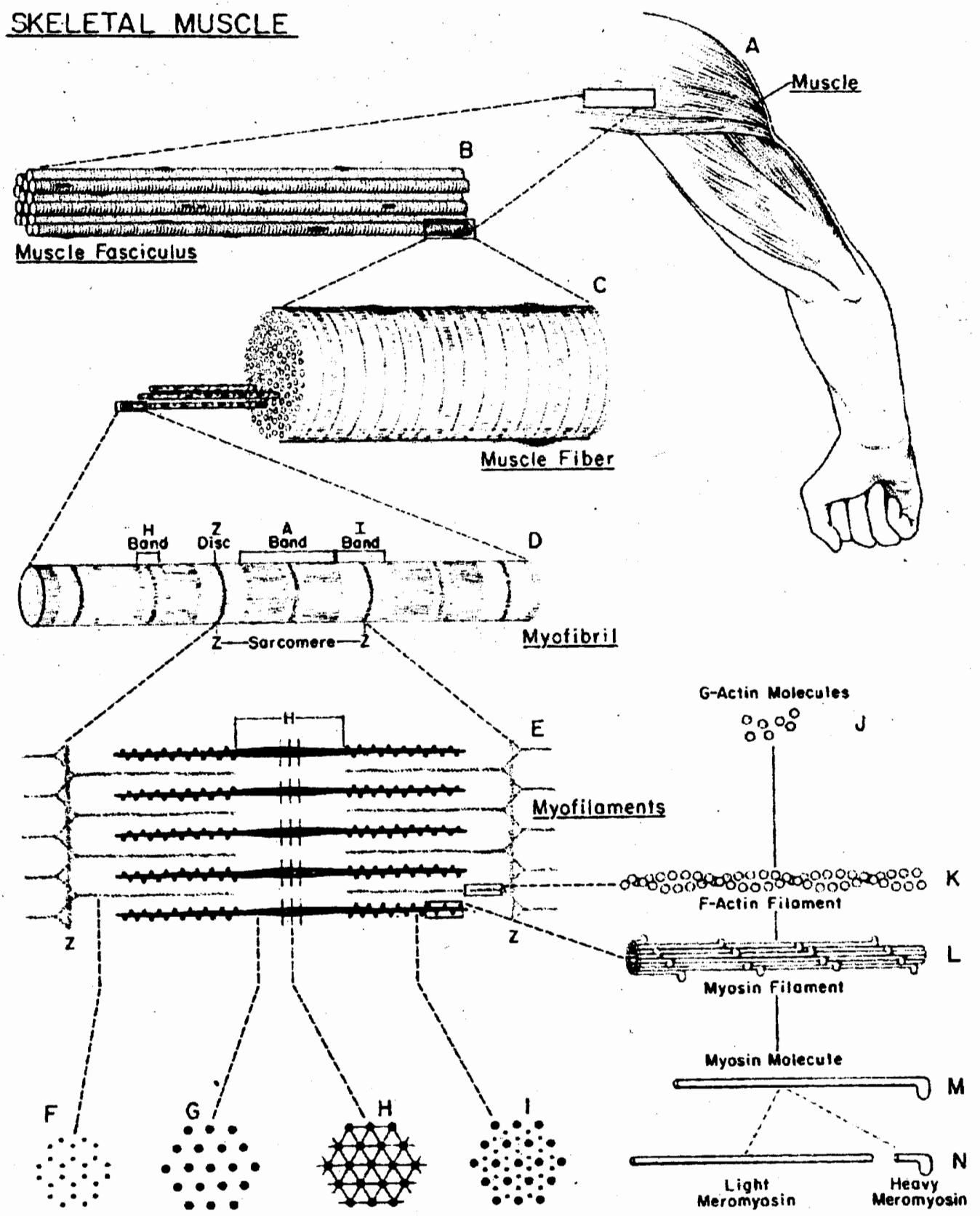

Figure 1: Anatomy of human skeletal muscle. A more detailed view of the muscle fiber $(\mathrm{C})$ is shown in figure 2. From Bloom and Fawcett [95]. 


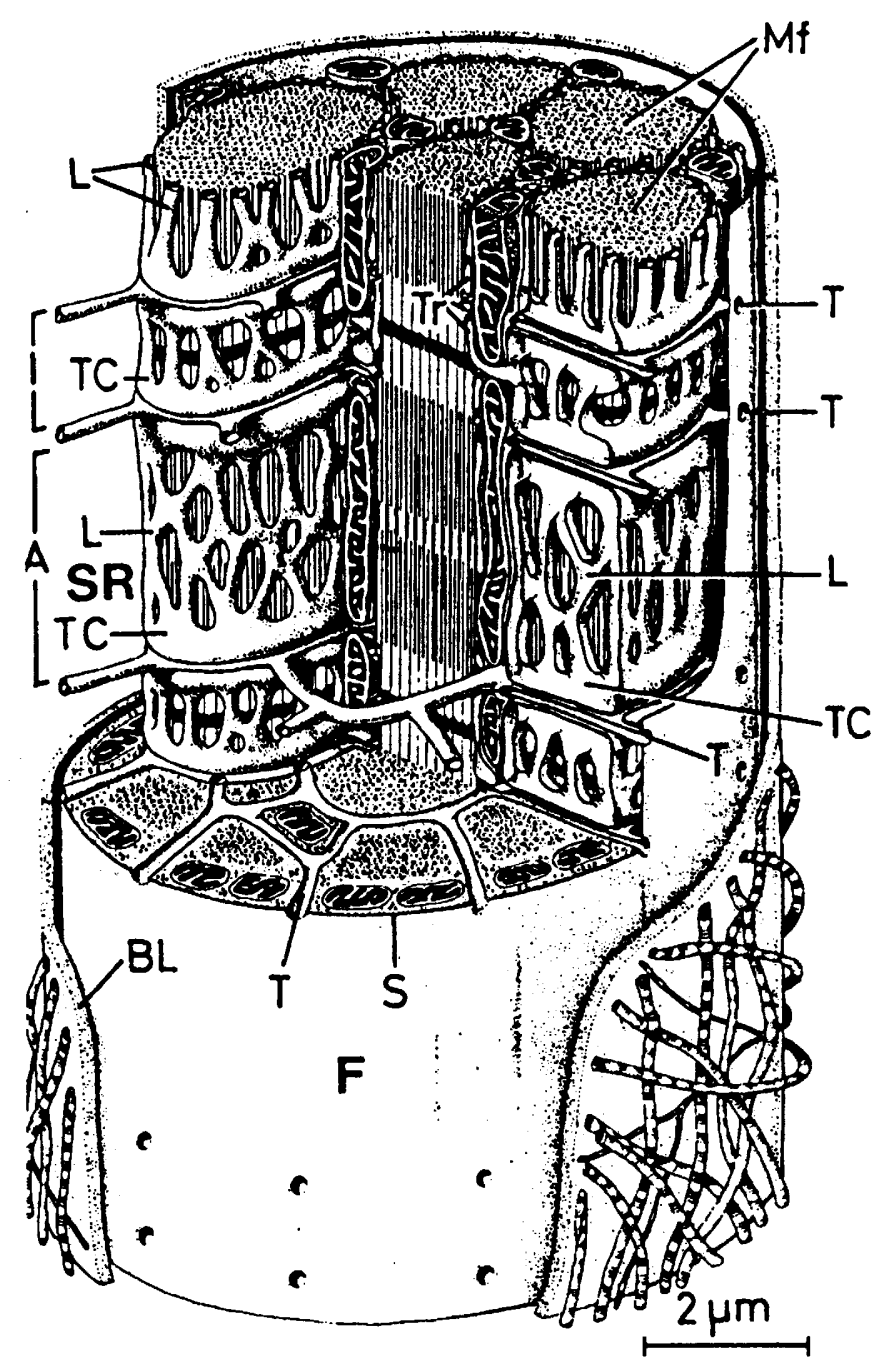

Figure 2: Schematic drawing of a muscle fiber. Mf...myofibril, $L$... longitudinal SR, $T C .$. terminal cisternae or longitudinal SR, $T$...transverse tubule (T-tubule). (From [59]) 
These cells contain individually striated myofibrils, each about $1 \mu \mathrm{m}$ in diameter (figure 1D). The myofibrils are the actual contractile mechanism. H. E. Huxley showed in 1958 that during contraction two kinds of filament, thick filaments and thin filaments, slide past each other so as to produce changes in the length of the muscle[45]. In the following years, after advances in electron microscopy, he and others were able to determine more details about the mechanism by which muscle contracts. In 1965, Huxley was able to determine the composition of the two filaments. The thick filament is composed mainly of the protein myosin, while the thin filament is primarily the protein actin [46]. A micrograph is shown in figure 3. The picture shows sharply defined bands. The bands are named after their optical properties and have specific functions. The thin actin filament traverses the Z-discs (I-band $\left.{ }^{1}\right)$. The $\mathrm{A}$ band ${ }^{1}$ contains both actin and myosin. The length of the $\mathrm{H}$ region and the $\mathrm{I}$ band change during contraction. In a relaxed muscle the distance between $\mathrm{Z}$ lines (one sarcomere) is such that about half of the length of a thin filament and two-thirds of the length of an adjacent thick filament overlap. In the region of overlap in a relaxed fiber the array contains twice as many thin filaments as thick ones (see figure 1I) [46].

In 1954 Huxley and Hanson proposed their "sliding filament model" [47]. According to this model the actin filaments are partly withdrawn from the A-band,

\footnotetext{
${ }^{1} I$ because they are isotropic to polarized light and appear light in electron micrographs. $A$ because it is anisotropic
} 


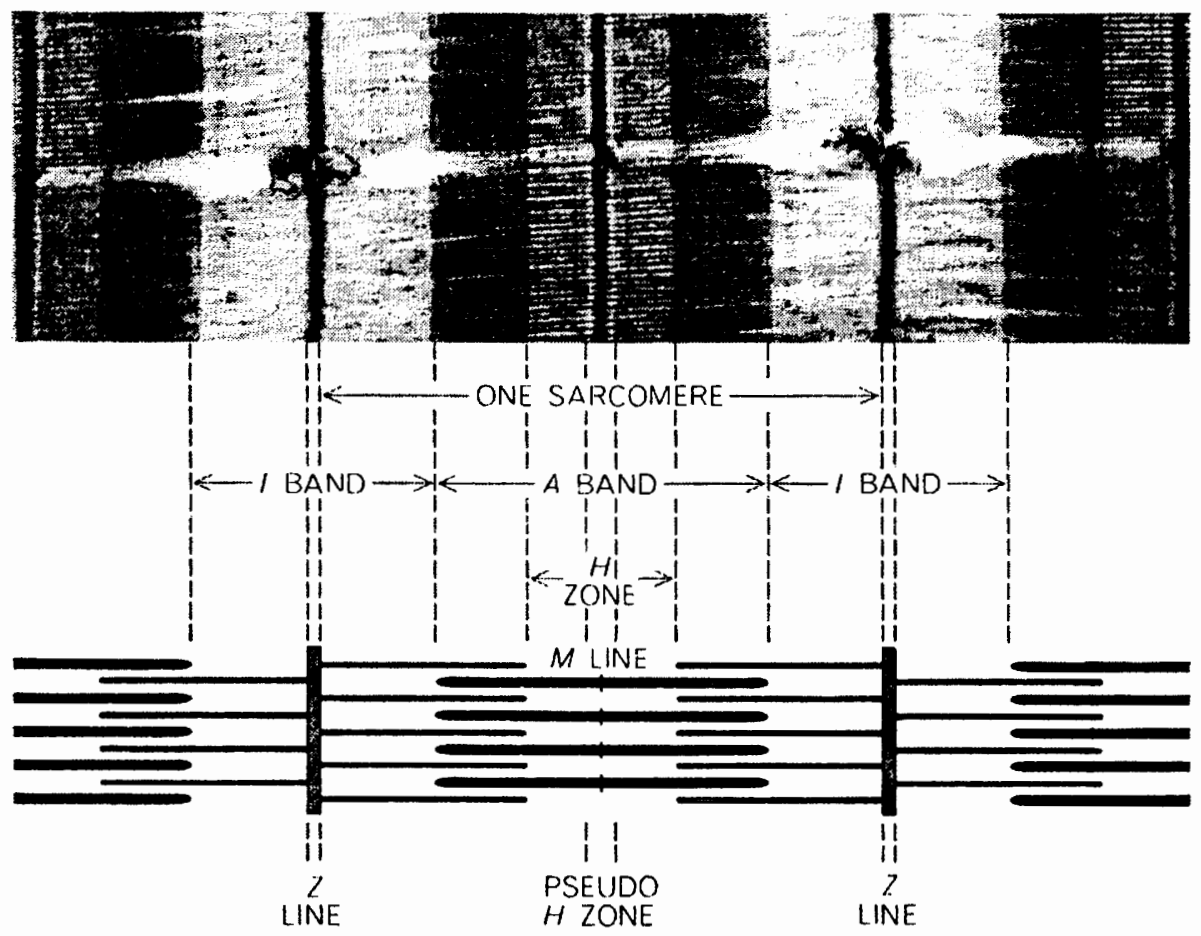

Figure 3: Micrograph and corresponding schematic diagram of a longitudinal section of a striated muscle from the leg of a frog. Enlargement: about 23,000. Reproduced from [46]. 
leaving an observed long lighter central region and stretching the S-filaments in the process. Electron micrographs show cross-bridges between the two filaments in regular intervals. These bridges are extensions of the myosin filaments and are called myosin heads. It is physically impossible for the cross-bridges to stay attached to the same point during muscle contraction. Huxley concluded that the cross-bridges generate and sustain the tension developed in the muscle. The crossbridges are attached to one site on the filament for part of the contraction. They then detach and reattach themselves at a new site further along the actin molecule. Huxley further suggested that at each of those sites one ATP molecule is split to generate the sliding force.

Muscle contraction is initiated by an action potential propagating down a neuron. The impulse is transmitted to the muscle membrane at the motor "end plate". A wave of depolarization spreads out along the sarcolemma (the membrane surrounding the muscle fiber) [45]. Invaginations of this membrane, called transverse tubules, are located at each Z-disc. These tubules transports the signal into the cells. Located adjacent to the transverse tubules is the intracellular membrane system called the sarcoplasmic reticulum (SR). The SR surrounds the contractile elements of the muscle and serves as an intracellular $\mathrm{Ca}^{2+}$ storage area.

Calcium release channels from the SR are triggered as a result of the action potential that propagates down the nerve. It is the increase of $\mathrm{Ca}^{2+}$ inside the 
contractile elements of the muscle that allow myosin to bind to actin. The hydrolysis of adenosine triphosphate to adenosine diphosphate and inorganic phospate is responsible for the conformational changes of the myosin head during contraction. This interaction between myosin and actin results in development of tension and length changes and finally muscle contraction. The cycle repeats itself as long as $\mathrm{Ca}^{2+}$ is present. Muscle relaxation is caused by the reabsorption of the released $\mathrm{Ca}^{2+}$ into the SR via ATP-driven pumps.

The linkage between membrane depolarization of the T-tubule and $\mathrm{Ca}^{2+}$ release from the SR is not fully understood. The functional interaction between the control system and the $\mathrm{Ca}^{2+}$-release channels in the $\mathrm{SR}$ is refered to as "excitation contraction (EC) coupling". Several different models have been proposed to explain this interaction. To understand the mechanism underlying contraction, further investigation of the transverse tubules, the $\mathrm{SR}$ and the $\mathrm{Ca}^{2+}$ release channels will be needed. The functionality of the calcium release channel ${ }^{2}$ and the influence of different substances on this mechanism are the subject of studies in our laboratory.

\footnotetext{
${ }^{2}$ of white rabbit skeletal muscle sarcoplasmic reticulum
} 


\subsection{Overview: Ion Channels}

Ion channels are macromolecular pores in cell membranes. The channels provide a mechanism for controlling both chemical and electric gradients across the membrane by selective ion exchange. Many types of channels are found within the muscle cell. Within one cell, two different channels can transport the same type of ion but exhibit different kinetics, conductance and threshold mechanism. Excitation and electrical signaling in the nervous system involve the movement of ions through ionic channels. Each channel is responsive to some stimulus: either a membrane potential change, a neurotransmitter, or other chemical stimulus, etc. The channel's response (called gating) is the opening or closure of the pore. The open pore allows some restricted class of small ions to flow passively down their electrochemical activity gradients (called selective permeability). This again influences the membrane potential. The described mechanism provides a regenerative and self-propagating electrical signal. In general, channels are named according to the specific ion that most favorably passes through them.

The membrane potential can be calculated from the Nernst equation. This equation is derived from the Boltzmann equation of statistical mechanics. The 
Boltzmann equation relates the relative probabilities of finding a particle in state 1 or in state 2 to the energy difference $u_{2}-u_{1}$ between these 2 states:

$$
\frac{p_{2}}{p_{1}}=\exp \left(-\frac{u_{2}-u_{1}}{k T}\right)
$$

$k$ is the Boltzmann's constant, $T$ is the absolute temperature. For the application of this equation, the probabilities are replaced by concentrations, the energies $u$ by molar energies $U$. With $U=u / N(N$ is Avogadro's number $)$ and $R=k \cdot N(R$ is the universal gas constant) this becomes

$$
\frac{c_{2}}{c_{1}}=\exp \left(-\frac{U_{2}-U_{1}}{R T}\right)
$$

Taking the natural logarithms of both sides gives

$$
U_{1}-U_{2}=R T \ln \frac{c_{2}}{c_{1}}
$$

$U_{1}-U_{2}$ is the molar electrical energy difference due to the membrane potential difference $E_{1}-E_{2}$. Considering one mole of an ion $S$ with charge $z_{s}, U_{1}-U_{2}$ becomes $z_{s} F\left(E_{1}-E_{2}\right)$. Substituted into (1):

$$
E_{S}=E_{1}-E_{2}=\frac{R T}{z_{s} F} \ln \frac{[S]_{2}}{[S]_{1}}
$$

This equation is called the Nernst Equation. According to this equation the ionic equilibrium potentials vary linearly with the absolute temperature and logarithmically with the ionic concentration ratio. 
Goldman (1943) and Hodgkin and Katz (1949) described the ionic permeability and selectivity of membranes in their constant-field theory. The ionic flux across the membrane is determined by the concentration gradient and by the electric field across the membrane. The Goldman-Hodgkin-Katz (GHK) current equation states that the current carried by a specific ion is equal to the permeability for that ion multiplied by a nonlinear function of the membrane potential. Goldman, Hodgkin and Katz also showed that the resting potential across the membrane (zero net current) is related to the concentrations and permeabilities of the ions on the two sides of the membrane. If there is only one permeant ion present this equation reduces to the Nernst potential.

Ion channels can be classified in two ways: according to their reactivity or according to their kinetics. The former group can be subdivided into two categories: Channel activation may occur due to ligand binding ("ligand activated") or due to changes in the transmembrane electrical potential ("voltage gated"). Ligand activation occurs when a chemical reagent binds to an appropriate site on the channel and modifies its gating characteristics. Voltage gated channels on the other hand are activated by a change in membrane potential. Examples of voltage gated channels are calcium channels in the brain and calcium, potassium and sodium channels in nerve cells. 
Susuma Hagiwara was one of the first to discover $\mathrm{Ca}^{2+}$ channels which show different kinetic responses to changes in membrane potential [36]. The characteristics used to distinguish these channels from starfish eggs are steady-state inactivation, activation threshold and selectivity. In 1985 Nowycky et al. proposed names for the different types of channels [78]. The L-type channel is found in heart and T-tubules and is characterized by long lasting $(>700 \mathrm{~ms})$, non-inactivating currents. They are activated by high voltage and have a high $\mathrm{Ba}^{2+}$ conductance ${ }^{3}$ of $25 \mathrm{pS}$ (the $\mathrm{Ba}^{2+}$ conductance is greater than that of $\mathrm{Ca}^{2+}$ ). In contrast, the $T$-type channel has a relatively small conductance. It shows a transient current, which inactivates completely after about $50 \mathrm{~ms}$. The $T$-type channels are activated by low voltages and have small $\mathrm{Ba}^{2+}$ conductance (about $8 \mathrm{pS}$ ). These channels are found in neurons. Nowycky et al. propose a third type of channel, that is neither $T$ nor $L$ type. $N$-type $\mathrm{Ca}^{2+}$ channels require strongly negative potentials for complete removal of inactivation (unlike $L$ ) and strong depolarization for activation (unlike T). This channel is intermediate in $\mathrm{Ba}^{2+}$ conductance $(\approx 13 \mathrm{pS})$. The $N$ type channel is linked to neurotransmitter release. For a review on $\mathrm{Ca}^{2+}$ channel types see [69].

Since the $\mathrm{Ca}^{2+}$ release channel of the SR is not located in the outer muscle cell membrane, it cannot be examined with the patch clamp technique. This method

\footnotetext{
${ }^{3}$ Unit $S:$ Siemens. $1 S=1 / \Omega$
} 
is the basis for the categorization each of the three channel-types found in the sarcolemma. The $\mathrm{Ca}^{2+}$ release channel from $\mathrm{SR}$ is not classified as a $\mathrm{L}, \mathrm{T}$ or $\mathrm{N}$ type channel.

\subsection{T-Tubule}

Transverse ( $\mathrm{T}$ ) tubules are periodic invaginations of the sarcolemma (SL). Although the $\mathrm{T}$ tubules are continuous with the SL membrane, the distribution of proteins in the membrane is not uniforme [110]. Venosa and Horowicz showed in their experiments on frog's sartorius muscle that the density of $\mathrm{Na}^{+}$pumps is substantially greater at the surface than in the tubular membranes (ratio 20:1). Narahara et al. also showed that $\mathrm{Mg}^{2+}$-stimulated $\left(\mathrm{Na}^{+}+\mathrm{K}^{+}\right)$-ATPase activity is 14 times higher in a surface membrane fraction of the SL than in the fraction containing the T-tubules [77]. Jaimovich et al. found in $\mathrm{TTX}^{4}$ binding studies that the density of voltage-gated $\mathrm{Na}^{+}$channels in the surface membrane is about four times as high as it is in the T-tubules [54]. On the other hand, $\mathrm{Ca}^{2+}$ channels are three to four times more common in the T-tubules than in the surface sarcolemma (see section 1.5 on page 15).

It has been shown that even though the sarcolemma and the SR are continuous structures, their junctional domains are distinct from their longitudinal domains.

\footnotetext{
${ }^{4}$ Tetrodotoxin
} 
Regions in which one terminal cisternae of the SR is adjacent to the sarcolemma (SL) are called diades. While structural units which include two junctional SR cisternae and one T-tubule segment are referred to as triads.

Due to the difficult isolation of proteins from the T-tubules, different sources refer to approximately 15 to 27 different proteins in T-tubular membrane. The proteins of major interest in the T-tubules are the $\left(\mathrm{Na}^{+}+\mathrm{K}^{+}\right)$-ATPase and $\mathrm{Ca}^{2+}$ channel proteins. Recent studies have focused on a protein of a molecular mass of $72 \mathrm{kDa}$ [88]. Chadwick et al. showed that the ryanodine receptor crosslinks selectively to this protein [19]. It has been proposed that this protein is in close association with the junctional foot protein in the SR. This suggests a possible role in EC coupling.

The junctional foot protein in the sarcoplasmic reticulum (SR) was the first structural component of the EC coupling-unit to be described. It connects the SR to the sarcolemma/T-tubule while maintaining a gap of about $10 \mathrm{~nm}$ between the two membrane systems. The foot protein has four large subunits symmetrically located around a less dense area. The large size and the characteristic shape of the foot proteins facilitated there identification as the ryanodine receptor.

It is believed that the first step in transverse tubule depolarization/SR calcium release is a membrane-sensitive conformational change of a charged voltage sensor molecule within the T-tubule membrane referred to as the dihydropyridine receptor 
(DHPR). It has been shown that charge movement at the T-tubule is directly coupled to calcium release from the SR.

\subsection{DHP-Receptor}

The dihydrophyridine (DHP) receptor is a slowly activating calcium channel responsible for most of the charge movement leading to the depolarization of the SL prior to muscle contraction. The name originated from its sensitivity to several DHPs, found both naturally and synthetically. The DHP receptor is believed to play two important roles in the process of muscle contraction [5] [103] [104].

The first is its function as a slow $\mathrm{Ca}^{2+}$ channel. Other than the RyR, the DHP receptor is not a link in EC coupling signal transmission [35]. The DHP receptor is responsible for $\mathrm{Ca}^{2+}$ replenishment.

As described earlier, the $\mathrm{Ca}^{2+}$ channels in skeletal muscle are mostly found in the T-tubules as opposed to the SL [104]. Analysis of DHP binding shows that Ttubules bind about 33 times more DHP per milligram membrane than does isolated sarcolemma (50 $\mathrm{pmol} / \mathrm{mg}$ as opposed to $1.5 \mathrm{pmol} / \mathrm{mg})$. Also, less than $0.005 \mathrm{U} / \mathrm{mg}$ $\mathrm{Ca}^{2+}$-ATPase activity ${ }^{5}$ is detected in SL compared to $2.42 \mathrm{U} / \mathrm{mg}$ activity in SR [88].

\footnotetext{
${ }^{5}$ Units: $1 \mathrm{U}=$ transport of $1 \mu \mathrm{mol} \mathrm{Ca}^{2+}$ per minute
} 


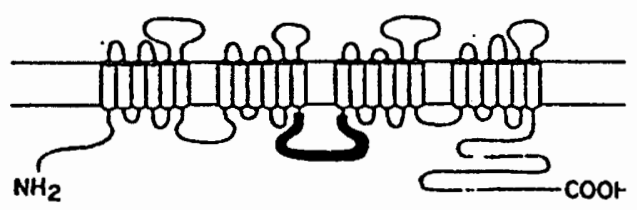

Figure 4: Schematic representation of the structure of the DHP receptor. The dark shaded area (II-III loop) indicates the critical region for skeletal type EC coupling [28] [102]. The four units of homology are displayed linerally and the six putative transmembrane segments in each repeat are shown by cylinders. Reproduced from [102]

However, studies by Schwartz et al., in which DHP binding was compared with voltage-clamp measurements, showed that less than $5 \%$ of the high affinity DHP binding sites are functional $\mathrm{Ca}^{2+}$ channels [91].

On the other hand, Rios and Brum showed later that low concentrations of a DHP are sufficient to inhibit both, $\mathrm{SR} \mathrm{Ca}^{2+}$ release and charge movement, which is observed just before contraction [86]. They speculate that the DHP-sensitive $\mathrm{Ca}^{2+}$ channel plays an integral role in EC coupling. Other authors have postulated that the DHP receptor is an intramembrane molecule that serves as a voltage sensor in the transverse tubules for SR calcium release in skeletal muscle [86] [103] [104].

At sites of peripheral coupling or in the junctional regions of the T-tubules, groups of four proteins (called tetrads) were identified with the help of electron microscopy (EM). These tetrads are very often found right above the four subunits 
of the junctional foot protein of the SR. This strongly suggests that feet and tetrads interact with each other. There are several lines of evidence that the tetrads are composed of four DHP receptors [100].

\subsection{Sarcoplasmic Reticulum}

The sarcoplasmic reticulum (SR) is a internal membrane system, similar to the endoplasmic reticulum of non-muscle cells. As mentioned before and seen in Fig. 2, the SR surrounds the myofibrils, i.e., the actin and myosin filaments. The function of the $\mathrm{SR}$ is to control the intracellular $\mathrm{Ca}^{2+}$ concentration in skeletal and cardiac muscle. The main proteins in the $\mathrm{SR}$ are the $\mathrm{Ca}^{2+}-\mathrm{Mg}^{2+}-\mathrm{ATP}$ ase and the $\mathrm{Ca}^{2+}$ release channel. The ATPase, a $105 \mathrm{kDa}$ protein, works as a $\mathrm{Ca}^{2+}$ pump and is responsible for generating a $\mathrm{Ca}^{2+}$ gradient across the $\mathrm{SR}$ membrane. The SR is organized in two distinct and functionally different regions. Meissner used isopycnic centrifugation to obtain "light" and "heavy" vesicles from the upper and lower ends of a $24 \%$ to $45 \%$ linear sucrose gradient [70]. He showed, that the light vesicles were isolated from the longitudinal part of the SR (LSR), that stretches along the length of each sarcomere. Ninety percent of the protein found in the LSR is the $\mathrm{Ca}^{2+}-\mathrm{Mg}^{2+}-\mathrm{ATPase}$. The heavy SR, also known as the junctional SR (JSR) or "terminal cisternae" is found on both sides of the $Z$-line and appears 
to be thicker than the longitudinal SR. The heavy SR fraction contains the $\mathrm{Ca}^{2+}$ release channel, calsequestrin, and the $\mathrm{Ca}^{2+}$ pump.

Calsequestrin is a $\mathrm{Ca}^{2+}$ binding protein. It binds $\mathrm{Ca}^{2+}$ with high-capacity and moderate affinity. It functions as a $\mathrm{Ca}^{2+}$ storage protein in the lumen of the SR. Besides calsequestrin, a set of other intralumenal $\mathrm{SR} \mathrm{Ca}^{2+}$ binding proteins have been identified. Calsequestrin is the most important of these proteins; it is the only one that is discretely localized to junctional SR [18]. Calsequestrin has been found to be associated with the $\mathrm{Ca}^{2+}$ release channel protein complex through protein-protein interactions. During the resting phase, most of the calcium in the SR diffuses to the terminal cisternae region and binds to calsequestrin. Ikemoto et al. proposed an essential role for calsequestrin in EC coupling [49]: They studied conformational changes at the calsequestrin protein preceding those of the calcium release channel. They presented data that shows no $\mathrm{Ca}^{2+}$ dissociation from casequestrin-free junctional SR by release triggers. After the reassociation of the dissociated calsequestrin and the junctional $\mathrm{SR}, \mathrm{Ca}^{2+}$ dissociation by triggers was restored. They proposed, that $\mathrm{Ca}^{2+}$ release triggers the production of a signal in the foot protein, that is then transmitted to calsequestrin, leading to the dissociation of the bound calcium. In SR vesicles this leads to a transient increase of intravesicular $\mathrm{Ca}^{2+}$ and subsequently to release across the membrane. 
The junctional foot protein (JFP) is a homotetramer, composed of 4 equal subunits and localized in the terminal cisternae region. Takeshima et al. determined the molecular weight of each subunit by amino acid sequencing to be $M_{r} \approx 535,000$ [101]. It remains unclear whether all four subunits are identical. The high molecular weight protein is a constituent of the SR. The material connecting the JFP and the T-tubules has been described as amorphous [31]. Takeshima's sequence analysis of the subunits suggests that approximately one tenths of the high molecular weight protein forms a transmembrane region, whereas the remaining nine tenth lie in the junctional gap, which makes up the "foot protein." The plant alkaloid ryanodine binds with high affinity to the JFP. $\left[{ }^{3} \mathrm{H}\right]$ ryanodine binding experiments show approximately two binding sites per subunit [51] (see section 1.7 on page 21).

The main protein in the longitudinal SR is the $\mathrm{Ca}^{2+}$ pump. The pump transports $\mathrm{Ca}^{2+}$ actively (ATP-driven) into the $\mathrm{SR}$ lumen. The $\mathrm{Ca}^{2+}$ pump is evenly distributed throughout the longitudinal SR. It consists of a single polypeptide chain of $100-150 \mathrm{kDa}$. For each mole of ATP that gets hydrolyzed, the protein transports two moles of $\mathrm{Ca}^{2+}$ into the SR. The pump is capable of lowering the cytoplasmic free calcium concentration below $10^{-8} \mathrm{M}$, and it can establish a $\mathrm{Ca}^{2+}$ gradient of 1,000 -fold or greater across the membrane. The concentration of $\mathrm{Ca}^{2+}$ pumps in the longitudinal SR is proportional to the rate of relaxation of a specific 
muscle (i.e. fast twitch muscle fiber has a a higher concentration of $\mathrm{Ca}^{2+}$ pumps than does slow twitch muscle).

The junctional SR is the region of the $\mathrm{SR}$ associated with $\mathrm{T}$ tubules. The gap between the SR and the T-tubule is approximately $100-130 \AA[31]$ [67]. The structure of the T-tubule - SR junction is strong enough to withstand the large forces exerted on it during contraction. In striated muscle fibers the alignment of SR and T-tubules is maintained during shortening. Nunzi and Franzini-Armstrong showed that this is due to radially oriented short filaments, which connect the $\mathrm{Z}$ disks to the SR and to the T-tubular membranes [79].

$\mathrm{Ca}^{2+}$ is released following an action potential. Through a mechanism referred to as excitation-contraction (EC) coupling, the $\mathrm{SR} \mathrm{Ca}^{2+}$ channel is opened. Due to the gradient across the membrane, $\mathrm{Ca}^{2+}$ then diffuses out of the $\mathrm{SR}$ within a few milliseconds. After the closure of the channel the $\mathrm{Ca}^{2+}$ pump transports the $\mathrm{Ca}^{2+}$ back into the SR. The whole cycle of release and uptake can be completed in 20 to 50 milliseconds [67]. 


\subsection{Ryanodine Receptor}

Two classes of $\mathrm{Ca}^{2+}$-release channels are essential for $\mathrm{Ca}^{2+}$ signaling in cells: The inositol $(1,4,5)$-triphosphate $\left(\mathrm{IP}_{3}\right)$ and the ryanodine receptors. The former induces $\mathrm{Ca}^{2+}$ release directly when the receptors are bound to the second messenger $\mathrm{IP}_{3}$. Although some authors have reported $\mathrm{IP}_{3} \mathrm{Ca}^{2+}$ release from the $\mathrm{SR}$, their observations have been disputed.

$\mathrm{Ca}^{2+}$ release can be mediated by the ryanodine receptor (RyR) $\mathrm{Ca}^{2+}$ release channel. This channel is triggered by a surface membrane action potential and/or a change in the concentration of a second messenger, by a mechanism referred to in muscle as excitation-contraction (EC) coupling. The classical description of the RyR includes $\mathrm{Ca}^{2+}$ and ATP activation, and inhibition by ruthenium red or $\mathrm{Mg}^{2+}$. The $\mathrm{RyR} / \mathrm{Ca}^{2+}$-release channel has also very high conductance for monoand divalent cations, compared to other $\mathrm{Ca}^{2+}$ channels. Commonly reported values for the conductance of the RyR are $\approx 110 \mathrm{pS}$ for $\mathrm{Ca}^{2+}, \approx 380 \mathrm{pS}$ for $\mathrm{Cs}^{+}$, and $\approx 400 \mathrm{pS}$ for $\mathrm{Na}^{+}[96][97]$.

The protein structure that is now known as the $\mathrm{RyR} / \mathrm{Ca}^{2+}$ release channel is located where the junctional SR comes in close contact with the T-tubules. These structures were formerly known as "feet" (see section 1.4 on page 13), but were 
renamed because of their $\mathrm{Ca}^{2+}$ channel activity and their ability to bind the plant alkaloid ryanodine with high affinity and specificity.

Immunolabeling studies of the SR indicate that some (18\% to $21 \%$ ) RyRs (or their subunits) are present in the longitudinal SR [26]. Franzini-Armstrong and Jorgensen [33] speculate that these might be molecules in transit from their site of synthesis to their final foot junction location. These molecules can probably not be resolved in electron microscopy studies, because the RyRs do not form arrays in this region. Further studies showed that these proteins do not significantly contribute to the calcium release and therefore EC coupling [44].

Using the zwitterionic detergent CHAPS and high ionic strength $(1.0 \mathrm{M} \mathrm{NaCl})$, the membrane bound RyR of a variety of tissues ${ }^{6}$ was solubilized and purified as a $30 \mathrm{~S}$ protein complex. SDS gel electrophoresis suggests that the purified RyR of mammalian skeletal and cardiac muscle contain a single major high molecular weight polypeptide with a calculated $M_{r}$ of $\approx 560,000 \mathrm{Da}$, as determined by cloning and sequencing of the complementary DNA (see [76] for cardiac and [101] for skeletal muscle DNA expression) of the mammalian skeletal and cardiac muscle RyR isoforms (for reference see [8], [50], [51] and [60]). Hydropathy plots suggest that the $M_{r} \approx 560,000$ polypeptides consist of two major structural regions: a carboxy-terminal pore region, and a large extramembrane region. The former is

\footnotetext{
${ }^{6}$ For reference on rabbit skeletal muscle that was used in this study, see [48], [60] and [97]
} 
thought to consist of as few as four [101] and as many as ten or possibly twelve [113] putative transmembrane segments.

Electron microscopy studies showed that the purified $30 \mathrm{~S}$ RyRs of mammalian skeletal, cardiac muscle and brain have an overall morphology identical to the protein bridges (feet, see section 1.6 on page 18), that span the gap between the T-tubules and the SR [33]. The four leaf clover-like (quatrefoil) appearance of negative-stained samples, the apparent sedimentation coefficient of $30 \mathrm{~S}$ [60], and cross-linking and scanning transmission electron microscopy studies have demonstrated a tetrameric assembly of the high molecular weight subunits of the CHAPSpurified skeletal RyR [74]. Lai et al. showed that the complete tetramer is necessary for ryanodine binding and channel activity [60].

Studies of averaged images of negatively stained [115] and frozen hydrated [84] specimens showed a more detailed view of the structure of the rabbit skeletal muscle RyR. These images have a resolutions of $\approx 3 \mathrm{~nm}$. They indicate an overall dimension of $27 \times 27 \times 14 \mathrm{~nm}$ for the skeletal RyR. They further suggest the presence of an ion-conducting structure comprised of a central (membrane-spanning) channel that branches into four radial channels in the cytoplasmic (foot) region of the complex. 

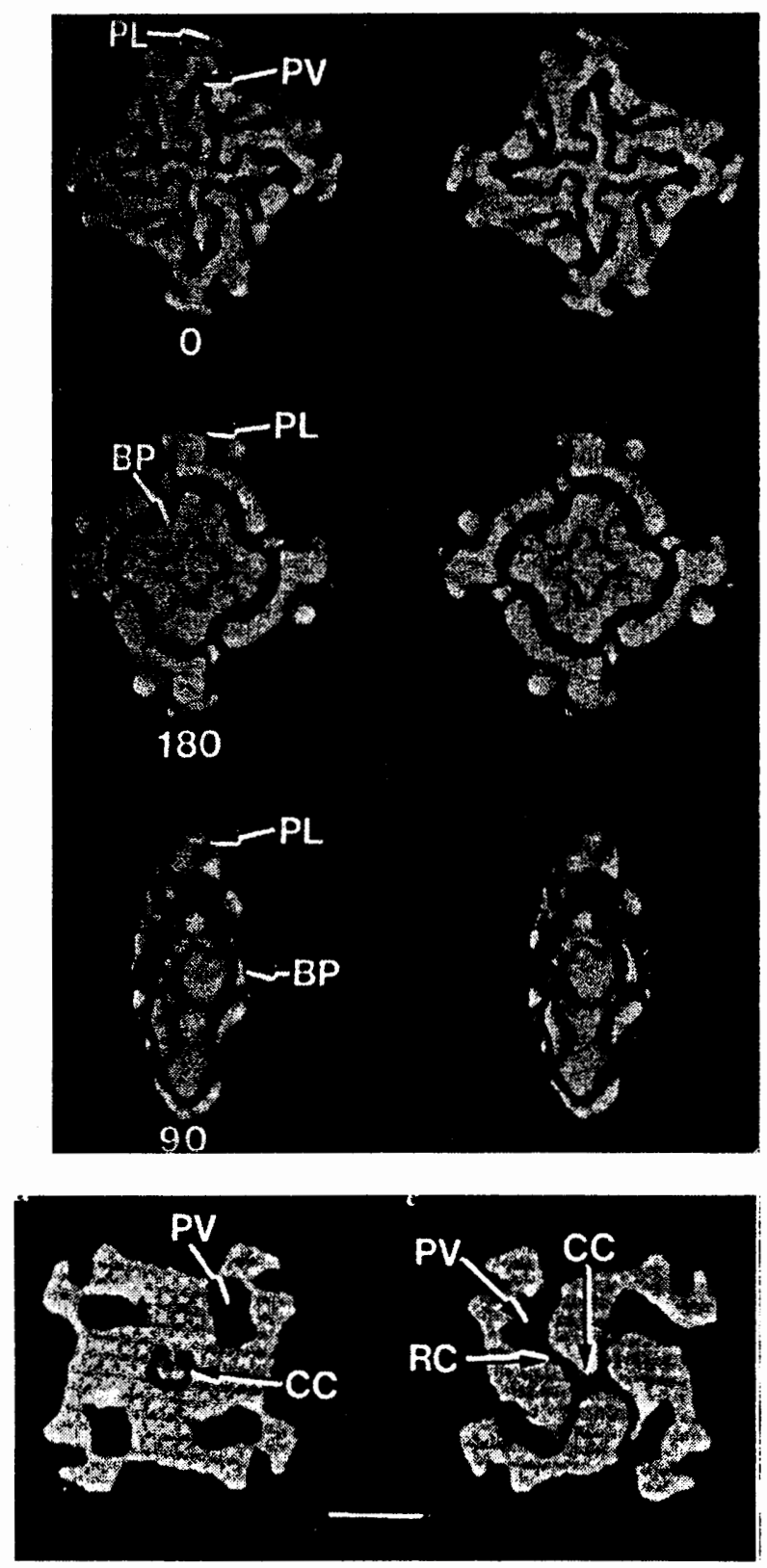

Figure 5: Computer generated surface of the three-dimensionally reconstructed junctional channel complex. Upper image: stereo pairs of the reconstruction in various orienations related by rotation about a vertical axis. Lower image: Two complementary halves of the reconstruction after slicing it in half to reveal internal structural features. Left picture: View from inside the channel towards the T-tubule surface, right picture: view from the same spot to the other direction. Abbreviations: $B P$ Base platform, $P L$ peripheral lobes, $P V$ peripheral vestibules, $C C$ central channel, $R C$ radial channels. The scale bar indicates $10 \mathrm{~nm}$. Reproduced from [115]. 


\subsection{EC Coupling}

The functional interaction between components of the calcium release mechanism and the control system is called excitation-contraction coupling (EC coupling). Events in this process include depolarization of the surface membrane, the detection of this depolarization by voltage sensors and the resultant release of calcium from the SR. In vertebrate skeletal muscle the functional components reside in the junctional membrane of the sarcoplasmic reticulum (SR) and the immediately adjacent transverse tubules of the sarcolemma membrane. After the depolarization of the sarcolemma, the transverse tubule system carries the signal radially into the muscle fibers for nearly synchronous initiation of SR calcium release throughout the fiber volume. The T-tubules establish specialized junctions (T-SR junctions, triads, or diads) with the SR (see section 1.4 on page 14); these junctions are involved in the transmission of excitation stimuli. The depolarization of the sarcolemma triggers a charge movement in these structures, which initiates a series of events that culminates in the release of stored calcium from the SR. Very little is known about the structure and function of the systems participating. Three major mechanisms for the actual signal transmission between T-tubules and SR have been considered. These are mechanical coupling, electrical coupling and chemical coupling. 


\subsubsection{Mechanical Coupling}

The earliest proposal for the EC coupling mechanism was a direct mechanical interaction between the T-tubule voltage sensor and the SR calcium release channel [20]. In this model the T-tubule voltage sensor was thought to block the release channel directly ("plunger model"). The plunger was removed by a voltage dependent movement of the sensor during TT depolarization. Upon the discovery of the high molecular weight ryanodine receptor (RyR), this model was modified in such a way that indicated that the interaction was now occurring at a domain of the RyR which was distinct from the $\mathrm{Ca}^{2+}$ release domain. The DHP receptor, as viewed in the mechanical model, could exert an inhibitory effect on the $\mathrm{RyR} / \mathrm{Ca}^{2+}$ release channel, while in its resting state. This would be possible via a voltage dependent conformational change of the DHP receptor during T-tubule depolarization.

Chandler's model gained new credibility when Block et al. presented structural evidence for a mechanical interaction between the junctional foot protein and the $\alpha_{1}$ subunit of the DHP receptor [12]. Block showed evidence for the presence of a large junctional complex spanning the two junctional membranes and intervening gap. Utilizing this complex, the DHP receptor could directly stimulate $\mathrm{Ca}^{2+}$ release from the SR.

Franzini-Armstrong, however, showed an alternate disposition of tetrads in some muscles, i.e., the distance between tetrads were twice the distance between 
adjacent feet [32]. This resulted in tetrads being associated with alternate feet. A variable ratio of tetrads to feet would greatly weaken the direct mechanical coupling hypothesis.

\subsubsection{Electrical Coupling}

The idea of an electrical coupling mechanism may seem reasonable, because muscle contraction is initiated by an electrical impulse. A direct current flow between the T-tubules and the SR would cause a depolarization of the SR and then induce $\mathrm{Ca}^{2+}$ release. Eisenberg showed, however, that no sign of depolarization was apparent in high impedance measurements of muscle cells [2T].

Mathias et al. proposed an influx current carried by ions as the coupling mechanism [68]. Meissner showed, however, that the sarcoplasmic reticulum membrane is uniquely permeable to various biologically relevant monovalent ions [71]. The only significant gradient over the membrane is the one of $\mathrm{Ca}^{2+}$. Stefani [99] and Eisenberg [27] demonstrated that none of these $\mathrm{Ca}^{2+}$ currents plays a direct role in EC coupling. In addition, single channel measurements in lipid bilayers showed very little voltage dependence for the $\mathrm{Ca}^{2+}$ release channel.

Schneider and Chandler proposed an electromechanical mechanism of EC coupling [89]. They observed charge movement across the T-tubules membrane. The range of membrane potentials, in which charge movement occurs is the range in 
which many of the electrical and mechanical properties of muscle are regulated. Schneider and Chandler suggested a physical movement of charged particles that could represent a molecular trigger.

\subsubsection{Chemical Coupling}

Several chemical compounds are capable of opening and closing the $\mathrm{Ca}^{2+}$ release channel. Many of them are not physiologically present, and therefore have no influence of the EC coupling process. $\mathrm{Ca}^{2+}$ is the chemical messenger in cardiac SR that triggers $\mathrm{Ca}^{2+}$ release (" $\mathrm{Ca}^{2+}$ induced $\mathrm{Ca}^{2+}$ release") [108]. In skeletal muscle, this mechanism is not applicable. Contraction is possible, even without any extracellular calcium [5] [86]. In addition, the DHP receptor would not be able to supply the $\mathrm{Ca}^{2+}$ that could trigger $\mathrm{Ca}^{2+}$ release from the SR. The function of the DHP receptor is slower and longer lasting than the activation of contraction. Finally, the blockade of the $\mathrm{Ca}^{2+}$ release ability of the DHP receptor by $\mathrm{Cd}^{2+}$ was shown not to prevent EC coupling [6].

Other chemical coupling mechanisms were proposed and include activation by the second messenger $\mathrm{IP}_{3}$, and gating by sulfhydryl oxidation. These are discussed in the following sections. 


\section{Phosphorylation by Inositol 1,4,5-triphosphat $\left(\mathrm{IP}_{3}\right)$}

Inositol 1,4,5-trisphospate $\left(\mathrm{IP}_{3}\right)$ has been shown to mobilize $\mathrm{Ca}^{2+}$ from intracellular stores, in the endoplasmic reticulum, in a variety of cell types [11]. Volpe et al. showed that $\mathrm{IP}_{3}$ also releases $\mathrm{Ca}^{2+}$ from isolated purified sarcoplasmic reticulum [114]. Ruthenium red, a blocker of terminal cisternae $\mathrm{Ca}^{2+}$ channels antagonized the release. Application of $\mathrm{IP}_{3}$ to skinned fibers also results in force production. In their article, Volpe et al. proposed a possible model for EC coupling in which after T-tubule depolarization $\mathrm{IP}_{3}$ is produced at the myoplasmic leaflet of the T-tubule membrane and released into the triadic junction. $\mathrm{IP}_{3}$ sensitive $\mathrm{Ca}^{2+}$ channels, localized in the junctional SR, open and free $\mathrm{Ca}^{2+}$ increases. Vergara presented further evidence for $\mathrm{IP}_{3}$ release in experiments where he electrically stimulated muscles fibers [111].

One problematic aspect of the $\mathrm{IP}_{3}$ hypothesis is that the sensitivity of skinned fibers to extrinsic $\mathrm{IP}_{3}$ increases when the $\mathrm{T}$-tubular membranes are depolarized [25]. This indicates that the putative receptor "knows" the state of the voltage sensor before receiving the $\mathrm{IP}_{3}$ message, thus suggesting the existence of another pathway of communication.

Another problem with this hypothesis is that $\mathrm{IP}_{3}$ does not cause $\mathrm{Ca}^{2+}$ release from SR vesicles or modify ryanodine binding, one of the most common probes for the state of the $\mathrm{Ca}^{2+}$ channel. 

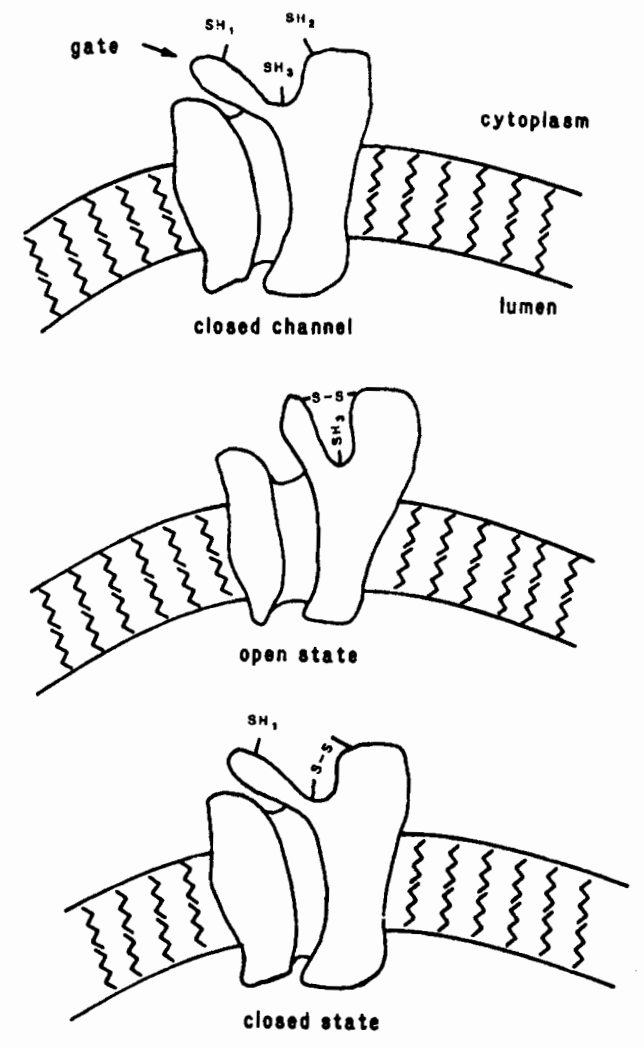

Figure 6: Model of the $\mathrm{Ca}^{2+}$ release protein gated by $\mathrm{SH}$ oxidation and reduction of three endogenous $\mathrm{SH}$ groups. Reproduced from [2].

\section{Sulfhydryl Oxidation}

Abramson and Salama have proposed a model in which $\mathrm{Ca}^{2+}$ channel gating is controlled by the oxidation state of critical sulfhydryl groups on the $\mathrm{Ca}^{2+}$ release channel [3] (see Fig. 6). The oxidation of two sulfhydryl groups to a disulfide linkage opens the channel while the reduction of this linkage closes it. The sulfhydryl groups can also bind heavy metals and release $\mathrm{Ca}^{2+}[4]$. The stimulation of $\mathrm{Ca}^{2+}$ release by heavy metals correlates strongly with the affinity of those metal ions for SH containing agents. 
Reactive disulfide reagents, that specifically react with $\mathrm{SH}$ groups, also stimulate $\mathrm{Ca}^{2+}$ release from $\mathrm{SR}$ vesicles and induce contraction in chemically skinned muscle fibers. Zaidi et al. showed that reducing agents reverse this effect and thus favor $\mathrm{Ca}^{2+}$ uptake [119].

Liu et al. used the fluorogenic sulfhydryl probe $\mathrm{CPM}^{7}$ to characterize the functional role and location of these thiol groups in skeletal and cardiac junctional SR [62]. They found that the kinetics of the formation of fluorescent CPM adducts with junctional membrane are strongly dependent on the presence of physiological and pharmacological modulators that are bound to the RyR. Treatment with RyR agonists (e.g., micromolar $\mathrm{Ca}^{2+}$ or nanomolar ryanodine), promote a slow SR thiolCPM reaction. In the presence of $\mathrm{Ca}^{2+}$ channel antagonists (e.g. millimolar $\mathrm{Ca}^{2+}$, millimolar $\mathrm{Mg}^{2+}$, or micromolar ryanodine) however, $\mathrm{CPM}$ rapidly forms adducts with a single class of highly reactive (hyperreactive) SR thiols. The apparent rate constants for the reaction with the agonists and antagonists are $k=0.0021 \mathrm{~s}^{-1}$ and $k=0.025 \mathrm{~s}^{-1}$, respectively.

Gel electrophoresis of CPM-labeled SR protein and Western plot analyses with antitriadin and antiryanodine antibodies show that the hyperreactive thiols labeled by CPM under conditions favoring channel closure are localized at the RyR protomer and triadin.

\footnotetext{
${ }^{7}$ 7-diethylamino-3-(4'-maleimidylphenyl)-4-methylcoumarin
} 
These results reveal that the RyR and triadin have a small number of highly reactive cysteine residues that selectively conjugate with CPM when channel closure is favored. Liu et al. suggest that either the redox state of the sulfhydryl group controls the state of the channel, or the accessibility of the thiols is determined by the functional state of the channel [62]. Other experiments support the first interpretation. Modification of the thiols with nanomolar $\mathrm{CPM}$ inhibited $\mathrm{Ca}^{2+}$ induced $\mathrm{Ca}^{2+}$ release, and the gating activity of single channels in bilayer experiments [62].

The data mentioned above strongly suggests the presence of hyperreactive residues on the RyR and triadin, and describes their functional role in the gating of the calcium release channel. The redox-sensitivity of the thiol controlled channels makes them an important target for physiologically relevant oxidizing agents (see section 2.1.1).

Even though sulfhydryl oxidation seems to be an important link in EC coupling, the physiologically relevant trigger mechanism for this model has still to be discovered. 


\subsection{Mechanisms of $\mathrm{Ca}^{2+}$ Release from Sar-}

\section{coplasmic Reticulum}

$\mathrm{Ca}^{2+}$ efflux from SR occurs by several mechanisms which may be interrelated. These mechanisms differ in sensitivity to physiological effectors or pharmacological agents as well as in their relevance to EC coupling. These mechanisms also include channel independent $\mathrm{Ca}^{2+}$ release such as $\mathrm{Ca}^{2+}$ leakage through SR membrane as well as reversal function of the $\mathrm{Ca}^{2+}$ pump. They are of minor interest for ryanodine receptor studies and will not be discussed further.

\subsubsection{Modulators of the SR $\mathrm{Ca}^{2+}$ Release Channel}

In the absence of other regulatory ligands such as $\mathrm{Mg}^{2+}$ and ATP, a bell-shaped $\mathrm{Ca}^{2+}$ dependence curve for $\mathrm{Ca}^{2+}$ efflux from $\mathrm{SR}$ vesicles has been obtained (for a review see [22]). The maximum $\mathrm{Ca}^{2+}$ efflux was observed at micromolar $\mathrm{Ca}^{2+}$ concentrations. The $\mathrm{Ca}^{2+}$ efflux rate decreased at both, higher $\left(10^{-3} \mathrm{M}\right)$ and lower $\left(10^{-9} \mathrm{M}\right) \mathrm{Ca}^{2+}$ concentrations. This suggests that the $\mathrm{Ca}^{2+}$ release channel possesses high-affinity activating and low-affinity inhibitory $\mathrm{Ca}^{2+}$ binding sites.

In contrast to $\mathrm{Ca}^{2+}, \mathrm{Mg}^{2+}$ inhibits $\mathrm{SR} \mathrm{Ca}^{2+}$ release. This happens by multiple mechanisms: a) competition with $\mathrm{Ca}^{2+}$ for the $\mathrm{Ca}^{2+}$ activation sites, b) binding to the low-affinity $\mathrm{Ca}^{2+}$ inhibitory sites, and c) blocking of the channel (i.e., $\mathrm{Mg}^{2+}$ 
binds to a site near the conduction pathway [73]). The effects of $\mathrm{Mg}^{2+}$ are physiologically relevant, because the free $\mathrm{Mg}^{2+}$ concentration in muscle cells is between $0.6 \mathrm{mM}$ and $1.0 \mathrm{mM}$.

Adenine nucleotides have been shown to be potent $\mathrm{Ca}^{2+}$ release stimulators. The concentrations of ATP, the primary energy source in the cell, have been estimated to be as high as $5 \mathrm{mM}$ in skeletal muscle. Adenine nucleotides (in the millimolar concentration range) enhance $\mathrm{Ca}^{2+}$-induced $\mathrm{Ca}^{2+}$ release [72]. They also promote heavy metal induced $\mathrm{Ca}^{2+}$ release [4], sulfhydryl oxidation induced $\mathrm{Ca}^{2+}$ release [107] and ryanodine stimulated $\mathrm{Ca}^{2+}$ release [82]. Various other adenine nucleotides besides ATP (e.g., AMP-PCP, cAMP, ADP, adenosine or AMP) potentiate $\mathrm{Ca}^{2+}$ release [82]. Since AMP-PCP is a non-hydrolyzable ATP analogue and is also a potent activator of $\mathrm{Ca}^{2+}$ release, this suggests that activation occurs because of binding to an effector site rather than covalent modification of the channel protein via a phosphorylation reaction. It is likely that MgATP, rather than free ATP, is a major physiological regulator of the RyR ion channel because most of the nucleotide in cells is complexed with $\mathrm{Mg}^{2+}$. The addition of $\mathrm{Mg}^{2+}$ and adenine nucleotide at concentrations approximating those in muscle $(5 \mathrm{mM}$ adenine nucleotide, $0.7 \mathrm{mM}$ free $\mathrm{Mg}^{2+}$ ) was strongly stimulatory at $\mu \mathrm{M}$ concentrations of $\mathrm{Ca}^{2+}$ and indicated the existence of a regulatory site that, upon binding of $\mathrm{MgATP}$, rendered the channel more sensitive to activation in a narrow $\mathrm{Ca}^{2+}$ 
concentration range [73]. In the cell adenine nucleotide and $\mathrm{Mg}^{2+}$ concentrations do not undergo rapid changes and so it is unlikely that these channel modulators play an important role in EC coupling.

Caffeine is known to activate muscle fiber contraction and to stimulate $\mathrm{Ca}^{2+}$ release from SR vesicles. $\left[{ }^{3} \mathrm{H}\right]$ ryanodine binding assays showed a decrease of the threshold for $\mathrm{Ca}^{2+}$ activation as well as an increase of maximum binding in the presence of caffeine [82].

Ryanodine is known to show a biphasic behavior. Nanomolar ryanodine (5 to $40 \mathrm{nM}$ ) activates the channel. Altered channel gating kinetics with low nanomolar ryanodine were shown to be fully reversible. This behavior is used in the $\left[{ }^{3} \mathrm{H}\right]$ ryanodine binding experiments that are described later (see section 3.2.2 on page 64). Micromolar concentrations $(\geq 70 \mu \mathrm{M})$ of ryanodine inhibit channel gating, whereas concentrations $>200 \mu \mathrm{M}$ cause complete closure of the channel [16].

Ruthenium Red, a polycationic dye, has been shown to inhibit $\mathrm{Ca}^{2+}$ release from isolated SR vesicles [73] [107]. The inhibitor is effective at concentrations $<5 \mu \mathrm{M}$. The inhibition is irreversible.

Anthraquinones, like doxorubicin, have been described to directly interact with the $\mathrm{SR} \mathrm{Ca}^{2+}$ release mechanism [1] [120]. Doxorubicin induced $\mathrm{Ca}^{2+}$ release from skeletal [120] and cardiac [57] SR vesicles. A detailed description of this effect is presented in section 2.2 on page 49. 


\begin{tabular}{|l|r||l|r|}
\hline \multicolumn{2}{|c||}{ Activators } & \multicolumn{2}{c|}{ Inhibitors } \\
Agent & $\begin{array}{l}\text { Effective } \\
\text { Concentration }\end{array}$ & Agent & $\begin{array}{l}\text { Effective } \\
\text { Concentration }\end{array}$ \\
\hline \hline Calcium & $0.1-100 \mu \mathrm{M}$ & Calcium & $>1 \mathrm{mM}$ \\
\hline Adenine Nucleotides & $1-5 \mathrm{mM}$ & Magnesium & $0.5-5 \mathrm{mM}$ \\
\hline Caffeine & $1-100 \mathrm{mM}$ & Ruthenium Red & $0.001-20 \mu \mathrm{M}$ \\
\hline Ryanodine & $5-40 \mathrm{nM}$ & Ryanodine & $>70 \mu \mathrm{M}$ \\
\hline Doxorubicin & $1-300 \mu \mathrm{M}$ & CPM & $10-100 \mathrm{nM}$ \\
\hline
\end{tabular}

Table 1: Modulators of the $\mathrm{Ca}^{2+}$ release channel of the sarcoplasmic reticulum. Data from [22]

An overview of some modulators of the $\mathrm{SR} \mathrm{Ca}^{2+}$ release channel is shown in Table 1. 


\section{Chapter 2}

\section{Doxorubicin, Dexrazoxane and}

\section{ADR-925}

\subsection{Doxorubicin}

The antitumor drug doxorubicin (or Adriamycin) belongs to the class of anthracyclines ${ }^{1}$. Anthracyclines engulf the widest spectrum of activity in human cancers. The chemical structure of some anthracyclines is shown in Fig. 7. Doxorubicin in fact was among the first two of these anthracyclines to be developed in the 1960s. The development of doxorubicin was the result of an effort of finding analogs of daunorubicin, which was the first known anthracycline. Clinical trials

\footnotetext{
${ }^{1}$ The name anthracycline is based on the presence of an anthraquinone chromophore and a ploycyclic ring system in the chemical structure.
} 


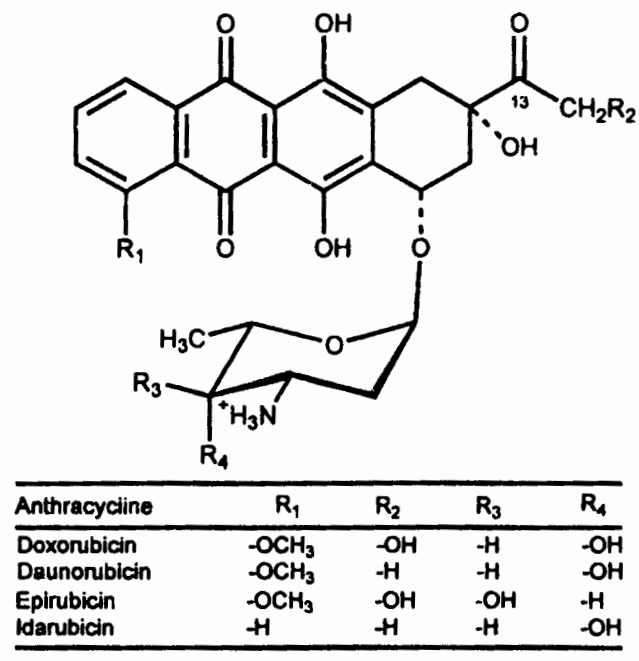

Figure 7: Structure of the antitumor anthraquinones. Reproduced from $[66]$.

of daunorubicin showed that this drug had high activity for acute leukemia (this cancer is still the only one for which it is effective), but produced fatal cardiac toxicity. Doxorubicin differs from daunorubicin only by a single hydroxyl group (see Fig. 7) and was shown to have greater activity against some murine cancers and a better therapeutic index than daunorubicin. Doxorubicin remains the antitumor drug with the widest spectrum of antitumor activity, but like daunorubicin, its usage is limited by its cumulative cardiotoxicity, which prohibits treatment for more than 9 months at usual doses (maximum cumulative dose: $\approx 550 \mathrm{mg} / \mathrm{m}^{2}$ ). In addition to that, it has been found that most cancers will develop resistance to doxorubicin [116]. 


\subsubsection{Cardiotoxicity}

The use of doxorubicin is often limited because of its dose-dependent cardiotoxicity [83]. Systolic and diastolic dysfunction can occur after either acute or chronic exposure to anthracyclines. The magnitude of the dysfunction depends on the duration of exposure to anthracyclines.

Doxorubicin has a number of effects on the cell. The most obvious damage is the degeneration of myofibrils. Microscopic lesions appear in the sarcoplasmic reticulum and mitochondria after just the first few hours ${ }^{2}$ after injection of the drug. The lesions progress in severity over the next couple of days. The SR degenerates, the mitochondria swell and finally disrupt [61]. Studies on isolated mitochondria showed that doxorubicin disables the mitochondria to sequester calcium. Doxorubicin was also shown to decrease ATP and creatine phosphate levels in rat heart preparations by $25 \%$.

Micromolar $^{3}$ doses of doxorubicin trigger complete calcium release from cardiac [57] and skeletal [120] SR. The effects of doxorubicin on the SR are discussed in section 2.2. Anthracyclines can also stimulate calcium influx through slow channels in the sarcolemma. Very low concentrations of doxorubicin $(<1 \mu \mathrm{M})$ can enhance

\footnotetext{
${ }^{2}$ Research done on mice

${ }^{3} \mathrm{IC}_{50}$ for skeletal muscle: $0.5 \mu \mathrm{M}$, for cardiac muscle: $5 \mu \mathrm{M}$.
} 
calcium influx by activating a $c \mathrm{AMP}^{4}$-dependent protein kinase ${ }^{5}$ that phosphorylates channel proteins. Anthracyclines may also increase cytoplasmic calcium by the inhibition of $\mathrm{Ca}^{2+}$-ATPase of the sarcolemma.

Despite the knowledge of these subcellular effects of anthracyclines, the mechanism of the cardiotoxicity is still elusive. Several hypotheses to explain cardiotoxicity have been proposed, and are discussed in the following sections.

\section{Free Radical Hypothesis}

Reports from as early as the mid 1970s indicate that quinone-containing anticancer drugs produce free radicals in NADPH-microsome systems. The nicotinamide dinucleotides, to which $\mathrm{NADP}^{6}$ belongs, represent a class of high-energy compounds. NADP is a coenzyme for a large number of dehydrogenase enzymes. It acts as an agent in the transfer of hydrogen atoms in oxidation-reduction reactions. NADPH symbolizes the reduced species of NADP. In the presence of an oxidized substrate and an appropriate reductase, NADPH is oxidized and acts as an electron (or hydrogen) donor. In the case of doxorubicin, this quinone can be reduced to the free radical semiquinone form (step 1 in Fig. 8). Other possible mechanisms of the quinone reduction, such as cytochrome P-450 reductase, NADH and NADH

\footnotetext{
${ }^{4}$ Adenosine-3',5'-cyclic monophosphate, a second messenger nucleotide

${ }^{5}$ Kinase: Reaction, where ATP acts as a donor of phosphate

${ }^{6}$ nicotinamide adenine dinucleotide phosphate
} 


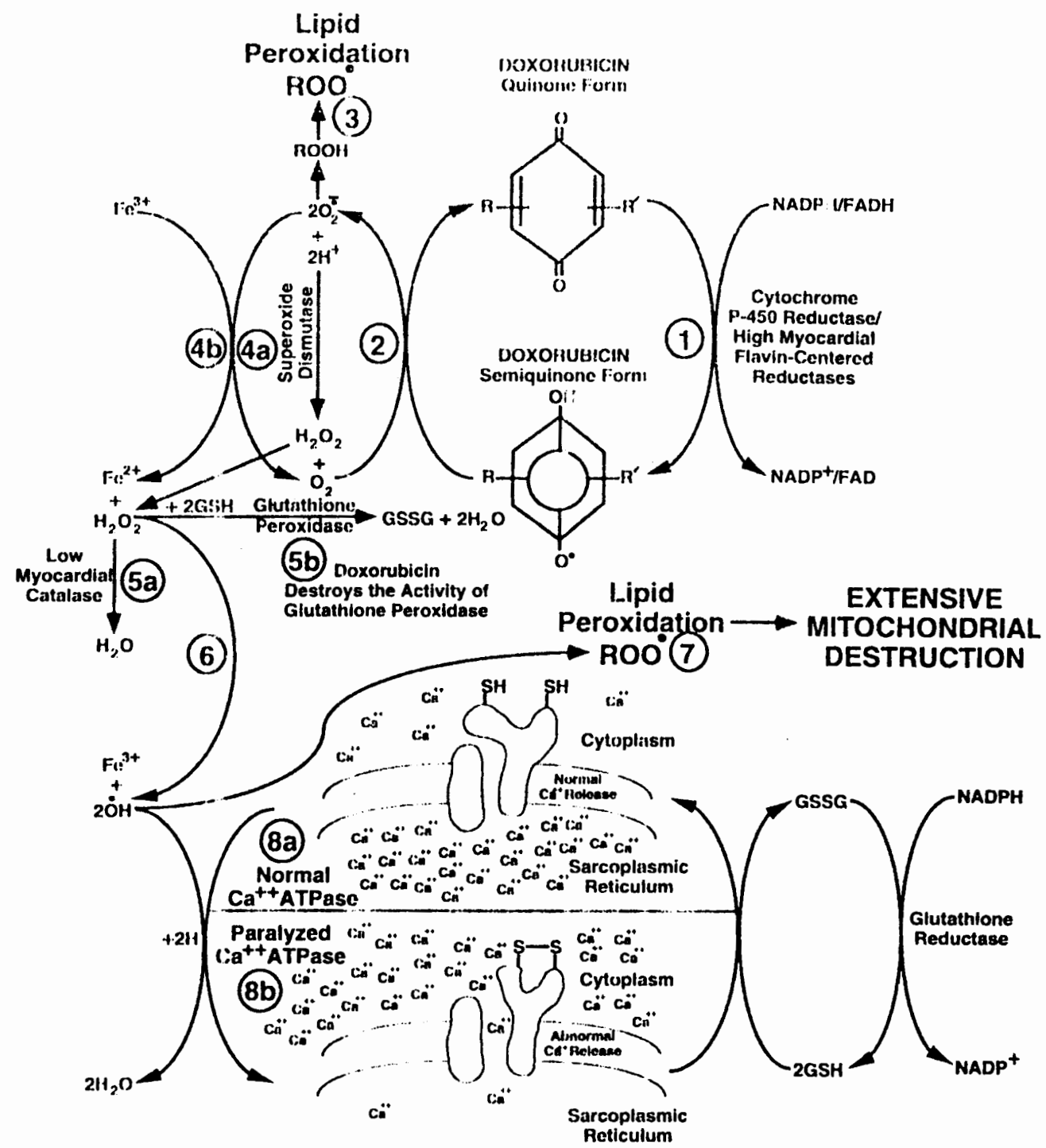

Figure 8: Proposed free radical hypothesis for doxorubicin-induced myocardial toxicity. Modified from [92]. 


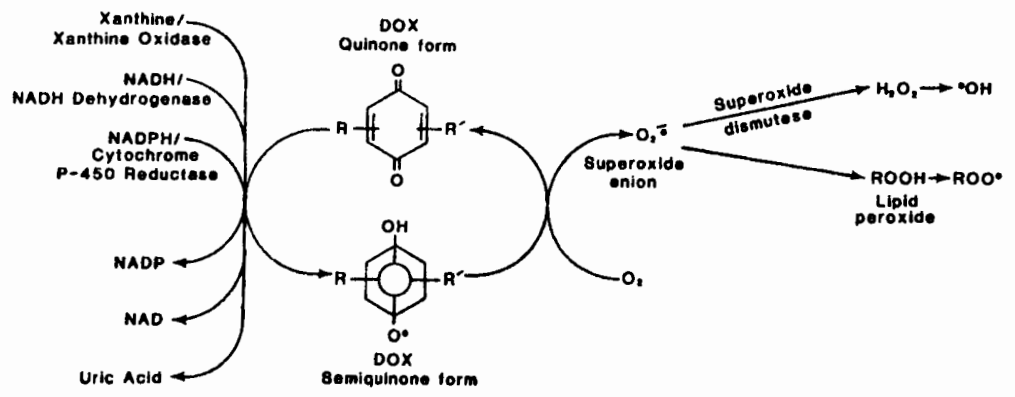

Figure 9: Enzymatic reactions in which reduction of doxorubicin leads to the formation of oxygen free radicals. Doxorubicin, in the quinone form, accepts an electron from various possible donor reactions. This yields the semiquinone free radical. As the semiquinone cycles to the quinone, it transfers an electron to molecular oxygen, yielding superoxide anions. The superoxide anion can either initiate formation of lipid peroxides or be dismutated to hydrogen peroxide. Both products decompose to oxygen-centered free radicals. Reproduced from [81].

dehydrogenase, or the xanthine/xanthine oxidase pathway, are shown in Fig. 9. The semiquinone free radical can be further oxidized to its original quinone form by $\mathrm{O}_{2}$ (Fig. 8,2 ), creating superoxide anions. The superoxide anion may initiate lipid peroxidation (3), or be dismutated via superoxide dismutase to hydrogen peroxide (4a). Superoxide radicals are also converted back to oxygen through ferric ion reduction to the ferrous iron (4b). Because of the low catalase activity of the heart (5a) and the destruction of glutathione peroxidase (5b) by doxorubicin, the natural defense mechanisms for disposing $\mathrm{H}_{2} \mathrm{O}_{2}$ are severely impaired. Together with reduced iron, $\mathrm{H}_{2} \mathrm{O}_{2}$ is converted to highly toxic hydroxy free radicals. These radicals cause severe lipid peroxidation and can also crosslink sulfhydryl groups 

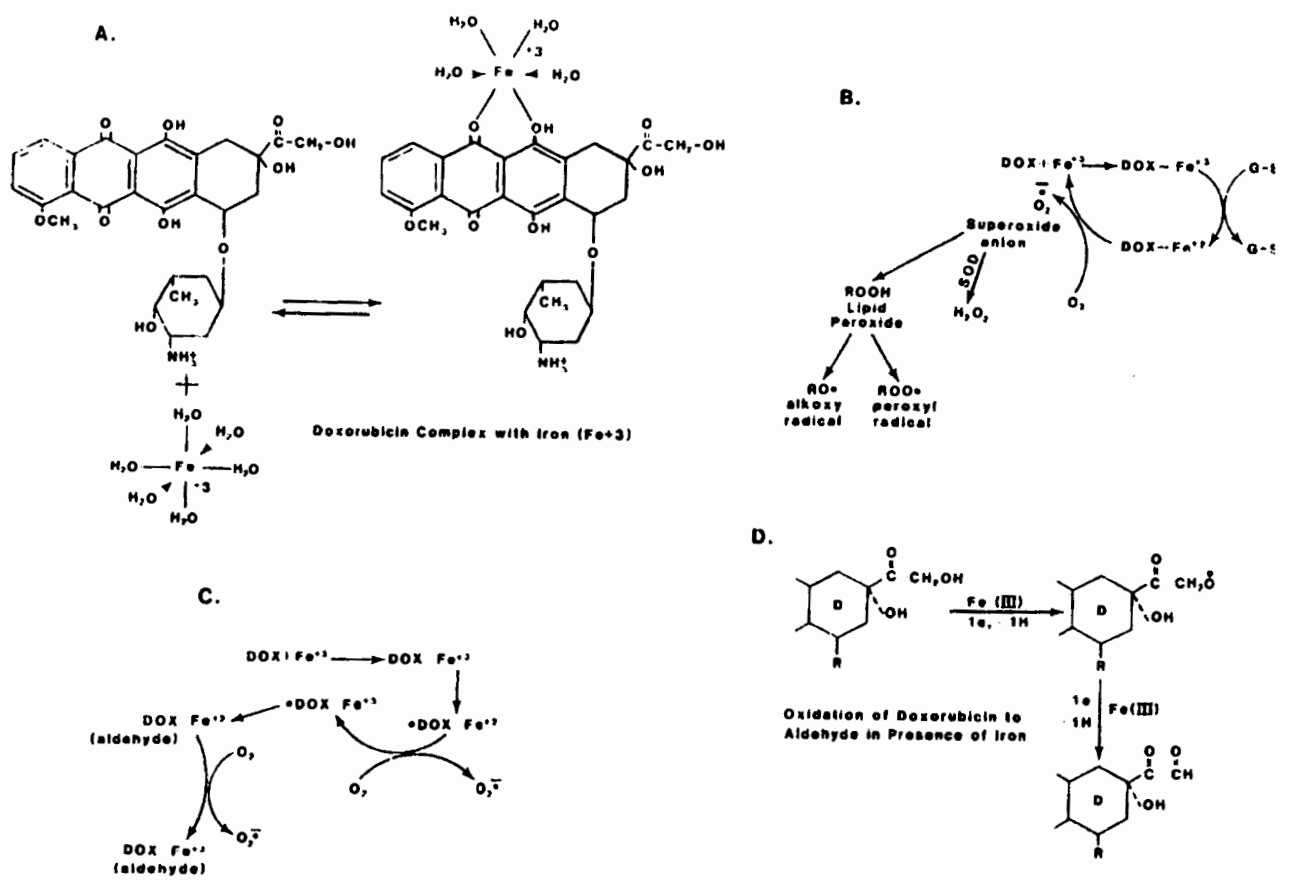

D.

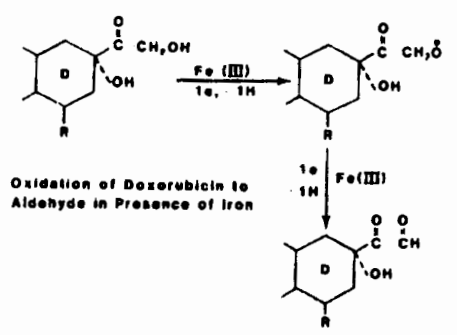

Figure 10: Nonenzymatic mechanism for free radical generation by doxorubicin. Doxorubicin complexes with ferric iron (A). The doxorubicin-iron(III) complex undergoes redox cycling $(\mathrm{B}, \mathrm{C})$ to form superoxide anions and peroxides. Electron donor is either reduced glutathione $(\mathrm{B},[121])$ or doxorubicin $(\mathrm{C}, \mathrm{D})$. Reproduced from [81].

of the calcium release channel $(8 \mathrm{a}, \mathrm{b})$, causing excessive flux of calcium into the cytoplasm. All three, superoxide anions, lipid peroxides and hydrogen peroxide can generate free radicals which damage membranes and cause myocardial injury.

Additional processes for the production of free radicals have been suggested. Besides the previously mentioned "enzymatic" mechanisms, some "nonenzymatic" reactions are possible. Nonenzymatic mechanisms include reactions of anthracycline and iron (Fig. 10). Only very little free iron is available in myocytes, but 


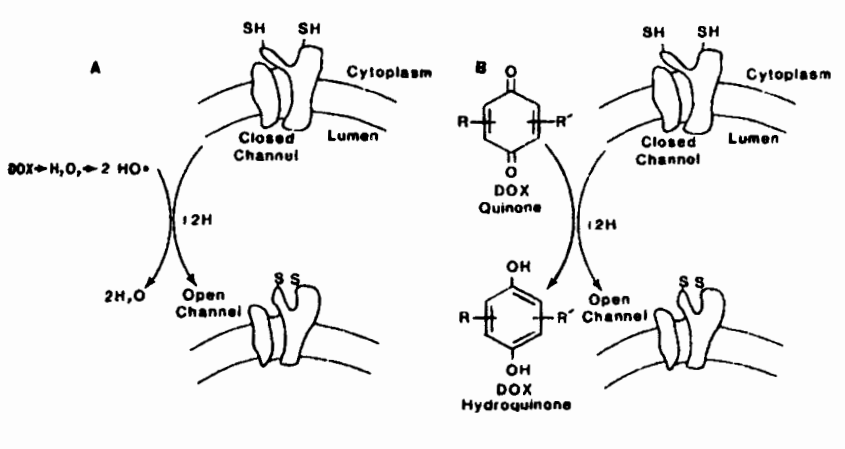

Figure 11: Illustration suggesting that doxorubicin, by oxidizing sulfhydryl groups on calcium release channels of sarcoplasmic reticulum, promotes release of calcium into the cytoplasm. Reproduced from [81] as a modification of Fig. 6.

Demant showed that doxorubicin can abstract iron from ferritin [24], i.e., bound iron can contribute to free radical production as well.

The immediate effect of free radicals on the SR is easily described with the sulfhydryl oxidation model of calcium release (see section 1.8.3, page 30). According to this model calcium release involves redox cycling of sulfhydryl groups at the terminal cisternae. Oxidation by peroxides or by the quinone/semiquinone redox cycle directly (Fig. 11), promote rapid release of calcium from the SR (Fig. 8, $(8 \mathrm{a}, \mathrm{b}))[2]$. In addition to the effects on the release channel itself, free radicals can also impair calcium sequestration by the SR. Both effects combined can lead to an impaired contractility (a decreased supply of calcium) and an impaired relaxation (an increased calcium in myofibrils). Besides the effects on the SR, free radicals can also injure mitochondria.

Yet many limitations of the free radical hypothesis were shown. Vitamin E, a lipid-soluble free radical scavenger, did not reduce lipoperoxidative damage, as 
it was predicted from the free radical hypothesis [109]. Furthermore vitamin E deficiency did not enhance doxorubicin cardiotoxicity. Another problem of the free radical hypothesis is the fact that the heart is a poor free radical generator. Oxygen consumption (a measure of lipid peroxidation) was shown to be 23 fold greater in liver than in cardiac microsomes. In addition Jackson et al. could not show any lipid peroxidation in rabbit, even with large doses of doxorubicin. Jackson also emphasizes that the glutathione peroxidase activity was not altered significantly [53]. Thus, in multiple cases there is no evidence of oxidative stress or free radical production at doxorubicin doses that are known to cause cardiac injury. From a comparison of doxorubicin and daunorubicin, another anthraquinone that is more cardiotoxic than doxorubicin but less potent $(\approx 1 / 6)$ to produce free radicals, it was shown that free radicals cannot be the only mechanism responsible for cardiotoxicity.

These limitations suggest that free radical generation in the heart may contribute to doxorubicin cardiotoxicity, but that other factors probably play a more important role in the origination and development of the myocardial damage.

\section{Calcium Overload Hypothesis}

According to the calcium overload hypothesis, anthracyclines increase intracellular calcium dramatically. Changes in the calcium equilibrium result in disrupted 
excitation-contraction coupling and mitochondrial dysfunction [80]. More recent studies suggest that calcium accumulation is a manifestation rather than a cause of anthracycline cardiotoxicity [55]. Jensen et al. provide evidence that calcium deficiency occurs rather than overload [55]. In addition, the calcium overload hypothesis fails to provide mechanisms of injury or specific injurious agents.

\section{Histamine Hypothesis}

Histamine has been suggested as a mediator of anthracycline cardiotoxicity. Histamine is the decarboxylation product of the aromatic amino acid histidine. Excessive production of histamine occurs during hypersensitive allergic reactions. Bristow et al. reported doxorubicin stimulated histamine release from isolated rabbit heart preparations [15]. Prior exposure of isolated hearts to cromolyn sodium, a compound that completely prevents histamine release from $5 \mu \mathrm{g} / \mathrm{ml}$ doxorubicin, produced significant protection against doxorubicin mediated cardiotoxocity [15].

It is known that free radicals can stimulate histamine release. Free radicals produced by the mechanism described by the free radical hypothesis could therefore be the origin of the observed histamine release. This concept is supported by studies of Klugmann et al., which show that the free radical scavenger $\mathrm{N}$-acetylcysteine inhibits anthracycline induced histamine release [58]. 
How histamine causes cardiotoxicity remains unclear. At present, there is little evidence that exposure to histamine causes cardiotoxic effects similar to anthracyclines [81].

\section{Anthracycline Metabolite Hypothesis}

A rather fundamental question in anthracycline cardiotoxicity is whether the anthracycline itself or a metabolite of it is the cardiotoxic agent. There is increasing evidence to support the role of doxorubicinol (a C-13 alcohol metabolite of doxorubicin) in the cardiotoxicity of doxorubicin therapy. Doxorubicinol is produced inside the myocytes via anthracycline reductase.

The time-delayed cardiotoxicity of doxorubicin promotes the hypothesis that doxorubicinol is the actual cardiotoxic agent. Doxorubicin, in heart, has a half-life of approximately 1-3 days. Doxorubicinol on the other hand has been observed to accumulate in cardiac tissue [23].

Doxorubicinol can impact cardiac function by inhibition of specific iondependent pumps of the SR. Examples are the $\mathrm{Ca}^{2+}$-stimulated ATPase in the $\mathrm{SR}$, the $\mathrm{Na}^{+}-\mathrm{K}^{+}$-ATPase of cardiac sarcolemma and the $\mathrm{Mg}^{2+}$-dependent ATPase in mitochondria [14]. Why doxorubicinol inhibits those enzymes, and why it is much more potent in doing that than doxorubicin is unclear. But according to the 
kinetics, it is probably unrelated to free radical production. Doxorubicinol inhibits the enzyme activities more rapidly than free radicals can be generated.

The inhibition of the ion transport systems could explain the potency of doxorubicinol, and therefore doxorubicin, as a cardiotoxin. Doxorubicinol could block calcium uptake into the SR. The result would impair both systolic and diastolic functions of the muscle.

\section{Summary}

Anthracyclines impair cardiac function, presumably by disturbing calcium homeostasis. Several hypotheses have been proposed, but none of them describes the cardiotoxicity adequately. The free radical hypothesis is popular, but has serious limitations. The metabolite hypothesis shows doxorubicinol to be a potent substance that inhibits systolic and diastolic functions and explains the time-course of the observed cardio desease. However, doxorubicin is known to have severe effects on subcellular prosseses involving calcium metabolism of the myocyte and does play an important role in cardiotoxicity as well. The investigations in this study will solely concentrate on the effects of doxorubicin; doxorubicinols impacts on ion pumps will not be discussed any further. 


\subsection{Effects on the Sarcoplasmic Reticulum}

\subsubsection{Effects on Skeletal Muscle SR}

Doxorubicin opens $\mathrm{Ca}^{2+}$ channels in the SR's terminal cisternae and causes $\mathrm{Ca}^{2+}$ release through the RyR. Doxorubicin also affects $\mathrm{Ca}^{2+}$ uptake by terminal cisternae regions of the SR. Active $\mathrm{Ca}^{2+}$ uptake into terminal cisternae SR vesicles is inhibited by doxorubicin $\left(\mathrm{IC}_{50}=0.5 \mu \mathrm{M}\right)[120] . \mathrm{Ca}^{2+}$ uptake by the longitudinal sections of SR is not affected. $\mathrm{Ca}^{2+}$ uptake is defined as the net difference between $\mathrm{Ca}^{2+}$ influx (mediated by ATP-driven pumps) and $\mathrm{Ca}^{2+}$ efflux (mainly through $\mathrm{Ca}^{2+}$ channels). Zorzato et al. showed that the $\mathrm{Ca}^{2+}$ pump in both longitudinal as well as terminal cisternae regions of the SR was not affected by doxorubicin [120]. Furthermore, the doxorubicin effect on $\mathrm{Ca}^{2+}$ uptake could be blocked by ruthenium red, a known antagonist of $\mathrm{Ca}^{2+}$ release. The change in $\mathrm{Ca}^{2+}$ uptake therefore seems to be due to the change in the efflux mechanisms. Experiments with $\mathrm{Ca}^{2+}$ loaded $\mathrm{SR}$ vesicles using radiolabeled ${ }^{45} \mathrm{Ca}^{2+}$ directly showed that doxorubicin greatly increases $\mathrm{Ca}^{2+}$ efflux from terminal cisternae SR.

Abramson et al. showed that anthraquinones directly interact with the protein complex by sensitizing the $\left[{ }^{3} \mathrm{H}\right]$ ryanodine-binding site to activation by $\mathrm{Ca}^{2+}[1]$. This observed effect was verified, as shown in Fig. 12B. It was also demonstrated 

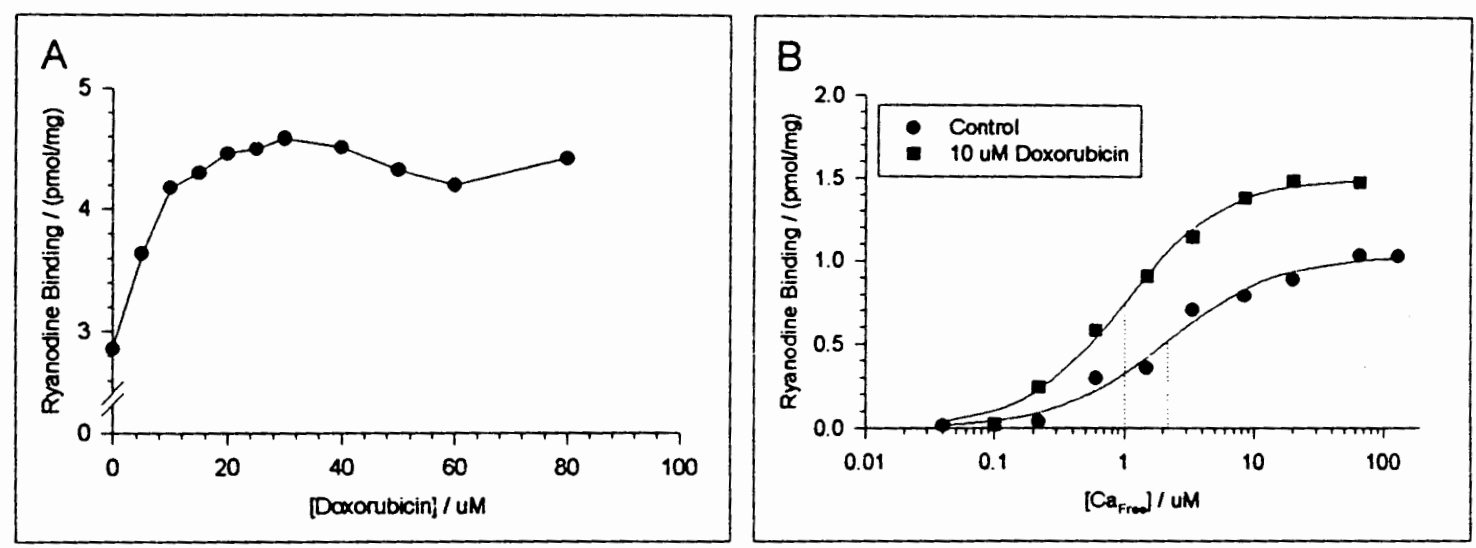

Figure 12: Doxorubicin dependence of Ryanodine Binding $(A)$ and $\mathrm{Ca}^{2+}$ dependence of Ryanodine Binding (B). A: $\left[{ }^{3} \mathrm{H}\right]$ ryanodine-binding assay carried out in regular assay buffer without $\mathrm{MgCl}_{2}$. Incubation: 3 hours as $37^{\circ} \mathrm{C}$. Nonspecific binding determined with 400 -fold excess of cold ryanodine, subtracted to obtain specific binding. $B:\left[{ }^{3} \mathrm{H}\right]$ ryanodine-binding assay carried out in regular assay buffer as described in section 3.2 .2 in the presence of $1 \mathrm{mM} \mathrm{MgCl}{ }_{2}$. Incubation: 3 hours at $37^{\circ} \mathrm{C}$. Nonspecific binding which was determined with a 400 -fold excess of cold ryanodine was subtracted for specific binding. $k_{d}\left(\mathrm{Ca}^{2+}\right)$ for the control: $2.18 \mu \mathrm{M}$, for the activation curve with $10 \mu \mathrm{M}$ doxorubicin: $1.01 \mu \mathrm{M}$. 
that doxorubicin induced $\mathrm{Ca}^{2+}$ release is inhibited by $\mathrm{Mg}^{2+}$ and is stimulated by adenine nucleotides.

The interactions between the $\mathrm{Ca}^{2+}$ release channel and doxorubicin resemble the interactions between caffeine and the $\mathrm{Ca}^{2+}$ release channel. Similarities with the effects of caffeine, a drug that acts directly on SR, suggests that doxorubicin and caffeine mobilize the same pool of $\mathrm{Ca}^{2+}$ in terminal cisternae [120]. However, comparison of caffeine induced contractions before and after exposure to anthraquinone shows that the anthraquinone interacts with a site distinct from the caffeine site [82]. Unlike caffeine, doxorubicin not only sensitizes the channel to $\mathrm{Ca}^{2+}$ activation, but it also enhances ryanodine receptor occupancy (Fig. 12A). Overall, anthraquinones are much more potent stimulators of $\mathrm{Ca}^{2+}$ release from SR vesicles than caffeine.

\subsubsection{Effects on Cardiac Muscle SR}

Kim et al. were the first ones to directly measure the effects of doxorubicin on $\mathrm{Ca}^{2+}$ fluxes in cardiac SR [57]. Their findings show that also cardiac SR shows a similar sensitivity to activation by caffeine and doxorubicin as does skeletal muscle $\mathrm{SR}$, the sensitivity of these two preparations to activation and inhibition by $\mathrm{Ca}^{2+}$ is markedly different. Maximal activation of doxorubicin or caffeine induced $\mathrm{Ca}^{2+}$ release in cardiac muscle occured at $\mathrm{Ca}^{2+}$ concentrations around $0.2 \mu \mathrm{M}$, whereas 
micromolar concentrations of $\mathrm{Ca}^{2+}$ inhibited $\mathrm{Ca}^{2+}$ release. This is in contrast with findings on skeletal muscle $\mathrm{SR}$ in which maximal $\mathrm{Ca}^{2+}$ release is observed at micromolar concentrations of $\mathrm{Ca}^{2+}$. Kim et al. conclude that the molecular mechanism of $\mathrm{Ca}^{2+}$ release in cardiac SR differs from that in skeletal SR.

\subsubsection{Summary}

Experiments presented in this study were carried out with skeletal muscle SR. This preparation is well understood and easily available. As previously described, the effect of doxorubicin on skeletal and cardiac SR are similar. In this study it is shown that ADR-925 protects skeletal muscle SR from modification by doxorubicin. Further studies using cardiac SR will be necessary to determine if the cardiac SR release channel is similary protected from doxorubicin modification by ADR-925.

\subsection{Dexrazoxane}

The singular success of doxorubicin on the one-hand and the limitations in clinical use on the other have stimulated investigations for a "better doxorubicin" [116]. Besides ongoing research for new anthracycline analogs and modifications of doxorubicin itself, one major research pathway is the administration of agents that protect against doxorubicin cardiotoxicity. 
Starting in the 1960s a series of derivatives of ethylenediamine tetra-acetic acid (EDTA) were synthesized and tested for antitumor activity [116]. One of the compounds which has undergone the most evaluation is dexrazoxane (cardioxane, ICRF-187, ADR-529). Dexrazoxane is a more water soluble EDTA analog and was proven to prevent anthracycline cardiotoxicity without compromising the drugs antitumor efficacy [92].

After over 20 years of ongoing research, dexrazoxane was approved in 1995 by the US. Food and Drug Administration (FDA) for preventing cardiotoxicity that occurs in women receiving doxorubicin for metastatic breast cancer, who have already received a cumulative doxorubicin dose of $\geq 300 \mathrm{mg} / \mathrm{m}^{2}$ [63].

Dexrazoxane itself is most likely not the active drug preventing cardiotoxicity. Vile et al. showed evidence that dexrazoxane is intracellulary converted to the fully open ring hydrolysis product ICRF-198 (ADR-925) [66] [112]. This is thought to occur in a two-step process with one-ring open intermediates, as shown in Fig. 13. The hypothesis, that the metabolite of dexrazoxane is the actual cardioprotective agent, is supported by multiple research groups and publications [37] [38] [43] [63] [112]. 


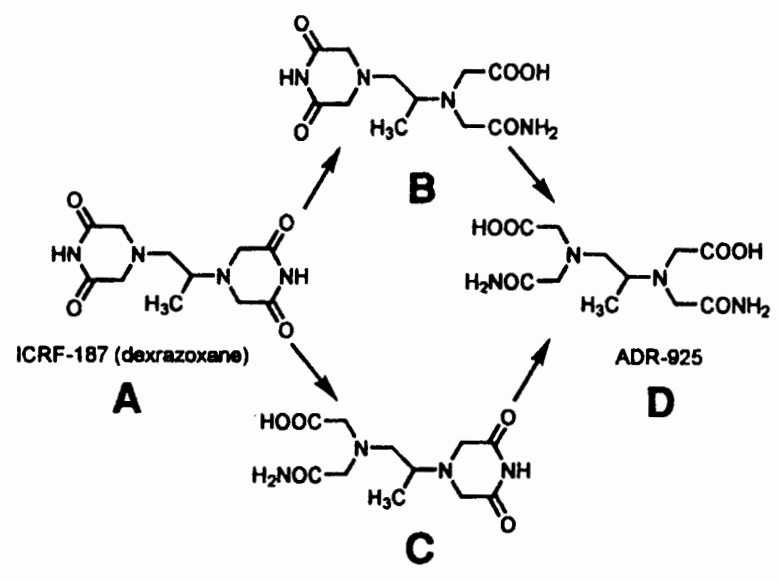

Figure 13: Structures of dexrazoxane ( $A$, ICRF-187), its one-ring open hydrolysis intermediates $B$ and $C$, and its two-ring open strongly metal ion binding product $D(\mathrm{ADR}$ 925). Reproduced from [66].

\section{$2.4 \quad$ ADR-925}

The molecular structure of ADR-925 (ICRF-198, dl-NN'-dicarboxamidomethyl$\mathrm{NN}^{\prime}$-dicarboxymethyl-1, 2-diaminopropane), the hydrolysis product of dexrazoxane, is shown in Fig. 13.

Dexrazoxane is able to diffuse through cell membranes passively and is hydrolyzed to ADR-925 internally as well as externally ${ }^{7}$ ADR-925 itself is too polar to be taken up by the cell directly. The kinetics of the hydrolysis were determined by Hasinoff [37]: dexrazoxane decays in a physiological environment with a halflife of 9.3 hours. The intermediate $B$ in Fig. 13 was observed to be created first, at about twice the rate of which intermediate $C$ is produced. The final product, ADR-925 is produced with a half-life of 23.0 hours.

\footnotetext{
${ }^{7}$ under physiological conditions. Dexrazoxane is not hydrolyzed in $\mathrm{H}_{2} \mathrm{O}$.
} 
Buss et al. showed that ferrous ion strongly promotes the ring opening of the hydrolysis intermediates ( $\mathrm{B}$ and $\mathrm{C}$ in Fig. 13) [17]. In the same publication they suggest that the intermediates chelate free iron or displace $\mathrm{Fe}^{2+}$ and $\mathrm{Fe}^{3+}$ from their doxorubicin complexes, and then undergo rapid conversions to $\mathrm{Fe}^{2+}-\mathrm{ADR}-925$.

Z.-X. Huang et al. showed that ADR-925 binds $\mathrm{Fe}^{2+}$ with high affinity [42]. The stability constants for ADR-925 and EGTA are shown in table 2. In ryanodine binding assays which are stronlgy $\mathrm{Ca}^{2+}$ dependent, experiments carried out with ADR-925 require the addition of appropriate amounts of $\mathrm{Ca}^{2+}$ to maintain the $\left[\mathrm{Ca}_{\text {free }}\right]$ within the assay. $\left[\mathrm{Ca}_{\text {free }}\right]$ were assayed using a $\mathrm{Ca}^{2+}$-selective electrode (see section 3.2 .1 on page 63$)$.

\subsection{Proposed Mechanisms of Cardioprotection}

The mechanism by which dexrazoxane/ADR-925 decreases doxorubicin cardiotoxicity is very controversial. Dexrazoxane was shown not to perturb doxorubicin's distribution, metabolism, or excretion in the body [41]. Thus these mechanisms can be eliminated a priori.

Every suggested mechanism of cardioprotection seems to be based on the free radical hypothesis of doxorubicin's cardiotoxicity and the strong metal ion chelating ability of ADR-925. 


\begin{tabular}{|l||r|r|}
\hline \multirow{2}{*}{$p q r$} & $L=$ EGTA & $L=$ ADR-925 \\
\cline { 2 - 3 } & $\log \left(\beta_{p q r}\right)$ & $\log \left(\beta_{p q r}\right)$ \\
\hline \hline$M=$ Proton \\
\hline 101 & 9.46 & 7.551 \\
102 & 18.24 & 11.348 \\
103 & 20.89 & 13.067 \\
104 & 22.89 & - \\
\hline \hline$M=$ Calcium(II) \\
\hline 110 & 10.97 & 6.887 \\
111 & 16.33 & 9.693 \\
210 & - & 8.183 \\
\hline \hline$M=$ Magnesium(II $)$ \\
\hline 110 & 5.21 & 5.081 \\
111 & 8.61 & 8.896 \\
210 & - & 6.912 \\
\hline \hline$M=$ Iron(II) \\
\hline 110 & 11.81 & 9.993 \\
111 & - & 12.208 \\
\hline \hline \multicolumn{3}{|c|}{$\beta_{p q r}=\frac{\left[L_{p} M_{q} H_{r}\right]}{[L]^{p}[M]^{q}[H]^{r}}$} \\
\hline
\end{tabular}

Table 2: Formation constants for EGTA and ADR-925 at $37^{\circ} \mathrm{C}$. The equation for the stability constants $\beta_{p q r}$ is shown in the last row. $M$ stands for the metal, $L$ symbolizes the ligand, and $H$ represents protons. The bracket symbol indicates the molar concentration of the specified compound. EGTA data based on [94], ADR-925 data from [42]. 


\subsubsection{Cardioprotection by Ion Chelation}

The ion chelating hypothesis is based on the effects of the hydrolyzed form of dexrazoxane, ADR-925. ADR-925 is a potent intracellular chelator of heavy metals. According to this theory, dexrazoxane crosses readily into the myocardial cell, where it is rapidly (half-time: 23 hours) hydrolyzed to ADR-925 [37]. ADR-925 then binds to intracellular iron, inhibiting the conversion of superoxide anions and $\mathrm{H}_{2} \mathrm{O}_{2}$ to the extremely toxic hydroxyl radicals. ADR-925 was even shown to be able to remove iron from ferritin [39], which was demonstrated to be another iron source for doxorubicin [24] (see section 2.1.1 on page 43). ADR-925 also supposedly prevents the recycling of ferrous ion back to ferric ion for use by superoxide anion radicals.

This hypothesis is questioned by different research groups. Thomas et al. showed that ADR-925 in combination with doxorubicin actually promotes hydroxyl radical production via the Fenton reaction ${ }^{8}$, and therefore cannot protect against intracellular $\mathrm{OH}$ production [106]. Hasinoff presents further evidence that the $\mathrm{Fe}^{2+}$-ADR-925 complex indeed produces hydroxyl radicals promoted by the NADPH-cytochrome-P450 reductase [38]. However, in the same article he postulates models in which the hydroxyl radical production of the $\mathrm{Fe}^{2+}-\mathrm{ADR}-925 \mathrm{com}$ plex might be less harmful than radicals generated by a iron-doxorubicin complex.

\footnotetext{
${ }^{8}$ Fenton reaction: $\mathrm{Fe}^{2+}+\mathrm{H}_{2} \mathrm{O}_{2} \longrightarrow \mathrm{Fe}^{3+}+\mathrm{OH}^{-}+\mathrm{OH}$
} 
Hasinoff shows that hydroxyl radical production by the iron-ADR-925 complex is much slower than by the iron-doxorubicin complex. Furthermore he speculates that the hydroxyl radical production by $\mathrm{Fe}^{2+}-\mathrm{ADR}-925$ might take place at a distinct, less harmful location than the one by the iron-doxorubicin complex.

Sobol et al. pointed out that ADR-925 might very well complex the free iron and even remove $\mathrm{Fe}^{3+}$ from the adriamycin- $\mathrm{Fe}^{3+}$ complex, but remarks that the iron supply in vivo is plentiful, so that this might not be the cardioprotective mechanism [98]. Furthermore, due to very high complex formation constants, doxorubicin might replace iron from iron-proteins like ferritin.

Sobol et al. determined that dexrazoxane could form a ternary complex with an existing anthracycline-iron complex in an isolated aqueous environment [98]. This was the result of computational simulations of the ternary complex and FT-NMR spectroscopy.

\subsubsection{Cardioprotection by Increased Glutathione Levels}

It is known that glutathione acts as the major intracellular reducing agent and as a potent free radical scavenger. It has been suggested that dexrazoxane acts as a cardioprotectant by scavenging free radicals and hence preventing loss of reduced intracellular GSH. However, Alderton et al. disproved this model [7]. After treatment of mice with doxorubicin, dexrazoxane or the combination of both 
drugs, no significant difference in reduced glutathione levels could be observed. Alderton et al. also showed that in spite of no difference in reduced glutathione levels, electron micrographs of mitochondria and myofibrils demonstrated that dexrazoxane is a potent cardiprotectant.

\subsubsection{Summary}

Dexrazoxane appears to act as a cardioprotectant by scavenging free radicals. Several different reaction mechanisms have been proposed, however no clear pciture describing the mode of action of this drug has evolved. Further research will be necessary to bring the biophysical/chemical understanding to the level of the empirical/clinical research. Once the mechanism of cardioprotection is understood, a directed approach to rational drug design should lead to improvements in protocols utilizing doxorubicin therapy.

\subsection{Medical Application as a Cardioprotective}

This section on the medical application of dexrazoxane is not intended to cover clinical studies and strategies. Its purpose is to give the necessary background for the usage of the drug in the described experiments. Important numbers include physiological concentration and the time-scale of doxorubicin/dexrazoxane 
therapy. For a medical review on dexrazoxane cytoprotection see reviews [75] and [92].

Clinical tests showed that dexrazoxane administration 30 minutes before the doxorubicin treatment produced the best cardioprotective results [41]. This effect could be further supported by similar results in experiments done on mice [10].

The reported ratio of dexrazoxane to doxorubicin varies between 10:1 and 30:1 (ratio by weight) [41]. For the usual doxorubicin treatment this results in an average dose $D$ of $600 \mathrm{mg} / \mathrm{m}^{2}$ body surface. Due to a lack of references, a rough molar concentration of dexrazoxane/ADR-925 inside the body was estimated as follows: The assumption of an equal distribution of the drug throughout a $m=$ $80 \mathrm{~kg}$ body with a surface $A=2 \mathrm{~m}^{2}$ and an average density $\rho$ of roughly $1 \mathrm{~kg} / \mathrm{dm}^{3}$ yields an overall concentration of

$$
c=\frac{A \cdot D \cdot M}{\rho \cdot m} \approx 50 \mu \mathrm{M}
$$

where $M$ is the molecular weight of ADR-925 $(M=304 \mathrm{~g} / \mathrm{mol})$. Most experiments presented in this study that involve ADR-925 or dexrazoxane were performed with a drug concentration of either $60 \mu \mathrm{M}$ in order to be close to physiological concentration, or at $300 \mu \mathrm{M}$ for an increased visibility of the effect. 


\section{Chapter 3}

\section{Materials and Methods}

\subsection{Materials}

\subsubsection{Chemicals}

Doxorubicin hydrochloride with purity approximately $98 \%$ was purchased from Sigma, St. Louis, Missouri. The compound was dissolved in double distilled $\mathrm{H}_{2} \mathrm{O}$ and stored at $-18^{\circ} \mathrm{C}$. Dexraxozane (ADR-529) was a gift from Adria Laboratories, Columbus, Ohio. Dexrazoxane was freshly prepared in $\mathrm{ddH}_{2} \mathrm{O}$ for every experiment and kept on ice throughout the experiment to prevent hydrolysis to ADR-925. ADR-925 was provided as a gift by Adria Laboratories. ADR-925 was dissolved in 
$\mathrm{ddH}_{2} \mathrm{O}$ in small aliquots and stored in the freezer at $-18^{\circ} \mathrm{C}$. An ADR-925 stock was never used longer than 4 weeks.

$\left[{ }^{3} \mathrm{H}\right]$ ryanodine was obtained from E. I. du Pont de Nemours and Co., Wilmington, $\mathrm{DE}$ and stored in the freezer at $-18^{\circ} \mathrm{C}$. Calcium chloride dihydrate was purchased from Mallinckrodt, St Louis, Missouri. Ethyleneglycol-bis-( $\beta$ aminoethyl ether) $N, N, N^{\prime}, N^{\prime}$-tetraacetic acid (EGTA) and all other reagents were purchased from Sigma, and stored at room temperature.

\subsubsection{SR-Preparation}

The sarcoplasmic reticulum vesicles used in all experiments were prepared from New Zealand White rabbit hind leg and back white skeletal muscle according to MacLennan [65]: After removing the fat and connective tissue, the muscles were placed in buffer $\mathrm{A}^{1}$ and quickly blended. The muscles were homogenized in the blender alternating low and high speed ${ }^{2}$. The resulting solution was centrifuged at $1600 \mathrm{~g}$ for 10 minutes. The supernatant was filtered through four layers of cheesecloth and adjusted to $\mathrm{pH} 7.4$ with dry imidazole. The filtrate was then centrifuged at $10,000 \mathrm{~g}$ for 14 minutes. The supernatant was poured through 4 layers of fresh cheesecloth. The brown pellet composed of mitochondria was discarded.

\footnotetext{
${ }^{1} 120 \mathrm{mM} \mathrm{NaCl}, 10 \mathrm{mM}$ Imidazole, $100 \mu \mathrm{M}$ DTT and $200 \mathrm{mg} / \mathrm{L}$ Leupeptin; $\mathrm{pH} 7.4$

${ }^{2}$ low speed for 15 seconds, high speed for 60 seconds. Cycle repeated 5 times with 30 second breaks between the cycles
} 
The resulting supernatant was then spun in an ultracentrifuge at $44,000 \mathrm{~g}$ for 70 minutes. The supernatant was discarded. The white pellet was homogenized with a glass homogenizer and then resuspended at approximately $10 \mathrm{mg} / \mathrm{ml}$ in buffer A. This solution was then centrifuged at $7500 \mathrm{~g}$ for $10 \mathrm{~min}$. The resulting myosin pellet was discarded and the supernatant was centrifuged at $78,000 \mathrm{~g}$ for $30 \mathrm{~min}-$ utes. The SR pellet from this last spin was suspended into buffer $B^{3}$. The SR was frozen and stored in liquid nitrogen. The protein concentration was determined by spectroscopy as described in [56].

\subsection{Methods}

\subsubsection{Determination of Free Calcium Concentration}

As described before, ADR-925 binds $\mathrm{Fe}^{2+}$ with high affinity (section 2.4). For its use in strongly $\mathrm{Ca}^{2+}$ dependent assays, the addition of appropriate amounts of $\mathrm{Ca}^{2+}$ was required to maintain the $\left[\mathrm{Ca}_{\mathrm{free}}\right]$ within the assay. For the theoretical determination of the amount of $\mathrm{Ca}^{2+}$ that had to be added to the system a computer program was created. The program is based on the formation constants of ADR-925 published in reference [42]. The software can handle the presence of other metals $\left(\mathrm{Mg}^{2+}\right.$ and $\left.\mathrm{Fe}^{2+}\right)$ as well as EGTA. EGTA was used as a $\mathrm{Ca}^{2+}$

\footnotetext{
${ }^{3} 100 \mathrm{mM} \mathrm{KCl}, 20 \mathrm{mM}$ Hepes; pH 7.0
} 
chelator to adjust $\mathrm{Ca}^{2+}$ levels in control experiments. However, for most of the experiments the calculated $\mathrm{Ca}^{2+}$ concentrations were checked by potentiometric measurements with the $\mathrm{Ca}^{2+}$ selective electrode (see section 3.2.3 on page 69). The calculations are very sensitive to the initial $\mathrm{Ca}^{2+}$ concentrations before the addition of ADR-925 or EGTA. In cases where the initial $\mathrm{Ca}^{2+}$ contents could be determined precisely the program predicted free calcium concentrations after ADR-925 or EGTA additions with an error $<10 \%$. A detailed description of the program and the algorithms used can be found in Appendix 5 (page 99).

\subsubsection{Ryanodine Binding Assays}

Ryanodine is a neutral alkaloid isolated from the stems of the plant Ryania speciosa Vahl. It is believed that the plant uses this substance to protect itself against insects. Taken up by an animal, ryanodine causes an irreversible contraction of skeletal and cardiac muscle by locking the $\mathrm{Ca}^{2+}$ channels in an open state.

Ryanodine increases the efflux of $\mathrm{Ca}^{2+}$ from heavy SR vesicles of skeletal muscle. It also activates $\mathrm{Ca}^{2+}$-transport ATPase and stimulates the $\mathrm{Ca}^{2+}$ uptake by junctional SR vesicles up to 10-fold at high ryanodine concentrations [29].

Furthermore tritium labeled Ryanodine $\left(\left[{ }^{3} \mathrm{H}\right]\right.$ ryanodine $)$ binding and the $\mathrm{Ca}^{2+}$ induced $\mathrm{Ca}^{2+}$-release share the following characteristics: localization in the terminal cisternae of the $\mathrm{SR}, \mathrm{Ca}^{2+}$ dependency (stimulated binding/release at $\mathrm{Ca}^{2+}$ 
concentrations $>1 \mu \mathrm{M}$; inhibited binding/release at $\mathrm{Ca}^{2+}$ concentrations $>1 \mathrm{mM}$ ), inhibition by $\mathrm{Mg}^{2+}$ and ruthenium red, and modulation by adenine nucleotides [29].

Pessah et al. and others concluded that $\left[{ }^{3} \mathrm{H}\right]$ ryanodine binds to the open state of the $\mathrm{Ca}^{2+}$ release channel. This makes it a powerful biochemical probe of the $\mathrm{Ca}^{2+}$ release mechanism.

$\left[{ }^{3} \mathrm{H}\right]$ ryanodine binds with a nanomolar affinity to a single class of receptors in the SR. $\left[{ }^{3} \mathrm{H}\right]$ ryanodine binding is a linear function of protein concentration. It is influenced by several factors, such as the presence of modulators of $\mathrm{Ca}^{2+}$ release (e.g., $\mathrm{Ca}^{2+}, \mathrm{Mg}^{2+}$, caffeine, and adenine nucleotides [82]), ionic strength, $\mathrm{pH}$ and temperature. The binding of $\left[{ }^{3} \mathrm{H}\right]$ ryanodine is sensitive to brief periods at elevated temperature, i.e., partial and complete loss of binding activity after incubation at $45^{\circ} \mathrm{C}$ and $50^{\circ} \mathrm{C}$, respectively, for $10 \mathrm{~min}$.

$\left[{ }^{3} \mathrm{H}\right]$ ryanodine binding was shown to be optimal at $100-1000 \mu \mathrm{M} \mathrm{Ca}^{2+}$. Binding decreased at higher concentrations $(>2 \mathrm{mM})$ The $k_{d}$ (the $\mathrm{Ca}^{2+}$ concentration for one-half of optimal binding) was determined to be $20 \mu \mathrm{M}$.

$\mathrm{Mg}^{2+}$ at $1 \mathrm{mM}$ inhibits radioligand binding to the soluble receptor at all $\mathrm{Ca}^{2+}$ concentrations. $\left[{ }^{3} \mathrm{H}\right]$ ryanodine binding is stimulated by $1 \mathrm{mM}$ cAMP, even in the presence of $1 \mathrm{mM} \mathrm{Mg}^{2+}$. In contrast, $1 \mathrm{mM}$ cGMP is inhibitory at $\mathrm{Ca}^{2+}$ concen-trations above $30 \mu \mathrm{M}[29]$. 
In addition to being able to examine changes in equilibrium binding of ryanodine, valuable information can be obtained by measuring changes in the kinetics of ryanodine binding in the presence of these activators and inhibitors. The dissociation rate of ryanodine is hardly affected by $\mathrm{Mg}^{2+}$, caffeine, AMP-PNP, AMP-PCP or high $\mathrm{Ca}^{2+}$, EGTA or $\mathrm{NaCl}$ levels. However, high concentrations of ruthenium red and unlabeled ryanodine slows down the rate of dissociation of bound $\left[{ }^{3} \mathrm{H}\right]$ ryanodine. AMP-PNP and AMP-PCP increase the rate of association of $\left[{ }^{3} \mathrm{H}\right]$ ryanodine. Both high ionic strength $(\mathrm{NaCl}$ or $\mathrm{KCl})$ and caffeine increase the rate of association of $\left[{ }^{3} \mathrm{H}\right]$ ryanodine to its receptor site. Ruthenium red and millimolar $\mathrm{Mg}^{2+}$ decrease the rate of association [21]. A major part of this thesis examines the effects of ADR-925 and dexrazoxane on the kinetics of $\left[{ }^{3} \mathrm{H}\right]$ ryanodine binding.

On $\left[{ }^{3} \mathrm{H}\right]$ ryanodine binding assays, the method described in [82] was used. Briefly, SR vesicles $(0.5 \mathrm{mg} / \mathrm{ml})$ were incubated at $37^{\circ} \mathrm{C}$ for 3 hours in buffer containing $250 \mathrm{mM} \mathrm{KCl}, 25 \mathrm{mM}$ HEPES, $15 \mathrm{mM} \mathrm{NaCl}, 14 \mathrm{nM}$ ryanodine and $1 \mathrm{nM}\left[{ }^{3} \mathrm{H}\right]$ ryanodine. Pessah et al. determined a half time of $24.8 \mathrm{~min}$ for the association of $\left[{ }^{3} \mathrm{H}\right]$ ryanodine with its binding site in buffer ${ }^{4}$ at $37^{\circ} \mathrm{C}$. The binding saturates after three hours ${ }^{5}$. Most binding assays were carried out at a free

\footnotetext{
${ }^{4}$ consisting of $60 \mu \mathrm{M} \mathrm{Ca}^{2+}, 10 \%$ sucrose, and $40 \mathrm{mM}$ Tris maleate; pH 7.1

${ }^{5}$ See Section 4.5: Time Dependencies (page 87)
} 
$\mathrm{Ca}^{2+}$ concentration of $65 \mu \mathrm{M}$ (adjusted with $\mathrm{CaCl}_{2}$ ). Depending on the assay, various channel modifiers were present during the incubation procedure. For details on individual experiments refer to figure captions.

Assays were quenched by rapid filtration trough Whatman GF/B glass fiber filters in a cell harvester (Brandel, Gaithersburg, MD). The filters were rinsed three times with $3 \mathrm{ml}$ washing buffer containing $250 \mathrm{mM} \mathrm{KCl}, 15 \mathrm{mM} \mathrm{NaCl}$, $20 \mathrm{mM}$ Hepes, and $50 \mathrm{mM} \mathrm{CaCl} 2 ; \mathrm{pH} 7.1$. The filters were placed in scintillation vials (polytubes, Fisher), filled with $2.5 \mathrm{ml}$ scintillation cocktail (ICN, CytoScint), shaken overnight and counted the following day.

Non-specific binding was measured in the presence of a 400 -fold excess of unlabeled ryanodine and subtracted from the data prior to the calculation of the specific binding per mg SR.

\section{Hill Analysis of Binding Data}

Dose dependent binding assays were fit to the Hill equation. The Hill equation is (for assays with activators, i.e., compounds that increase binding with increasing concentration)

$$
B=B_{\max } \frac{[x]^{n}}{k_{d}+[x]^{n}}
$$


where $B_{\max }$ is the maximum binding, $[x]$ is the concentration of the activator or inhibitor, and $k_{d}$ is the apparent affinity of the binding site for the activator/inhibitor. $n$ is called the apparent Hill coefficient. Experiments with inhibitors (i.e., substances that decrease binding) were fit to

$$
B=B_{\max }\left(1-\frac{[x]^{n}}{k_{d}+[x]^{n}}\right)
$$

The data were fit by nonlinear regression using the Marquardt-Levenberg algorithm. This algorithm seeks the coefficients of the independent variables ("xvalues") in a way that the sum of the squared differences between the observed and predicted values of the dependent variables ("y-values") are minimized. This algorithm was implemented in the graphing software Sigma Plot ${ }^{6}$ and could be applied on graphs easily.

Using the fit-parameters, the $\mathrm{EC}_{50}$ (in case of activators) or the $\mathrm{IC}_{50}$ (for inhibitors) could be calculated from

$$
\left.\begin{array}{l}
\mathrm{EC}_{50} \\
\mathrm{IC}_{50}
\end{array}\right\}=k_{d}^{\left(\frac{1}{n}\right)}
$$

\section{Association Kinetic Experiments}

Assays for the determination of the association kinetics of $\left[{ }^{3} \mathrm{H}\right]$ ryanodine with its binding site were carried out with two different heat reservoirs (water baths). One

\footnotetext{
${ }^{6}$ Sigma Plot Scientific Graphing Software, Version 2.01 by Jandel Cooperation
} 
was set to the desired incubation temperature of $37^{\circ} \mathrm{C}$ and held stable within a range of $\pm 0.5^{\circ} \mathrm{C}$ by an electronic regulator. The second incubator was held below $3^{\circ} \mathrm{C}$ with ice water. The rate of binding of $\left[{ }^{3} \mathrm{H}\right]$ ryanodine is known to slow down about 8 fold at room temperature $\left(20^{\circ} \mathrm{C}\right)$ compared to $37^{\circ} \mathrm{C}$. A negligible amount of binding occurs at $3^{\circ} \mathrm{C}$ over the time course of these experiments.

One of the problems with time dependent association experiments is the limited lifetime of protein at $37^{\circ} \mathrm{C}$. A control experiment (data not shown) demonstrated that incubation times longer than 15 hours are not appropriate, because of artifacts probably due to protein denaturation.

\subsection{3 $\mathrm{Ca}^{2+}$ selective Potentiometry}

\section{The $\mathrm{Ca}^{2+}$ sensitive Electrode}

Measurements of free calcium concentrations and transport of $\mathrm{Ca}^{2+}$ across SR vesicles were performed with a $\mathrm{Ca}^{2+}$ selective electrode. This electrode was made by spreading over the end of a graphite rod a PVC membrane, in which a liquid ion-exchanger was incorporated. The ion exchanger used was IE200 which was purchased from World Precision Instruments (WPI) [9]. 
The $\mathrm{Ca}^{2+}$ electrode sets up an electrical potential across a membrane which is selective for $\mathrm{Ca}^{2+}$. In the absence of interfering ions, the response of the calcium electrode is given by the Nernst equation:

$$
E=E_{0}+\frac{2.3 R T}{n F} \log A_{\mathrm{Ca}^{2+}}
$$

where $E$ is the measured potential, $E_{0}$ is a constant including effects of the reference electrode, $R$ is the gas constant, $T$ is the temperature, $F$ is the Faraday constant and $n$ is the charge on the ion being measured ( 2 in the case of $\left.\mathrm{Ca}^{2+}\right) \cdot A_{\mathrm{Ca}^{2+}}$ is the calcium activity. $2.3 R T / n F$ is called the Nernst factor and has a theoretical value of $29.58 \mathrm{mV}$ for the calcium ion at $25^{\circ} \mathrm{C}$.

The experimental setup includes the sensing electrode, a reference electrode and a $\mathrm{pH}$ meter. The reference electrode used in our setup is a porous glass electrode which is saturated with $\mathrm{KCl}(3 \mathrm{M} \mathrm{KCl})$. For the visualization of the data a recorder is connected to the $\mathrm{pH}$ meter. For long-time data acquisition and easy calibration/transformation, the data are digitized and processed using an IBM XT computer. Experiments at different temperatures could be carried out with an electronically regulated water bath.

\section{Data Acquisition}

Prior to every experiment the $\mathrm{Ca}^{2+}$ selective electrode needed to be calibrated in the specific buffer that was going to be used in the experiment. Transport assays 
were performed in a buffer containing $100 \mathrm{mM} \mathrm{KCl}, 20 \mathrm{mM}$ HEPES, $1 \mathrm{mM} \mathrm{MgCl} \mathrm{M}_{2}$ at $\mathrm{pH}$ 7.0. In cases, where the electrode was used for the determination of free calcium concentrations, it was calibrated in the buffer that was used for the specific solution of interest. The recalibration for different kinds of buffer was necessary, because the $\mathrm{Ca}^{2+}$ selective electrode had minor sensitivity for other ions (mainly $\mathrm{Mg}^{2+}$ ) and reacted differently on buffers with distinct salt concentrations. The ionic strength of the solution influenced the sensitivity of the electrode because of ionic shielding.

According to the Nernst equation (6) the relationship between the measured electrical potential and the calcium concentration is logarithmic. Linear regression of the calibration data in a voltage $(V)$ versus $\log \left[\mathrm{Ca}_{\text {free }}\right]$ diagram yields slope and intercept that can then be used to convert the measured voltage to [Cafree]. As one can see in Nernst's equation, the slope of the regression is proportional to the absolute temperature $T$. Experiments at different temperatures therefore required a recalibration of the electrode. For a buffer at $20^{\circ} \mathrm{C}$ with low ionic strength the calibration of the electrode used for our experiments yielded a slope close to the theoretical value of $29 \mathrm{mV}$.

Once calibrated, the system with the connected PC could be used for direct $\mathrm{Ca}^{2+}$ concentration readings. Another benefit of the use of a personal computer was the ability to monitor and store transient processes. The sampling rate for 
digitized data on the PC was 10 samples per second, which was adequate for the observed processes.

\section{Transport Assays}

$\mathrm{Ca}^{2+}$ fluxes were monitored with the $\mathrm{Ca}^{2+}$ selective electrode. Transport assays were carried out in $3 \mathrm{ml}$ of buffer with $100 \mathrm{mM} \mathrm{KCl}, 20 \mathrm{mM}$ HEPES, $1 \mathrm{mM}$ $\mathrm{MgCl}_{2}$ at $\mathrm{pH}$ 7.0. During the experiment, the extravesicular $\mathrm{Ca}^{2+}$ concentration was monitored on an $\mathrm{x}-\mathrm{y}$ recorder as well as the on the connected PC. After the addition of $20 \mu \mathrm{M} \mathrm{CaCl}_{2}$ to the buffer, $0.2 \mathrm{mg} \mathrm{SR}$ per $\mathrm{ml}$ buffer was added. The SR usually introduced another 2 to $3 \mu \mathrm{M} \mathrm{Ca}^{2+}$ to the buffer. After equilibration $0.5 \mathrm{mM} \mathrm{MgATP}$ were added to initiate $\mathrm{Ca}^{2+}$ uptake into the SR vesicles. After complete uptake the calcium concentration remaining in the buffer was $\approx 1.5 \mu \mathrm{M}$. At this point the $\operatorname{drug}(s)$ of interest were added to initiate $\mathrm{Ca}^{2+}$ release. $\mathrm{Ca}^{2+}$ efflux rates were determined from the maximal slope of the extravesicular $\mathrm{Ca}^{2+}$ versus time. For this purpose the digitized recorder data on the PC was of great help. A graphed sample data file with linear regression line is shown in Fig. 14. At the end of each experiment the $\mathrm{Ca}^{2+}$ ionophore $\mathrm{A} 23187$ was added to the solution in order to determine the amount of $\mathrm{Ca}^{2+}$ remaining in the $\mathrm{SR}$ vesicles. 


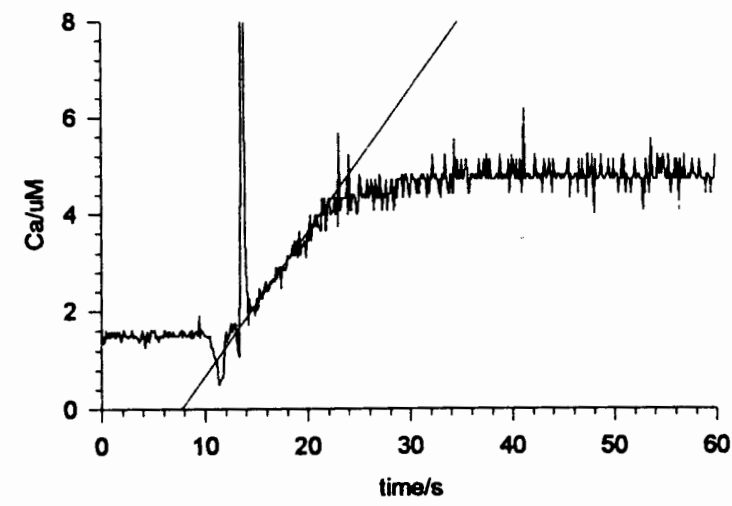

Figure 14: Sample recorder reading of sample $\mathrm{Ca}^{2+}$ efflux assay. The slope of linear regression is the efflux rate. The huge peak at $t=14 \mathrm{~s}$ is due to the injection of doxorubicin (the concentration of doxorubicin in this experiment was $3.3 \mu \mathrm{M}$ ) 


\section{Chapter 4}

\section{Results}

\section{1 $\mathrm{Ca}^{2+}$ Efflux Assays}

\subsubsection{Effects of Dexrazoxane on Doxorubicin Induced $\mathrm{Ca}^{2+}$ Release}

Doxorubicin induced $\mathrm{Ca}^{2+}$ efflux from actively loaded $\mathrm{SR}$ vesicles was measured in the presence of different concentrations of dexrazoxane. These measurements were carried out with a $\mathrm{Ca}^{2+}$ selective electrode as described in section 3.2.3. Preliminary experiments were performed to ensure that the $\mathrm{Ca}^{2+}$ selective electrode was properly calibrated and exhibited a sufficiently fast response time to changes in 
the free $\mathrm{Ca}^{2+}$ concentration. A sample recorder reading of this type of measurement was shown in section 3.2.3 (Fig. 14).

SR vesicles were suspended in transport buffer as described in Materials and Methods, section 3.2.3. After the system was stabilized, $\mathrm{Ca}^{2+}$ uptake was initiated by the addition $0.5 \mathrm{mM}$ MgATP. Within minutes, $\mathrm{Ca}^{2+}$ was taken up by the SR lowering the extravesicular free $\mathrm{Ca}^{2+}$ concentration to approximately $1.5 \mu \mathrm{M}$. At this point, the specific concentrations of dexrazoxane were added and allowed to stir for about one minute. $\mathrm{Ca}^{2+}$ release was initiated by the addition of $10 \mu \mathrm{M}$ doxorubicin. The efflux rate, normalized per mg SR, was determined from the digitized data as described in Materials and Methods. The results of these measurements are shown in Fig. 15. The concentrations of dexrazoxane used in these experiments exceeded the range in which it has been used in medical applications. According to previous publications [41], dexrazoxane to doxorubicin ratios ranging from 10:1 up to $30: 1$ have been used in medical applications (see section 2.6).

As shown in Fig. 15, doxorubicin induced $\mathrm{Ca}^{2+}$ efflux was not affected by dexrazoxane. The fluctuations in the maximal $\mathrm{Ca}^{2+}$ release rate for different dexrazoxane concentrations is most likely due to uncertainties in the determination of the maximum slope of $\mathrm{Ca}^{2+}$ release. In addition, slightly different amounts of $\mathrm{Ca}^{2+}$ uptake by the vesicles in each experiment contribute to the experimental error. 


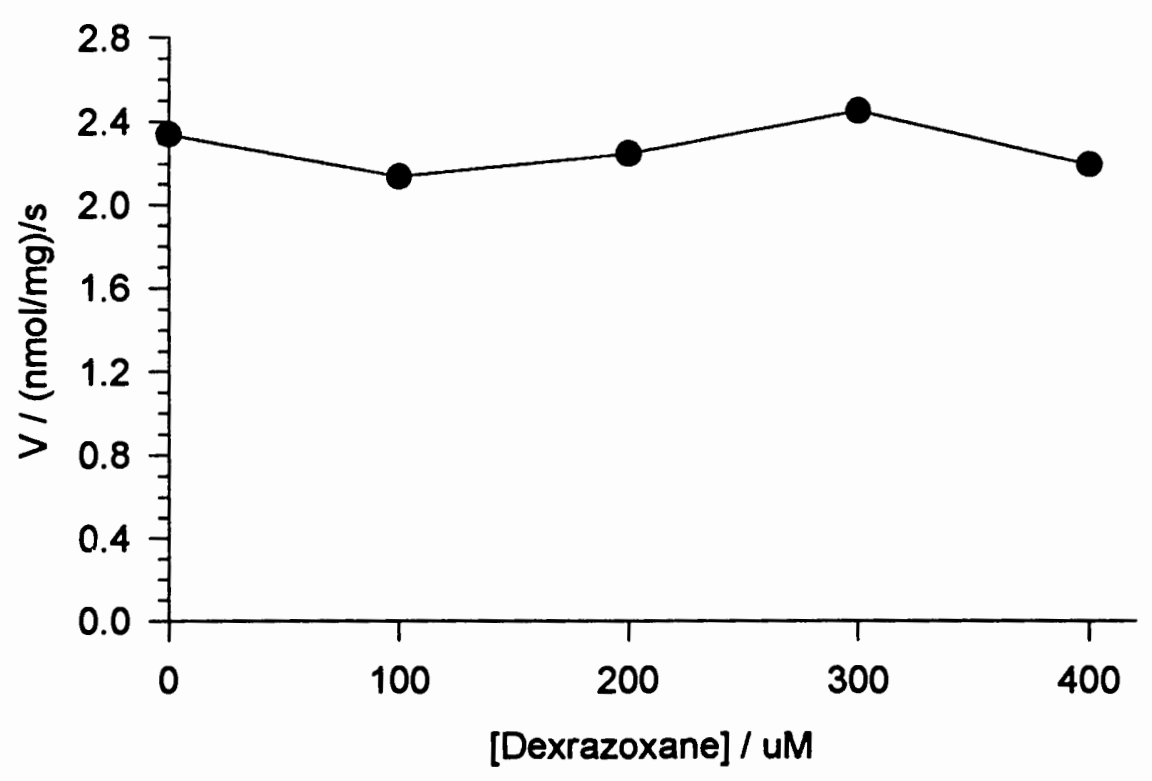

Figure 15: Doxorubicin induced $\mathrm{Ca}^{2+}$ efflux as a function of dexrazoxane concentration. SR vesicles $(0.2 \mathrm{mg} / \mathrm{ml})$ were suspended in $100 \mathrm{mM} \mathrm{KCl}, 1 \mathrm{mM} \mathrm{MgCl}{ }_{2}$, $10 \mu \mathrm{M} \mathrm{CaCl}_{2}, 20 \mathrm{mM}$ HEPES; $\mathrm{pH} 7.0$, at a protein concentration of $0.2 \mathrm{mg} / \mathrm{ml}$. $\mathrm{Ca}^{2+}$ uptake was initiated by the addition of $0.5 \mathrm{mM} \mathrm{MgATP}$. Different concentrations of dexrazoxane were added after $\mathrm{Ca}^{2+}$ uptake was complete and $60 \mathrm{sec}$ prior to the addition of doxorubicin $(10 \mu \mathrm{M})$. Prior to the addition of doxorubicin, the free $\mathrm{Ca}^{2+}$ was adjusted to $1.5 \mu \mathrm{M}$ (by addition of another $1 \pm 0.3 \mu \mathrm{M} \mathrm{CaCl}_{2}$ ). $V$ was measured from the maximum slope of the $\mathrm{Ca}^{2+}$ concentration versus time and normalized per mg protein. 


\subsubsection{Limitations of Transport Assays in Experiments In- volving Strong $\mathrm{Ca}^{2+}$ Chelators}

The $\mathrm{Ca}^{2+}$ efflux assay described in the previous section was also used to examine the effects of ADR-925 on doxorubicin induced $\mathrm{Ca}^{2+}$ release. However, due to its ability to chelate $\mathrm{Ca}^{2+}, \mathrm{ADR}-925$ itself affected the response of the $\mathrm{Ca}^{2+}$ selective electrode. Following $\mathrm{Ca}^{2+}$ efflux from the SR, a large fraction of the released $\mathrm{Ca}^{2+}$ bound to ADR-925 and was therefore not detected by the electrode. The computer program WORSE (described in section 3.2.1) was used to transform the acquired concentration of free $\mathrm{Ca}^{2+}$ at every timepoint in the experiment to the total concentration of $\mathrm{Ca}^{2+}$ present outside the $\mathrm{SR}$ vesicles.

Analysis of this final data (not shown) revealed a number of problems associated with this method. First, minor uncertainties in the initial $\mathrm{Ca}^{2+}$ concentration, before the addition of doxorubicin, translate to major fluctuations in the efflux rate. This is due to the fact that the transformation of $\mathrm{Ca}_{\text {free }}^{2+}$ to $\mathrm{Ca}_{\text {total }}^{2+}$ is not linear. The calculated rate of $\mathrm{Ca}^{2+}$ release is therefore a function of the initial $\mathrm{Ca}^{2+}$ concentration. Second, with increasing concentrations of ADR-925 the amount of $\mathrm{Ca}^{2+}$ release observed gets smaller (more released $\mathrm{Ca}^{2+}$ is chelated, and the change in the free $\mathrm{Ca}^{2+}$ concentration becomes smaller). For ADR-925 concentrations above $80 \mu \mathrm{M}$, signal acquisition became impossible because of the limited resolution 
of the digitizer. And, finally, the transformation of the acquired free concentrations to total concentrations increased the noise in the signal dramatically. Whereas the signal itself got smaller for increased ADR-925 concentrations, the noise stayed the same. Therefore the signal to noise ratio decreased for increasing ADR-925 concentrations. In summary, ion selective potentiometry is not an appropriate method for the determination of $\mathrm{Ca}^{2+}$ efflux from $\mathrm{SR}$ vesicles in the presence of ADR-925. In order to study the effects of ADR-925 on the calcium release channel, other experimental methods and procedures must be utilized.

\subsection{Effects of ADR-925 and Dexrazoxane on Ryanodine Binding}

The ability of dexrazoxane and ADR-925 to modify high affinity $\left[{ }^{3} \mathrm{H}\right]$ ryanodine binding to its receptor were examined in Fig. 16. SR vesicles were suspended in the binding buffer as described in Materials and Methods, section 3.2.2. Dexrazoxane stock solutions were prepared fresh before each experiment at a concentration of $100 \mathrm{mM}$. ADR-925 stock solution was prepared in water at a concentration of $100 \mathrm{mM}$. The stock solutions were then diluted $1: 10$ with $\mathrm{ddH}_{2} \mathrm{O}$ several times and stored on ice. To adjust free $\mathrm{Ca}^{2+}$ levels in the presence of ADR-925, appropriate $\mathrm{CaCl}_{2}$ aliquots were added, as determined by the software program WORSE. The 
free $\mathrm{Ca}^{2+}$ levels for each individual sample were verified with the $\mathrm{Ca}^{2+}$ selective electrode and were found to be within $10 \%$ of their expected value.

The data were fit to the Hill equation as described in Materials and Methods, section 3.2.2. The $\mathrm{IC}_{50}$ (concentration of the titrated compound that yields $1 / 2$ of maximum binding) for ADR-925 in this experiment was determined to be $90 \mu \mathrm{M}$. The calculated $\mathrm{IC}_{50}$ for dexrazoxane was $3.7 \mathrm{mM}$.

Fig. 16 shows that ADR-925 inhibits high affinity ryanodine binding. Dexrazoxane also seems to inhibit binding, but only at very high concentrations of the drug. The $\mathrm{IC}_{50}$ for dexrazoxane is about 40 times the $\mathrm{IC}_{50}$ of $\mathrm{ADR}-925$.

\subsection{Doxorubicin Dependence of Ryanodine}

\section{Binding: Effect of ADR-925 on Doxorubi-}

\section{cin Dependence}

Fig. 17 shows the doxorubicin dependence of ryanodine binding in the presence and absence of $300 \mu \mathrm{M}$ ADR. The assay was carried out at a free calcium concentration of $7.5 \mu \mathrm{M}$, in the presence of $1 \mathrm{mM} \mathrm{MgCl}_{2}$. Abramson et al. have previously reported that doxorubicin's effect on ryanodine binding is highly affected by the 


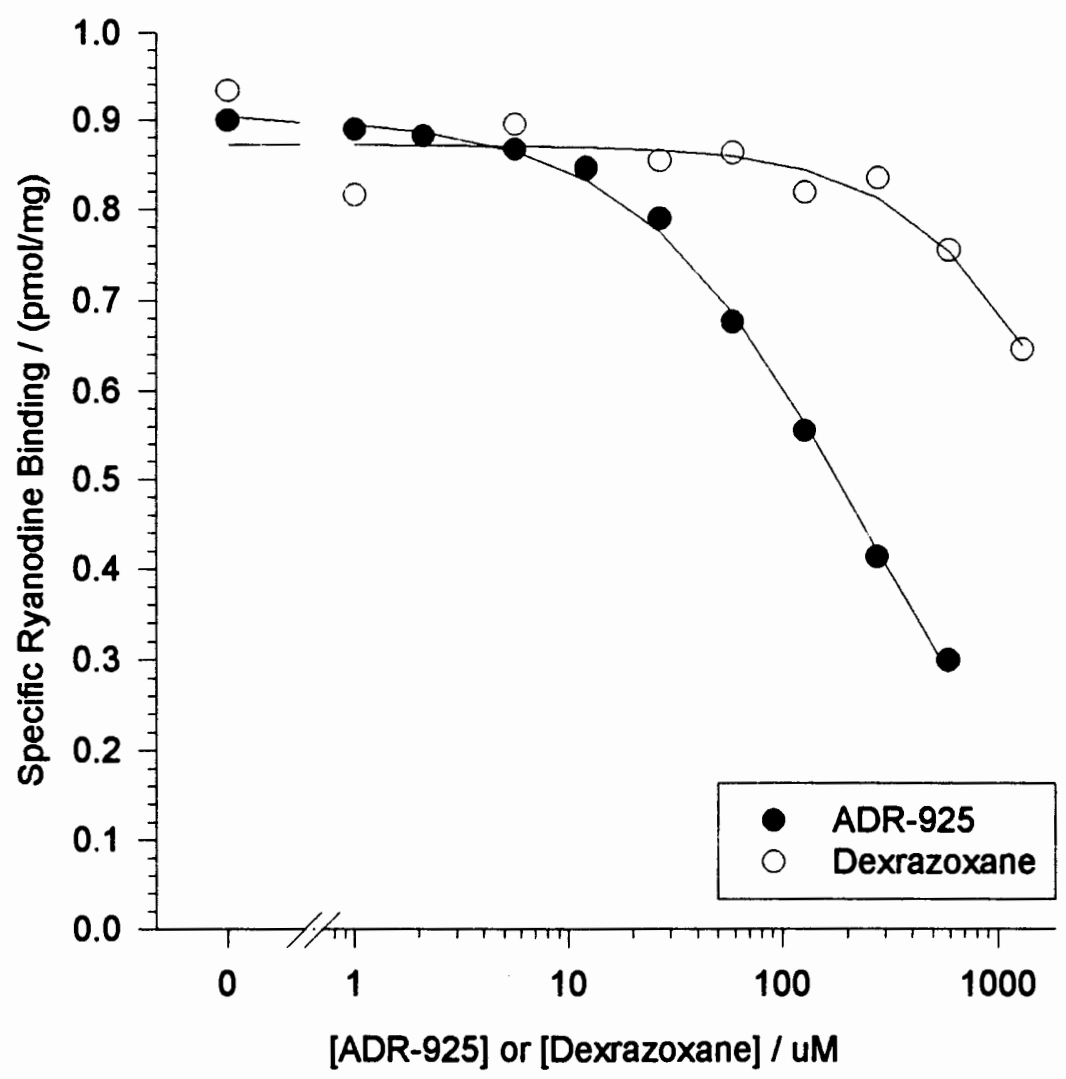

Figure 16: Effect of ADR-925 and dexrazoxane on ryanodine binding. $\left[{ }^{3} \mathrm{H}\right]$ ryanodine binding assay carried out as described in Materials and Methods, section 3.2.2. The buffer contained $1 \mathrm{mM}$ free $\mathrm{Mg}^{2+}$ and $7.5 \mu \mathrm{M}$ free $\mathrm{Ca}^{2+}$. The concentrations of free $\mathrm{Mg}^{2+}$ and $\mathrm{Ca}^{2+}$ were held constant by appropriate additions of $\mathrm{MgCl}_{2}$ and $\mathrm{CaCl}_{2}$, respectively. The concentration of free $\mathrm{Ca}^{2+}$ for every data point was double checked by potentiometric $\mathrm{Ca}_{\text {free }}^{2+}$ determinations as described in Materials and Methods, section 3.2.1, and was found to be within $10 \%$ of the calculated value. The samples were incubated at $37^{\circ} \mathrm{C}$ for 4.5 hours. Nonspecific binding was determined with a 400 -fold excess of ryanodine. Assays were terminated by rapid filtration through Whatman GF/B glass fiber filters as described in section 3.2.2. The data for ADR-925 are an average of two experiments carried out in duplicate; the data for dexrazoxane are the average of duplicates of one experiment. The data were fit to a modified Hill equation for inhibitors as described in section 3.2.2. For the fit parameters see text. 
presence of inhibitors like $\mathrm{Mg}^{2+}[1]$. Specific ryanodine binding was monitored over the range of 0 to $500 \mu \mathrm{M}$ doxorubicin.

In this experiment, doxorubicin activation of ryanodine binding did not reach saturation in the observed concentration range. However, $300 \mu \mathrm{M}$ ADR-925 was an effective inhibitor of ryanodine binding. The amount of inhibition by ADR-925 appears to be independent of the doxorubicin concentration. The data were fit to the modified Hill equation (Eqn. (3) plus a constant offset representing binding at $0 \mu \mathrm{M}$ doxorubicin).

\subsection{Effect of ADR-925 on the Calcium Activa- tion of Ryanodine Binding}

High affinity ryanodine binding to the SR is strongly $\mathrm{Ca}^{2+}$ dependent [82]. The effects of ADR-925 on the calcium activation of ryanodine binding were studied. The free $\mathrm{Ca}^{2+}$ concentration in this study was varied by various additions of either EGTA or $\mathrm{CaCl}_{2}$ as calculated by WORSE. The absolute values of $\left[\mathrm{Ca}_{\text {free }}\right]$ were verified by measurements with the $\mathrm{Ca}^{2+}$ electrode, where applicable (usable range of the electrode: $\approx 1.5$ to $100 \mathrm{uM}$ ). The free $\mathrm{Ca}^{2+}$ concentrations for corresponding data points outside of this range were brought to the same level by additions of 


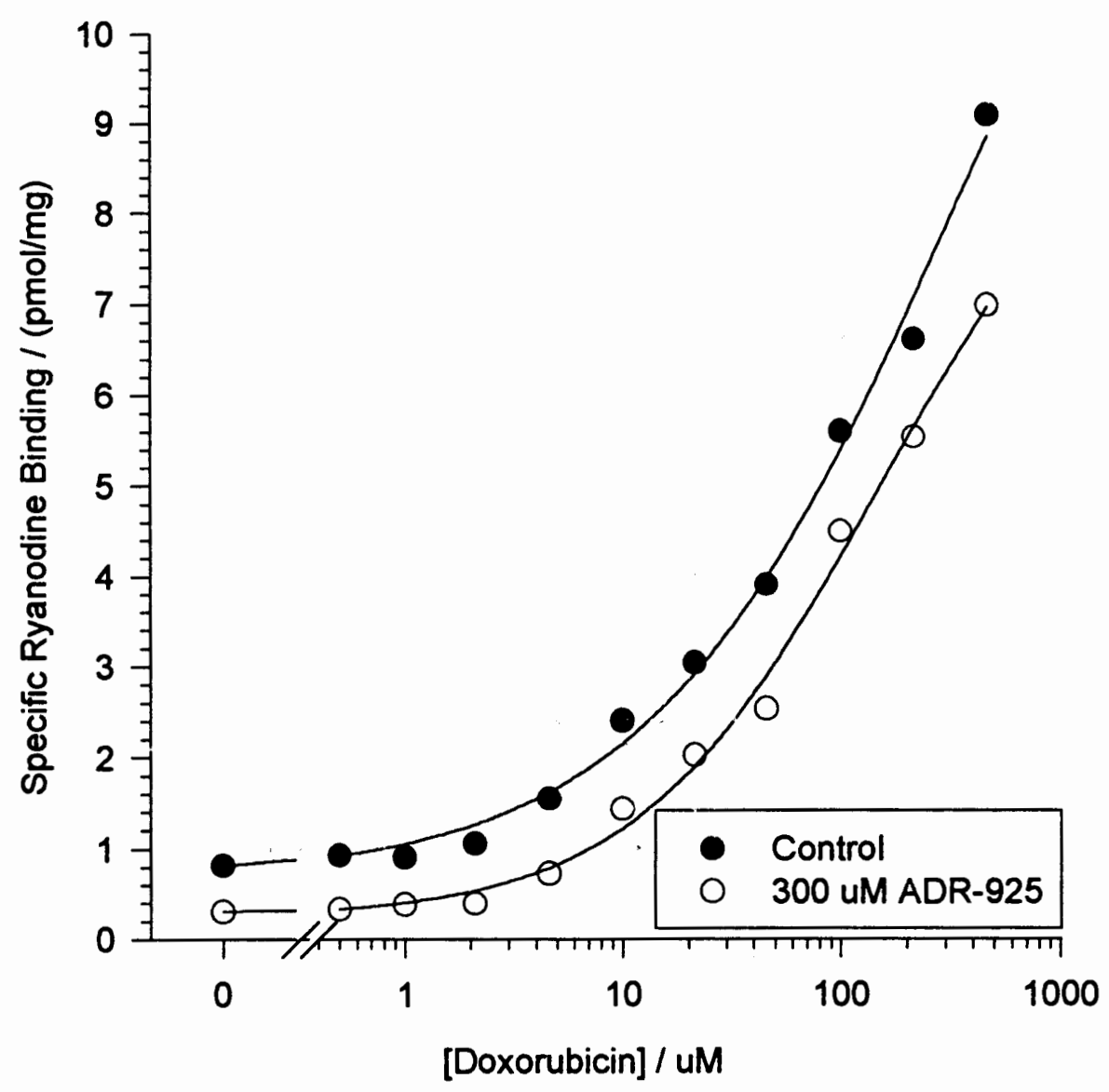

Figure 17: Effects of $300 \mu \mathrm{M}$ ADR-925 on the doxorubicin dependence of ryanodine binding. SR vesicles $(0.5 \mathrm{mg} / \mathrm{ml})$ were incubated at $37^{\circ} \mathrm{C}$ for 3 hours, in a buffer containing $250 \mathrm{mM} \mathrm{KCl}, 15 \mathrm{mM} \mathrm{NaCl}, 20 \mathrm{mM}$ Hepes, $1 \mathrm{mM} \mathrm{MgCl} 2,14 \mathrm{nM}$ ryanodine and $1 \mathrm{nM}\left[{ }^{3} \mathrm{H}\right]$ ryanodine. [Ca free $]$ was adjusted to $7.5 \mu \mathrm{M}$ for both the control and the ADR-925 treated samples. Non-specific binding was determined with a 400 -fold excess of cold ryanodine. The data were fit to a modified Hill equation for activators including an additive constant representing the binding at $0 \mu \mathrm{M}$ doxorubicin. 
EGTA and $\mathrm{CaCl}_{2}$ so that the same $\mathrm{mV}$ reading on the electrode was obtained for all four samples.

Fig. 18 shows the calcium activation of ryanodine binding for SR vesicles incubated in a buffer containing $250 \mathrm{mM} \mathrm{KCl}, 15 \mathrm{mM} \mathrm{NaCl}, 20 \mathrm{mM}$ HEPES, $14 \mathrm{nM}$ cold ryanodine and $1 \mathrm{nM}\left[{ }^{3} \mathrm{H}\right]$ ryanodine. After 3 hours of incubation at $37^{\circ} \mathrm{C}$ the experiment was quenched by rapid filtration as described in section 3.2.2.

High affinity ryanodine binding increases with $\mathrm{Ca}^{2+}$ concentration until saturation is reached at $\left[\mathrm{Ca}_{\text {free }}\right]=50 \mu \mathrm{M}$. Binding decreases for $\mathrm{Ca}^{2+}$ levels above $100 \mu \mathrm{M} .10 \mu \mathrm{M}$ doxorubicin increases ryanodine binding compared to the control from approximately $2.8 \mathrm{pmol} / \mathrm{mg}$ to approximately $3.5 \mathrm{pmol} / \mathrm{mg}$. ADR-925 $(300 \mu \mathrm{M})$ did not significantly change the $B_{\max }$. However, the $\mathrm{Ca}^{2+}$ activation was shifted to the right, towards higher $\left[\mathrm{Ca}_{\text {free }}\right]$ levels. The $\mathrm{EC}_{50}\left(\right.$ free $\mathrm{Ca}^{2+}$ concentration that yields $1 / 2$ maximum binding) for the experiment without doxorubicin was shifted from $0.4 \mu \mathrm{M}$ to $1.1 \mu \mathrm{M}\left[\mathrm{Ca}_{\text {free }}\right]$.

This did not appear to be the case in the presence of doxorubicin $(10 \mu \mathrm{M})$. When treated with doxorubicin, the ADR-925 did not shift the $\mathrm{Ca}^{2+}$ activation curve. The $\mathrm{EC}_{50}$ was determined to be $\approx 0.3 \mu \mathrm{M}$ in the presence of the anthraquinone. However, the $\mathrm{Ca}^{2+}$ activation of ryanodine binding appeared to be less steep, when ADR-925 was present. This, indeed, is reflected by the Hill coefficient $n$ from the corresponding Hill fits. The Hill coefficients for the $\mathrm{Ca}^{2+}$ titrations 


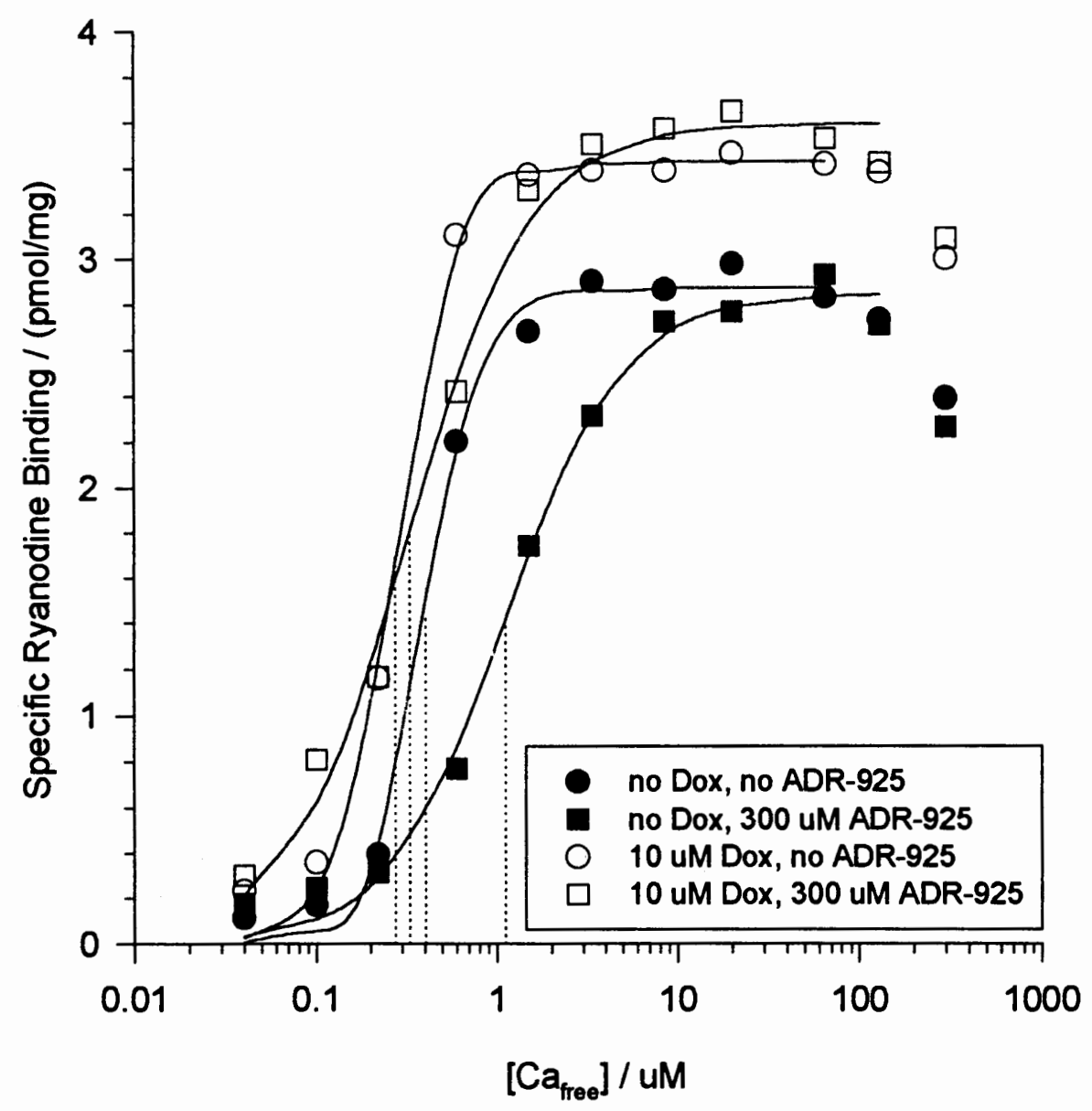

Figure 18: Effects of doxorubicin and ADR-925 on $\mathrm{Ca}^{2+}$ activation of ryanodine binding in the absence of $\mathrm{Mg}^{2+}$. SR vesicles $(0.5 \mathrm{mg} / \mathrm{ml})$ were suspended in buffer containing $250 \mathrm{mM} \mathrm{KCl}, 25 \mathrm{mM}$ HEPES, $15 \mathrm{mM} \mathrm{NaCl}, 14 \mathrm{nM}$ ryanodine and $1 \mathrm{nM}\left[{ }^{3} \mathrm{H}\right]$ ryanodine. The concentration of free $\mathrm{Ca}^{2+}$ was adjusted as described in the text. The samples were incubated for 3 hours at $37^{\circ} \mathrm{C}$ and then filtered as described in Materials and Methods. The rising edge of the data were fit to the Hill equation. The parameters of the fit are discussed in the text. 
without ADR-925 were 2.8 and 2.6 (without and with $10 \mu \mathrm{M}$ doxorubicin, respectively). The experiments with ADR-925 yielded Hill coefficients of 1.3 without and with $10 \mu \mathrm{M}$ doxorubicin. In the absence of $\mathrm{Mg}^{2+}, \mathrm{ADR}-925$ decreased the degree of positive cooperativity associated with $\mathrm{Ca}^{2+}$ activation of the ryanodine receptor.

The addition of $\mathrm{Mg}^{2+}$ increases the effects of doxorubicin and ADR-925 on the $\mathrm{Ca}^{2+}$ activation (Fig. 19). In this figure, doxorubicin increased total binding compared to the control. In the presence of $1 \mathrm{mM} \mathrm{Mg}^{2+}$, the $B_{\max }$ values were generally lower than in Fig. 18. Doxorubicin was observed to sensitize the receptor to activation by $\mathrm{Ca}^{2+}$. This was in agreement with both Fig. 18 as well as previously published data by Abramson et al. [1]. ADR-925 did not significantly alter the $B_{\max }$ of high affinity ryanodine binding. The fit parameters from the Hill analysis reveal a large increase in the $\mathrm{EC}_{50}$ for titrations in the presence of $300 \mu \mathrm{M}$ ADR925. The $\mathrm{EC}_{50}$ for the experiments without doxorubicin are $1.9 \mu \mathrm{M}$ and $8.4 \mu \mathrm{M}$, without and with $300 \mu \mathrm{M}$ ADR-925, respectively. The activation assays in the presence of $10 \mu \mathrm{M}$ doxorubicin show a shift of the $\mathrm{EC}_{50}$ from $1.0 \mu \mathrm{M}$ to $3.6 \mu \mathrm{M}$ in the presence of $300 \mu \mathrm{M}$ ADR-925. The Hill parameters in this experiment do not show significant differences for the four titrations. The Hill fit parameters are summarized in Table 3. 


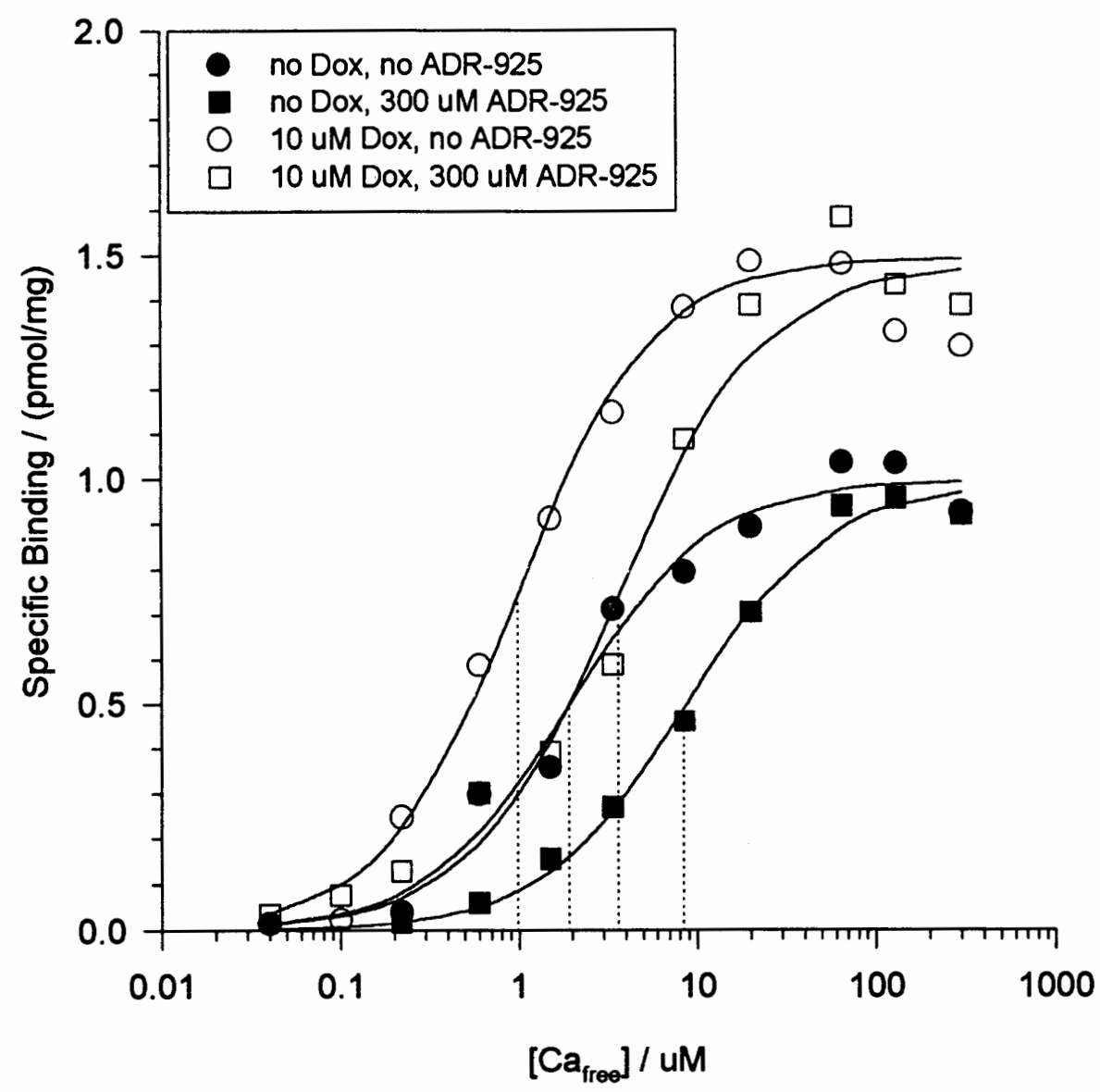

Figure 19: Effects of doxorubicin and ADR-925 on $\mathrm{Ca}^{2+}$ activation of ryanodine binding in the presence of $1 \mathrm{mM} \mathrm{Mg}^{2+}$. The experiment is carried out as described in Fig. 18 with the addition of $1 \mathrm{mM}$ free $\mathrm{Mg}^{2+}$. 


\begin{tabular}{r|rrrr} 
& $\begin{array}{c}B_{\max } \\
{[(\mathrm{pmol} / \mathrm{mg})]}\end{array}$ & $\begin{array}{c}k_{d} \\
{[\mu \mathrm{M}]}\end{array}$ & $n$ & $\begin{array}{r}\mathrm{EC}_{50} \\
{[\mu \mathrm{M}]}\end{array}$ \\
\hline $0 \mu \mathrm{M}$ ADR-925, $0 \mu \mathrm{M}$ doxorubicin & 1.0 & 2.1 & 1.1 & 1.9 \\
$300 \mu \mathrm{M}$ ADR-925, $0 \mu \mathrm{M}$ doxorubicin & 1.0 & 10.4 & 1.1 & 8.4 \\
$0 \mu \mathrm{M}$ ADR-925, $10 \mu \mathrm{M}$ doxorubicin & 1.5 & 1.0 & 1.1 & 1.0 \\
$300 \mu \mathrm{M}$ ADR-925, $10 \mu \mathrm{M}$ doxorubicin & 1.5 & 3.9 & 1.1 & 3.6
\end{tabular}

Table 3: Hill parameters for $\mathrm{Ca}^{2+}$ activation assay in the presence of $1 \mathrm{mM}$ $\mathrm{Mg}^{2+}$ (Fig. 19).

Double reciprocal analysis of the data reveals that the mechanism by which ADR-925 inhibits the binding of $\left[{ }^{3} \mathrm{H}\right]$ ryanodine is by competing with $\mathrm{Ca}^{2+}$ binding to its activation site on the RyR complex (Fig. 20).

\subsection{Ryanodine Association Experiments}

To better describe the interaction between ADR-925 and the ryanodine receptor, ryanodine association experiments were conducted. An example of an association experiment is shown in Fig. 21.

Chu et al. showed that $\mathrm{Mg}^{2+}$ slows ryanodine binding to the RyR [21]. The same effect can be seen for inhibition of $\left[{ }^{3} \mathrm{H}\right]$ ryanodine binding by low calcium concentrations (data not shown). In the presence of $\mathrm{Mg}^{2+}$, the inhibitor ADR-925 further slowed the time dependent process of $\left[{ }^{3} \mathrm{H}\right]$ ryanodine binding (Fig. 21). 


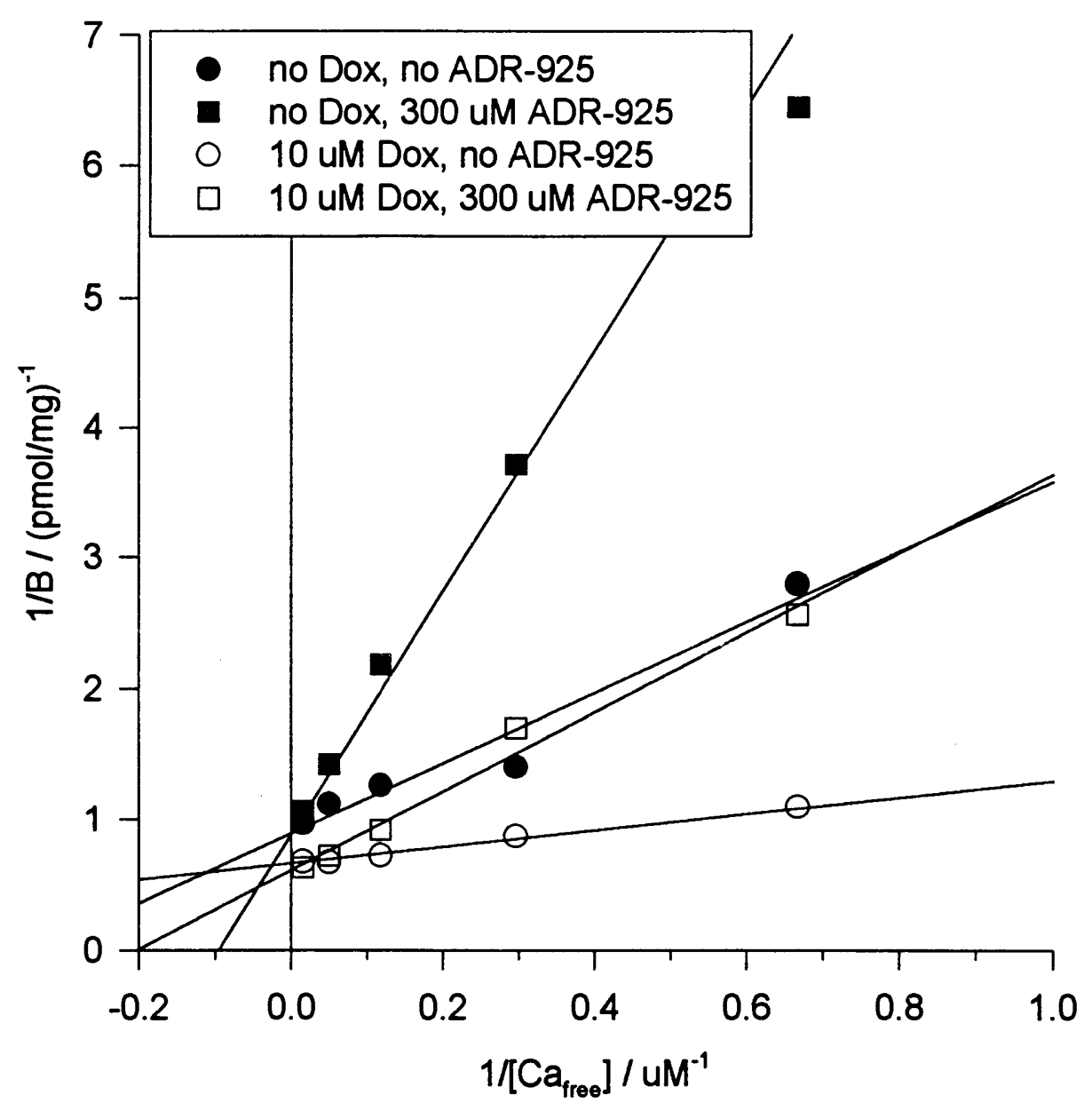

Figure 20: Double reciprocal analysis of ryanodine binding assay carried out in assay buffer containing $1 \mathrm{mM} \mathrm{Mg}^{2+}$ (Fig. 19). The linear regressions of $1 / \mathrm{B}$ vs. $1 /\left[\mathrm{Ca}_{\text {free }}\right]$ for both sets of experiments, without and with $10 \mu \mathrm{M}$ doxorubicin, intersect on the $y$-axes. This suggests that ADR-925 directly competes with $\mathrm{Ca}^{2+}$ at the activation site on the RyR. 


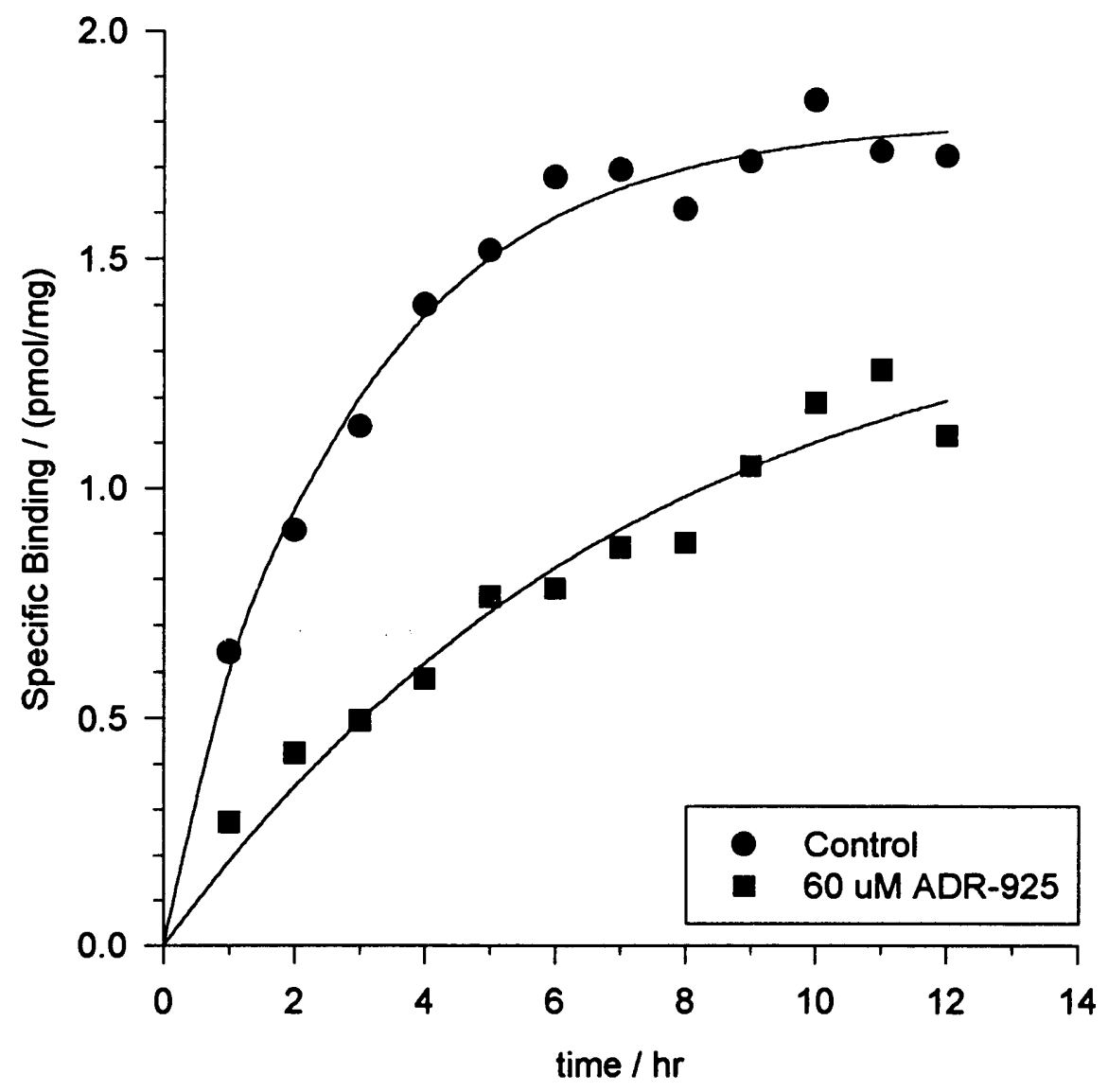

Figure 21: Time dependence of ryanodine binding. The assay was the same as described above. [Ca free] was adjusted to $1.5 \mu \mathrm{M}$ by additions of $70 \mu \mathrm{M}$ EGTA for the control experiment and $63 \mu \mathrm{M}$ EGTA for the experiment with $60 \mu \mathrm{M}$ ADR925. After the given time, samples were placed on ice in order to stop incubation. After 12 hours the samples were filtered as described in section 3.2.2. The data were fit to Eqn. (7) shown in the text. 
The binding data from this experiment were fit to a first order ligand receptor interaction equation:

$$
B=B_{\max }\left(1-e^{-k_{\text {obs }} \cdot t}\right)
$$

where $B$ is the amount of ryanodine bound at the time $t$. The fit from Fig. 21 yielded a $k_{\mathrm{obs}}=0.346 \mathrm{hr}^{-1}$ for the control and $k_{\mathrm{obs}}=0.133 \mathrm{hr}^{-1}$ in the presence of $60 \mu \mathrm{M}$ ADR-925. Therefore, in the presence of $1 \mathrm{mM} \mathrm{Mg}^{2+}$ and $1.5 \mu \mathrm{M} \mathrm{Ca}^{2+}$, the time required for $1 / 2$ of the maximum binding to occur was 2.0 hours and 5.2 hours for the control and the experiment with $60 \mu \mathrm{M}$ ADR-925, respectively. Interestingly, both fits reached the same maximal level of binding, approximately $1.6 \mathrm{pmol} / \mathrm{mg}$. In an experiment carried out over a longer time period than the one shown in Fig. 21, it was observed that ryanodine binding becomes unstable after incubation for longer than approximately 15 hours $\left(\right.$ at $\left.37^{\circ} \mathrm{C}\right)$. Therefore, equilibrium binding for the experiment shown in Fig. 21 is not reached before the receptor is damaged.

\subsection{Effects of ADR-925 on the $\left[\mathrm{H}_{2} \mathrm{O}_{2}\right]$ Depen- dence of Ryanodine Binding}

As described above it has been reported that doxorubicin in vivo becomes easily reduced to the semiquinone, which is oxidized by molecular $\mathrm{O}_{2}$ back to doxorubicin. 
This results in the production of superoxide anion. In the cell, superoxide is readily converted to hydrogen peroxide $\left(\mathrm{H}_{2} \mathrm{O}_{2}\right)$. High concentrations of $\mathrm{H}_{2} \mathrm{O}_{2}$ were shown to have a potent inhibitory effect on the $\mathrm{SR} \mathrm{Ca}^{2+}$ release mechanism [30]. The effects of ADR-925 on inhibition of receptor binding by $\mathrm{H}_{2} \mathrm{O}_{2}$ were examined in Fig. 22. The inhibition of $\left[{ }^{3} \mathrm{H}\right]$ ryanodine binding by $\mathrm{H}_{2} \mathrm{O}_{2}$ was significantly altered by $300 \mu \mathrm{M}$ ADR-925. The $\mathrm{IC}_{50}$ for $\mathrm{H}_{2} \mathrm{O}_{2}$ inhibition of binding shifted from $60 \mu \mathrm{M}$ (no ADR-925) to $200 \mu \mathrm{M}(+300 \mu \mathrm{M}$ ADR-925). 


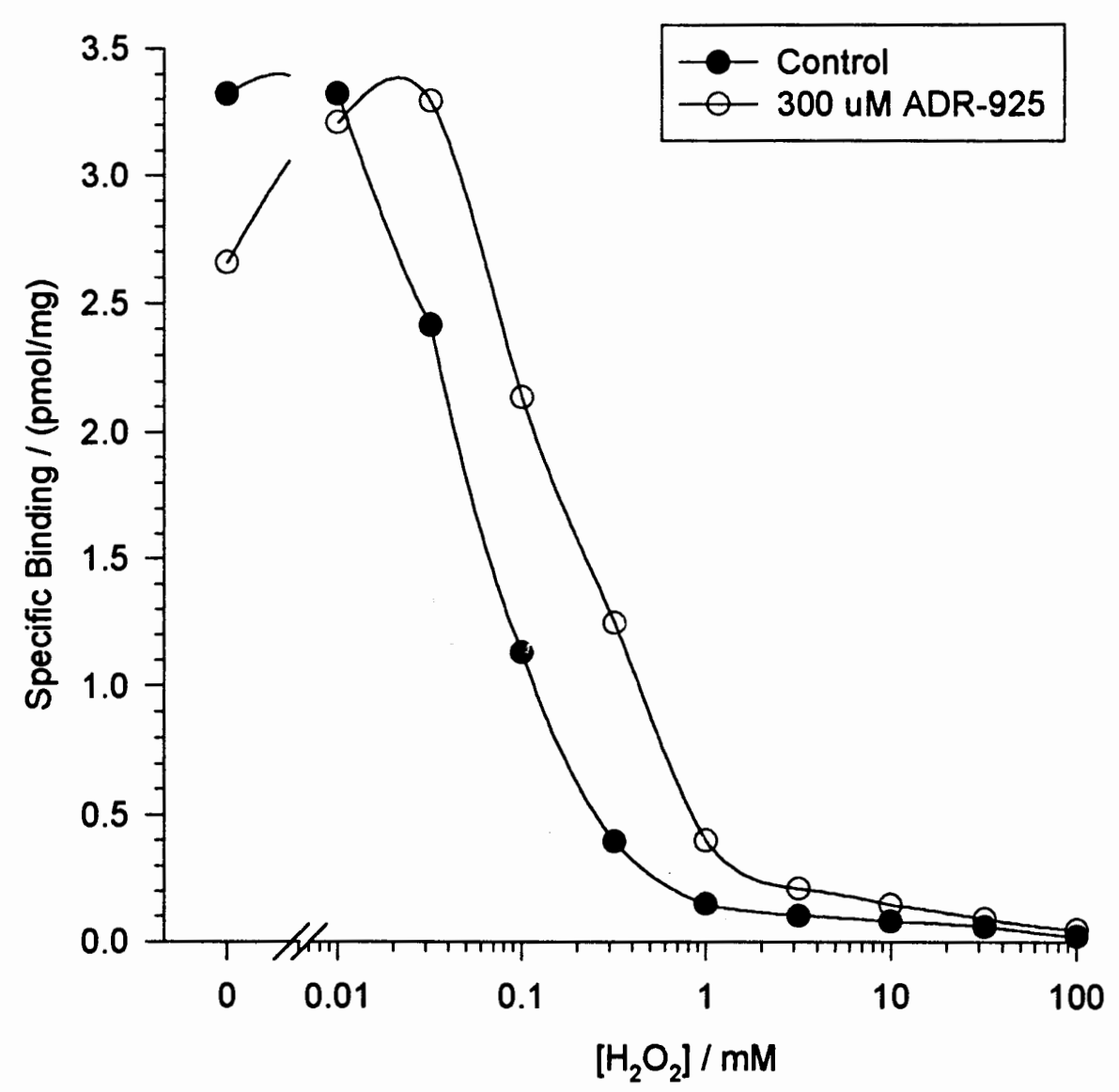

Figure 22: The effect of ADR-925 on the peroxide dependence of ryanodine binding. The binding assay was performed as described in Materials and Methods, (section 3.2.2) at $50 \mu \mathrm{M}\left[\mathrm{Ca}_{\text {free }}\right]$ and various concentrations of $\mathrm{H}_{2} \mathrm{O}_{2}$, in the presence or absence of ADR-925 $(300 \mu \mathrm{M})$. In the presence of ADR-925 the free calcium was adjusted to $50 \mu \mathrm{M}$ by the addition of $300 \mu \mathrm{M} \mathrm{CaCl}_{2}$. 


\section{Chapter 5}

\section{Discussion and Conclusion}

In this report, the combined interactions between doxorubicin and dexrazoxane on the $\mathrm{RyR} / \mathrm{Ca}^{2+}$ release channel have been examined. Dexrazoxane is a compound used as a cardioprotectant in doxorubicin cancer treatment. Once administered to the body, dexrazoxane is metabolized resulting in the formation of ADR-925. Initial experiments in this study have indicated that dexrazoxane has little effect on the transport properties of doxorubicin induced $\mathrm{Ca}^{2+}$ efflux from SR vesicles. This observation was supported by high affinity ryanodine binding measurements. Dexrazoxane had little effect on $\mathrm{Ca}^{2+}$ activated $\left[{ }^{3} \mathrm{H}\right]$ ryanodine binding. In contrast, the dexrazoxane metabolite ADR-925 was shown to directly modulate ryanodine binding. ADR-925 appears to alter the sensitivity of the ryanodine receptor to $\mathrm{Ca}^{2+}$ activation. It was clearly shown that ADR-925 but not dexrazoxane is the 
active compound responsible for the alteration of the calcium sensitivity of the RyR. Under physiological conditions and in the absence of activators, ADR-925 $(300 \mu \mathrm{M})$ increased the $\mathrm{EC}_{50}$ for $\mathrm{Ca}^{2+}$ activation approximately four-fold. Double reciprocal analysis of the $\mathrm{Ca}^{2+}$ activation data indicates a competitive interaction between $\mathrm{Ca}^{2+}$ activation and ADR-925 inhibition. This suggests that $\mathrm{Ca}^{2+}$ and ADR-925 interact with the same site on the RyR.

Surprisingly, ADR-925 did not reverse doxorubicin stimulated ryanodine binding. It appears that the inhibitory effect of ADR-925 on the release channel is independent of the doxorubicin concentration. Moreover, ADR-925 competitively interacts with the $\mathrm{Ca}^{2+}$ activation site of the ryanodine receptor. Abramson et al. have previously reported that doxorubicin sensitizes the $\mathrm{Ca}^{2+}$ activation of the ryanodine receptor. One possible cardioprotective mechanism of dexrazoxane may therefore be the reversal of this effect by ADR-925.

The effect of ADR-925 on $\mathrm{Ca}^{2+}$ activation of ryanodine binding may underlie a deeper physiological significance. Dexrazoxane/ADR-925 is administered to patients to combat the deleterious effects of doxorubicin on cardiac muscle. $\mathrm{Ca}^{2+}$ is thought to be the chemical trigger of EC coupling in cardiac muscle. Influences on $\mathrm{Ca}^{2+}$ induced $\mathrm{Ca}^{2+}$ release will therefore affect the EC coupling mechanism directly, and gain increased importance. Yet, it still has to be shown that the desensitizing effect of ADR-925 on $\mathrm{Ca}^{2+}$ activation also persists in cardiac muscle. 
Analysis of the stability constants [42] indicates that ADR-925 has a high binding affinity for iron (table 2). As described in section 2.1.1, iron has been speculated to play a primary role in free radical induced cardiotoxicity. However, this hypothesis has remained controversial. The significance of iron in cardiotoxic and cardioprotective mechanisms was not addressed in this report. The amount of iron available in vivo and in the SR preparations shown was not directly measured. The cardioprotective mechanism of dexrazoxane is not only due to the strong iron chelating action of its metabolite, ADR-925, but also may involve direct, ironindependent effects on the ryanodine receptor of the sarcoplasmic reticulum. These effects may be relevant to disrupting normal $\mathrm{Ca}^{2+}$ homeostasis in the muscle.

This laboratory has investigated the role of thiol oxidation in EC coupling and SR calcium release. The ability of the cardioprotective drug, ADR-925 to protect the release channel from oxidation by $\mathrm{H}_{2} \mathrm{O}_{2}$ supports the hypothesis that the redox state of critical thiols associated with the release channel play a role in EC coupling. The demonstrated ability of ADR-925 to protect the RyR from inhibition by peroxide suggests a significant role for ADR-925 in the free radical hypothesis of cardiotoxicity. $\mathrm{H}_{2} \mathrm{O}_{2}$ is a reactive byproduct produced during the generation of free radicals (Fig. 8). Therefore it is possible that alteration of peroxide induced channel inhibition by ADR-925 may play an important role in dexrazoxane's cardioprotection. However, further investigations will be necessary 


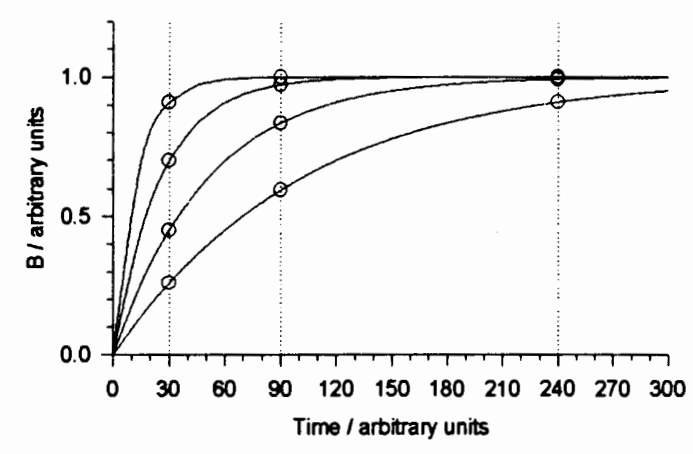

Figure 23: Example for the effect of different rate constants in a first order ligand receptor interaction.

to determine which mechanisms are directly responsible for dexrazoxane's action in the heart. At the present time, too little is known about the interactions of $\mathrm{H}_{2} \mathrm{O}_{2}$, ADR-925 and the RyR to draw further conclusions. It remains to be determined if ADR-925 and $\mathrm{H}_{2} \mathrm{O}_{2}$ competitively interact with one specific site on the RyR, if ADR-925 is shielding the $\mathrm{H}_{2} \mathrm{O}_{2}$ sensitive site, or if ADR-925 is modifying $\mathrm{H}_{2} \mathrm{O}_{2}$ or any of the other reactive oxygen intermediates.

Errors are sometimes introduced when alterations in parameters (i.e., $\mathrm{EC}_{50}$ ) are measured that may be time-dependent. This is demonstrated in Fig. 23. In this figure, first order ligand receptor interaction is shown for four different $k_{\text {obs }}$. Experiments carried out at earlier time points will yield less ryanodine binding but show differences in time kinetics more dramatically than experiments carried out closer to saturation. Therefore, the choice of the incubation time for ryanodine binding is an important factor in the design of the experiment. 
A good example of this are the $\mathrm{Ca}^{2+}$ activation assays presented in this thesis. In its role as an activator, $\mathrm{Ca}^{2+}$ affects the kinetics of ryanodine binding. The absence of the inhibitor, $\mathrm{Mg}^{2+}$ may bring $\left[{ }^{3} \mathrm{H}\right]$ ryanodine binding kinetics close to saturation and therefore mask the effect. This hypothesis is supported by the data presented for $\mathrm{Ca}^{2+}$ activation in absence of $\mathrm{Mg}^{2+}$. ADR-925 does not seem to shift the $\mathrm{Ca}^{2+}$ dependence significantly in the presence of doxorubicin, but does affect the control.

The mechanism of interaction between ADR-925 and the ryanodine receptor remains unclear. On the surface, at least two obvious possibilities exist which might explain this interaction. ADR-925 may inhibit the gating activity of the $\mathrm{Ca}^{2+}$ channel directly. This would be reflected in the ability of ADR-925 to decrease channel sensitivity to $\mathrm{Ca}^{2+}$ activation, which would result in lowered channel open probability. The decreased channel open probability would allosterically hinder ryanodine binding. Alternatively, ADR-925 may directly affect the binding affinity of the receptor for ryanodine. The ryanodine binding to its site is known to be calcium activated. Alterations in the ligand receptor kinetics may not directly reflect functional changes in the $\mathrm{Ca}^{2+}$ channel but may represent an artifact produced by the experimental assay. Either of these mechanisms would reflect the observations presented in this thesis. Further investigations using more direct assays measuring channel activity may help to resolve this issue. 
The results of this report may represent the basis of future investigations of the effects of ADR-925 on cardiac muscle SR. Single channel experiments should help detail changes in the gating characteristics as a result of exposure to ADR925. The role of iron in the process of cardiotoxocity and cardioprotection by dexrazoxane remains to be determined. This report may represent an important first step in understanding the role of the ryanodine receptor in cardiotoxicity and the mechanisms of cardioprotection. 


\section{Appendix}

\section{Software Description: WORSE}

The strong metal chelating abilities of ADR-925 required a tool for simple calculation of free concentrations of various metals in the presence of ADR-925. The different computer programs available in our laboratory were not able to include ADR-925 in the calculation. The software $B A D$ (Bound And Determined) did not allow input of new binding constants for substances not already included; the program CALCIUM did allow the input of new data, but could not handle the specific types of complexes that ADR-925 forms with metals. ADR-925 can either form a complex involving one ADR-925 molecule and one metal ion or two ADR925 molecules and one ion. The solution for these problems was the creation of a new computer program that could handle the substances used in this investigation. WORSE is able to determine the free concentrations of the metals $\mathrm{Ca}^{2+}, \mathrm{Mg}^{2+}$ and $\mathrm{Fe}^{2+}$ and the ligands EGTA and ADR-925. An additional algorithm allows 
the determination of a required total concentration to add to a solution to yield a given free concentration.

\section{Algorithms}

The flowchart of the program is shown in Fig. 24. The two central computational procedures are the determination of the free concentrations, and the modification of the total concentrations to yield a desired free concentration for one of the substances.

The algorithm for the determination of the free concentrations is shown in Fig. 25. Briefly, the iteration was initialized by setting the free concentrations equal to the total concentrations. As a first step in the iteration the free EGTA concentration was calculated as a function of the free ion concentrations according to the apparent stability constants:

$$
\left[\mathrm{EGTA}_{\text {free }}\right]=\frac{\left[\mathrm{EGTA}_{\text {tot }}\right]}{1+k_{11}\left[\mathrm{Ca}_{\text {free }}^{2+}\right]+k_{12}\left[\mathrm{Mg}_{\text {free }}^{2+}\right]+k_{13}\left[\mathrm{Fe}_{\text {free }}^{2+}\right]}
$$

$k_{i j}$ stands for the apparent stability constant for ligand $i$ and metal $j$. The apparent stability constants for EGTA were calculated on the base of equilibrium constants 


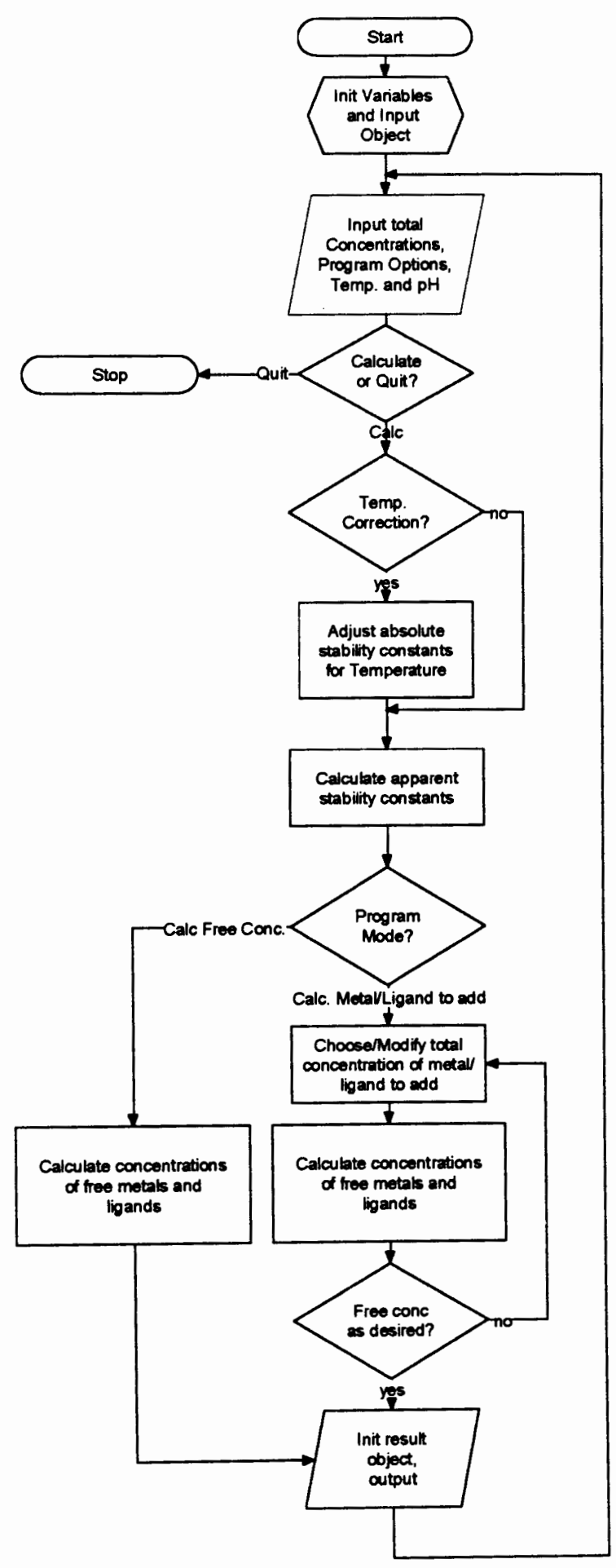

Figure 24: WORSE Flowchart. The two basic algorithms "Calculate concentrations of free metals and ligands" and "Choose/Modify total concentration of metal/ligand to add" are shown in detail in Fig. 25 and Fig. 26, respectively 


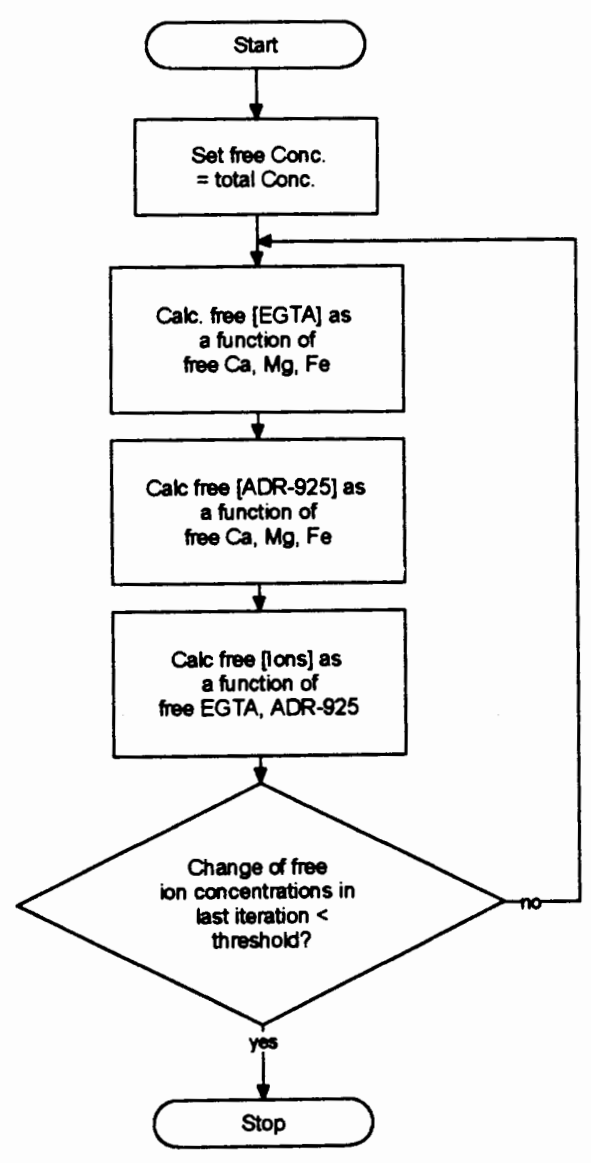

Figure 25: Flowchart of the algorithm used to determine the concentration of free metals and ligands 
given in [94]; the apparent stability constants for ADR-925 originated from [42]. A similar equation was used for ADR-925:

$$
\begin{aligned}
& {\left[\mathrm{ADR}-925_{\mathrm{free}}\right]} \\
& =\frac{\left[\mathrm{ADR}-925_{\mathrm{tot}}\right]}{1+k_{21}\left[\mathrm{Ca}_{\text {free }}^{2+}\right]+k_{21}^{*}\left[\mathrm{Ca}_{\text {free }}^{2+}\right]^{2}+k_{22}\left[\mathrm{Mg}_{\text {free }}^{2+}\right]+k_{22}^{*}\left[\mathrm{Mg}_{\text {free }}^{2+}\right]^{2}+k_{23}\left[\mathrm{Fe}_{\text {free }}^{2+}\right]}
\end{aligned}
$$

$k_{2 j}^{*}$ is the apparent stability constant for the complexes of ADR-925, that include two molecules of ADR-925 and one molecule of metal $j$. Based on the calculated free concentrations for the two ligands, the free concentration of the metals could be calculated.

$$
\begin{aligned}
b & =1+k_{1, j}[\mathrm{EGTA}]_{\text {free }}+k_{2, j}[\mathrm{ADR}-925]_{\text {free }} \\
{[\text { Ion }]_{\text {free }} } & =\frac{-b+\sqrt{b^{2}+8 k_{2, j}^{*} \cdot[\mathrm{ADR}-925]_{\text {free }} \cdot[\mathrm{Ion}]_{\text {tot }}}}{4 k_{2, j}^{*} \cdot[\mathrm{ADR}-925]_{\text {free }}}
\end{aligned}
$$

The iteration repeats, using the newly obtained free concentrations. The iteration was stopped after the relative change of the free concentration in the last cycle was below $0.1 \%$ for every compound.

The algorithm used for the calculation of the total concentration that yields a desired free concentration is shown in Fig. 26. The algorithm chooses a start value for the total concentration of the substance that is supposed to be varried. After the calculation of the resulting free concentration with the algorithm described before, the program adjusts the total concentration accordingly. The iteration stops if the yielded free concentration is in the range of $0.1 \%$ of the desired value. 


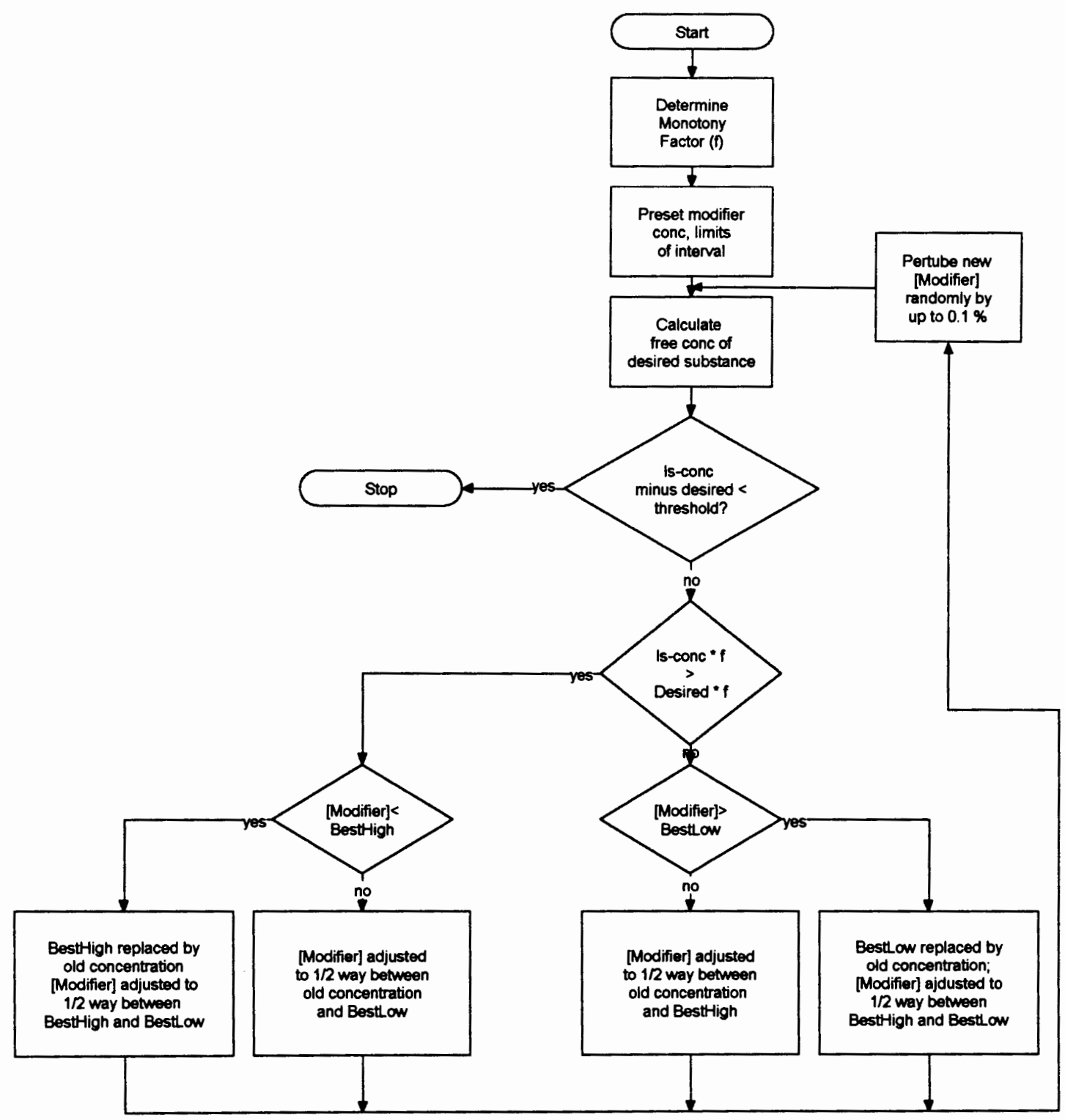

Figure 26: Flowchart of the algorithm that calculates the total concentration needed to yield a desired free concentration for one of the substances. [Modifier] is the total concentration of the substance that is varied in order to adjust the desired free concentration 


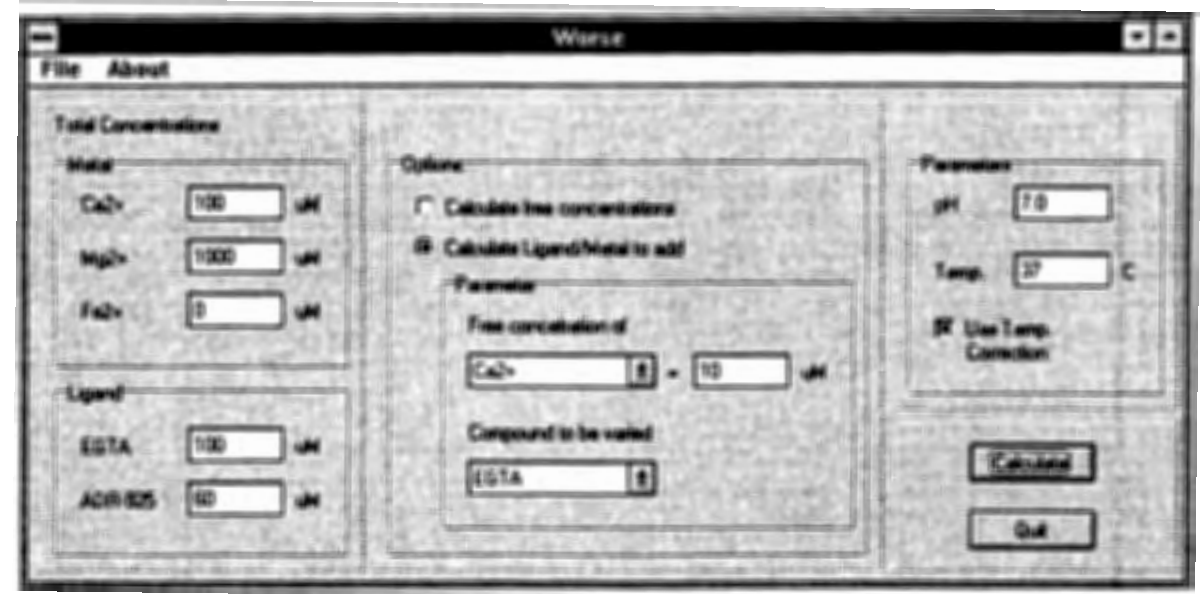

Figure 27: WORSE main screen

\section{Usage}

The present version of WORSE was supplied with a user friendly interface for Windows ${ }^{\circledR}$ 3.1. The program is started by a double click on the program icon in the program manager. The main window appears on the screen (Fig. 27). The total concentrations, the temperature and the $\mathrm{pH}$ can be entered. The program option Calculate free concentrations uses the input values to determine the free concentrations. The option Calculate Ligand/Metal to add finds the total concentration of the substance entered in Compound to be varied that is needed to obtain the free concentration of the substance chosen in Free concentration of. If the checkbox Use Temp. Correction is selected, the binding constants for EGTA will be corrected for the temperature given in temperature. Due to a lack of the 


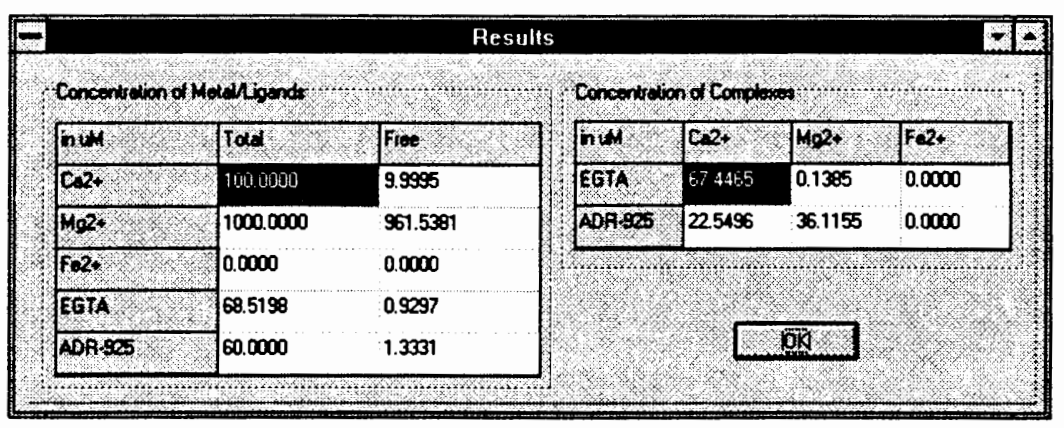

Figure 28: WORSE result screen

necessary information, the binding constants for ADR-925 can not be corrected for temperatures. If the temperature correction is off, the program calculates correct results for $37^{\circ} \mathrm{C}$. After clicking the calculate button, a separate result window (see Fig. 28) will pop up and display the total and free concentrations of the substances as well as the concentration of the complexes that emerge. The result screen has to be closed before modifications in the main screen are possible. The Quit button on the main screen ends the program. 


\section{Bibliography}

[1] J. J. Abramson, E. Buck, G. Salama, J. E. Casida, and I. N. Pessah. Mechanism of anthraquinone-induced calcium release from skeletal muscle sarcoplasmic reticulum. Journal of Biological Chemistry, 263(35):18750-18758, December 1988.

[2] J. J. Abramson and G. Salama. Sulfhydryl oxidation and $\mathrm{Ca}^{2+}$ release from sarcoplasmic reticulum. Molecular and Cellular Biochemistry, 82(1-2):81-84, July-August 1988.

[3] J. J. Abramson and G. Salama. Critical sulfhydryls regulate calcium release from sarcoplasmic reticulum. Journal of Bioenergetics and Biomembranes, 21(2):283-294, April 1989.

[4] J. J. Abramson, J. L. Trimm, L. Weden, and G. Salama. Heavy metals induce rapid calcium release from sarcoplasmic reticulum vesicles isolated 
from skeletal muscle. Proceedings of the National Academy of Sciences of the United States of America, 80(6):1526-1530, March 1983.

[5] W. S. Agnew. Dual roles for dhp receptors in excitation-contraction coupling? [news]. Nature, 328(6128):297, July 1987.

[6] W. S. Agnew. Excitation-contraction coupling. proteins that bridge the gap [news]. Nature, 334(6180):299-300, July 1988.

[7] P. Alderton, J. Gross, and M. D. Green. Role of (+-)-1,2-bis(3,5dioxopiperazinyl-1-yl)propane (ICRF-187) in modulating free radical scavenging enzymes in doxorubicin-induced cardiomyopathy. Cancer Research, 50(16):5136-5142, August 1990.

[8] K. Anderson, F. A. Lai, Q.Y. Liu, E. Rousseau, H. P. Erickson, and G. Meissner. Structural and functional characterization of the purified cardiac ryanodine receptor- $\mathrm{Ca}^{2+}$ release channel complex. Journal of Biological Chemistry, 264(2):1329-1335, January 1989.

[9] A. Ansaldi and S. I. Epstein. Calcium ion-selective electrode in which a membrane contacts graphite directly. Analytical Chemistry, 45(3):595-596, Mar 1973. 
[10] J. R. Baldwin, B. A. Phillips, S. K. Overmyer, N. Z. Hatfield, and P. K. Narang. Influence of the cardioprotective agent dexrazoxane on doxorubicin pharmacokinetics in the dog. Cancer Chemotherapy and Pharmacology, 30(6):433-438, 1992.

[11] M. J. Berridge and R.F. Irvine. Inositol trisphosphate, a novel second messenger in cellular signal transduction. Nature, 312(5992):315-321, November 1984.

[12] B. A. Block, T. Imagawa, K. P. Campbell, and C. Franzini-Armstrong. Structural evidence for direct interaction between the molecular components of the transverse tubule/sarcoplasmic reticulum junction in skeletal muscle. Journal of Cell Biology, 107(6.2):2587-2600, December 1988.

[13] Robert C. Bohinski. Modern Concepts in Biochemistry. Allyn and Bacon Inc., Boston, London, Sydney, Toronto, 3rd edition, 1979.

[14] R. J. Boucek Jr., R. D. Olson, D. E. Brenner, E. M. Ogunbunmi, M. Inui, and S. Fleischer. The major metabolite of doxorubicin is a potent inhibitor of membrane-associated ion pumps. a correlative study of cardiac muscle with isolated membrane fractions. Journal of Biological Chemistry, 262(33):15851-15856, November 1987. 
[15] M. R. Bristow, N. E. Kantrowitz, W. D. Harrison, W. A. Minobe, W. S. Sageman, and M. E. Billingham. Mediation of subacute anthracycline cardiotoxicity in rabbits by cardiac histamine release. Journal of Cardiovascular Pharmacology, 5(6):913-919, Nov-Dec 1983.

[16] E. Buck, I. Zimanyi, J. J. Abramson, and I. N. Pessah. Ryanodine stabilizes multiple conformational states of the skeletal muscle calcium release channel. Journal of Biological Chemistry, 267(33):23560-23567, November 1992.

[17] J. L. Buss and B. B. Hasinoff. Ferrous ion strongly promotes the ring opening of the hydrolysis intermediates of the antioxidant cardioprotective agent dexrazoxane (ICRF-187). Archives of Biochemistry and Biophysics, 317(1):121-127, February 1995.

[18] S. E. Cala, B. T. Scott, and L. R. Jones. Intralumenal sarcoplasmic reticulum $\mathrm{Ca}^{2+}$-binding proteins. Seminars in Cell Biology, 1(4):265-275, August 1990.

[19] C. C. Chadwick, M. Inui, and S. Fleischer. Identification and purification of a transverse tubule coupling protein which binds to the ryanodine receptor of terminal cisternae at the triad junction in skeletal muscle. Journal of Biological Chemistry, 263(22):10872-10877, August 1988. 
[20] W. K. Chandler, R. F. Rakowski, and M. F. Schneider. Effects of glycerol treatment and maintained depolarization on charge movement in skeletal muscle. Journal of Physiology, 254(2):285-316, January 1976.

[21] Alice Chu, Mauricio Diaz-Munoz, Mary Jane Hawkes, Kevin Brush, and Susan L. Hamilton. Ryanodine as a probe for the functional state of the skeletal muscle sarcoplasmic reticulum calcium release channel. Molecular Pharmacology, 37(5):735-741, May 1990.

[22] R. Coronado, J. Morrissette, M. Sukhareva, and D. M. Vaughan. Structure and function of ryanodine receptors. [review]. American Journal of Physiology, 266(6.1):C1485-1504, June 1994.

[23] M. Del Tacca, R. Danesi, M. Ducci, C. Bernardini, and A. Romanini. Might adriamycinol contribute to adriamycin-induced cardiotoxicity? Pharmacological Research Communications, 17(11):1073-1084, November 1985.

[24] E. J. Demant. Transfer of ferritin-bound iron to adriamycin. FEBS Letters, 176(4):97-100, October 1984.

[25] S. K. Donaldson, N. D. Goldberg, T. F. Walseth, and D. A. Huetteman. Voltage dependence of inositol 1,4,5-trisphosphate-induced $\mathrm{Ca}^{2+}$ release in peeled 
skeletal muscle fibers. Proceedings of the National Academy of Sciences of the United States of America, 85(15):5749-5753, August 1988.

[26] A. D. Dulhunty, P. R. Junankar, and C. Stanhope. Extra-junctional ryanodine receptors in the terminal cisternae of mammalian skeletal muscle fibres. Proceedings of the royal society of London. Series B: Biological Sciences, 247(1318):69-75, January 1992.

[27] R. S. Eisenberg. Membranes, calcium, and coupling. Canadian Journal of Physiology and Pharmacology, 65(4):686-690, April 1987.

[28] Roque El-Hayek, Bozena Antoniu, Jianping Wang, Susan L. Hamilton, and Noriaki Ikemoto. Identification of calcium release-triggering and blocking regions of the ii-iii loop of the skeletal muscle dihydropyridine receptor. The Journal of Biological Chemistry, 270(38):22116-22118, September 1995.

[29] Isaac N. Pessah et al. Calcium-ryanodine receptor complex. Journal of Biological Chemistry, 261(19):8643-8648, July 1986.

[30] T. G. Favero, A. C. Zable, and J. J. Abramson. Hydrogen peroxide stimulates the ca2+ release channel from skeletal muscle sarcoplasmic reticulum. Journal of Biological Chemistry, 270(42):25557-25563, October 1995. 
[31] C. Franzini-Armstrong. Studies of the triad I. structure of the junction in frog twitch fibers. Journal of Cell Biology, 47:488-499, 1970.

[32] C. Franzini-Armstrong and J. W. Kish. Alternate disposition of tetrads in peripheral couplings of skeletal muscle. Journal of Muscle Research and Cell Motility, 16(3):319-324, June 1995.

[33] Clara Franzini-Armstrong and Annelise O. Jorgensen. Structure and development of e-c coupling units in skeletal muscle. Annu. Rev. Physiol., 56:509-534, 1994.

[34] L. X. Fu, F. Waagstein, and $\AA$ Hjalmarson. A new insight into adriamycininduced cardiotoxicity. International Journal of Cardiology, 29:15-20, 1990.

[35] H. Gonzalez-Serratos, R. Valle-Aguilera, and D. A. Lathrop. Slow inward calcium currents have no obvious role in muscle excitation-contraction coupling. Nature, 298(5871):292-294, July 1982.

[36] S. Hagiwara, S. Ozawa, and O. Sand. Voltage clamp analysis of two inward current mechanisms in the egg cell membrane of a starfish. Journal of General Physiology, 65(5):617-644, May 1975. 
[37] B. B. Hasinoff. Pharmacodynamics of the hydrolysis-activation of the cardioprotective agent (+)-1,2-bis(3,5-dioxopiperazinyl-1-yl)propane. Journal of Pharmaceutical Sciences, 83(1):64-67, January 1994.

[38] B. B. Hasinoff. NADPH-cytochrome-P450 reductase promotes hydroxyl radical production by the iron complex of ADR-925, the hydrolysis product of ICRF-187 (dexrazoxane). Free Radical Research, 22(4):319-325, April 1995.

[39] B. B. Hasinoff and S. V. Kala. The removal of metal ions from transferrin, ferritin and ceruloplasmin by the cardioprotective agent ICRF-187 [(+)-1,2bis(3,5-dioxopiperazinyl-1-yl)propane] and its hydrolysis product ADR-925. Agents and Actions, 39(1-2):72-81, May 1993.

[40] Bertil Hille. Ionic channels of excitable membranes. Sinauer Associates Inc., Sunderland, Massachusetts, 1984.

[41] H. Hochster et al. Pharmacokinetics of the cardioprotector ADR-529 (ICRF187) in escalating doses combined with fixed-dose doxorubicin. Journal of the National Cancer Institute, 84(22):1725-1730, November 1992.

[42] Z-X. Huang, P. M. May, K. M. Quinlan, D. R. Williams, and A. M. Creighton. Metal binding by pharmaceuticals. part 2. interactions of $\mathrm{Ca}$ (II), $\mathrm{Cu}(\mathrm{II}), \mathrm{Fe}(\mathrm{II}), \mathrm{Mg}(\mathrm{II}), \mathrm{Mn}(\mathrm{II})$ and $\mathrm{Zn}(\mathrm{II})$ with the intracellular hydrolysis 
product of the antitumor agent ICRF 159 and its inactive homologue ICRF 192. Agents and Actions, 12:536-542, 1982.

[43] B. C. Husken, J. de Jong, B. Beekman, R. C. Onderwater, W. J. van der Vijgh, and A. Bast. Modulation of the in vitro cardiotoxicity of doxorubicin by flavonoids. Cancer Chemotherapy and Pharmacology, 37(1-2):55-62, 1995.

[44] A. F. Huxley. The activation of striated muscle and its mechanical response. Proceedings of the royal society of London. Series B: Biological Sciences, 178(50):1-27, June 1971.

[45] H. E. Huxley. The contraction of muscle. Scientific American, November 1958.

[46] H. E. Huxley. The mechanism of muscle contraction. Scientific American, 213:18-27, 1965.

[47] Hugh Huxley and Jean Hanson. Changes in the cross-striations of muscle during contraction and stretch and their structural interpretation. Nature, 173:973-976, May 1954.

[48] L. Hymel, M. Inui, S. Fleischer, and H. Schindler. Purified ryanodine receptor of skeletal muscle sarcoplasmic reticulum forms $\mathrm{Ca}^{2+}$-activated oligomeric 
$\mathrm{Ca}^{2+}$ channels in planar bilayers. Proceedings of the National Academy of Sciences of the United States of America, 85(2):441-445, January 1988.

[49] N. Ikemoto, B. Antoniu, J. J. Kang, L. G. Meszaros, and M. Ronjat. Intravesicular calcium transient during calcium release from sarcoplasmic reticulum. Biochemistry, 30(12):5230-5237, May 1991.

[50] T. Imagawa, J. S. Smith, R. Coronado, and K. P. Campbell. Purified ryanodine receptor from skeletal muscle sarcoplasmic reticulum is the $\mathrm{Ca}^{2+}-$ permeable pore of the calcium release channel. Journal of Biological Chemistry, 262(34):16636-16643, December 1987.

[51] M. Iniu, A. Saito, and S. Fleischer. Purification of the ryanodine receptor and identity with feet structures of junctional terminal cisternae of sarcoplasmic reticulum from fast skeletal muscle. Journal of Biological Chemistry, 262(4):1740-1747, February 1987.

[52] Donald G. Ivey. Physics in two volumes, classical mechanics and introductory statistical mechanics. The Ronald Press Company, New York, 1974.

[53] J. A. Jackson, J. P. Reeves, K. H. Muntz, D. Kruk, R. A. Prough, J. T. Willerson, and L. M. Buja. Evaluation of free radical effects and catecholamine alterations in adriamycin cardiotoxicity. American Journal of 
Pathology, 117(1):140-153, October 1984.

[54] E. Jaimovich, R. A. Venosa, P. Shrager, and P. Horowicz. Density and distribution of tetrodotoxin receptors in normal and detubulated frog sartorius muscle. Journal of general physiology, 67(4):399-416, April 1976.

[55] R. A. Jensen. Doxorubicin cardiotoxicity: contractile changes after long-term treatment in the rat. Journal of pharmacology and experimental therapeutics, 236(1):197-203, January 1986.

[56] H.M. Kalckar. Differential spectrophotometry of purine compounds by means of specific enzymes. Journal of Biological Chemistry, 167:461-475, 1047.

[57] D. H. Kim, A. B. 3rd. Landry, Y. S. Lee, and A. M. Katz. Doxorubicininduced calcium release from cardiac sarcoplasmic reticulum vesicles. Journal of Molecular and Cellular Cardiology, 21(5):433-436, May 1989.

[58] FB. Klugmann, G. Decorti, L. Candussio, V. Grill, and L. Mallardi, F. Baldini. Inhibitors of adriamycin-induced histamine release in vitro limit adriamycin cardiotoxicity in vivo. British Journal of Cancer, 54(5):743-748, November 1986.

[59] Radivoj V. Krstic. Illustrated encylcopedia of human histology. SpringerVerlag, Berlin, New York, 1984. 
[60] F. A. Lai, H. P. Erickson, E. Rousseau, and Q. Y. Liu. Purification and reconstitution of the calcium release channel from skeletal muscle. Nature, 331(6154):315-319, January 1988.

[61] G. Lambertenghi-Deliliers, P. L. Zanon, E. F. Pozzoli, and O. Bellini. Myocardial injury induced by a single dose of adriamycin: an electron microscopic study. Tumori, 62(5):517-528, Sep-Oct 1976.

[62] G. Liu, J. J. Abramson, A. C. Zable, and I. N. Pessah. Direct evidence for the existence and functional role of hyperreactive sulfhydryls on the ryanodine receptor-triadin complex selectively labeled by the coumarin maleimide 7-diethylamino-3-(4'-maleimidylphenyl)-4-methylcoumarin. Molecular Pharmacology, 45(2):189-200, February 1994.

[63] Pharmaceutical Information Associates Ltd. Dexrazoxane for cardioprotection in breast cancer therapy. Medical Sciences Bulletin, July 1995.

[64] Xiangyang Lu, Le Xu, and Gerhard Meissner. Activation of the skeletal muscle calcium release channel by a cytoplasmic loop of the dihydropyridine receptor. The Journal of Biological Chemistry, 269(9):6511-6516, March 1994. 
[65] DH. MacLennan. Purification and properties of an adenosine triphosphatase from sarcoplasmic reticulum. Journal of Biological Chemistry, 245(17):4508$4518,1970$.

[66] K. L. Malisza and B. B. Hasinoff. Doxorubicin reduces the iron(iii) complexes of the hydrolysis products of the antioxidant cardioprotective agent dexrazoxane (icrf-187) and produces hydroxyl radicals. Archives of Biochemistry and Biophysics, 316(2):680-688, February 1995.

[67] A. N. Martonosi. Mechanisms of $\mathrm{Ca}^{2+}$ release from sarcoplasmic reticulum of skeletal muscle. Physiological Reviews, 64(4):1240-1320, October 1984.

[68] R. T. Mathias, R. A. Levis, and R. S. Eisenberg. Electrical models of excitation-contraction coupling and charge movement in skeletal muscle. Journal of General Physiology, 76(1):1-31, July 1980.

[69] E. W. McCleskey, A.P. Fox, D. Feldman, and R. W. Tsien. Different types of calcium channels. Journal of Experimental Biology, 124:177-190, September 1986.

[70] G. Meissner. Isolation and characterization of two types of sarcoplasmic reticulum vesicles. Biochimica et Biophysica Acta, 389(1):51-68, April 1975. 
[71] G. Meissner. Monovalent ion and calcium ion fluxes in sarcoplasmic reticulum. Molecular and Cellular Biochemistry, 55(1):65-82, 1983.

[72] G. Meissner. Adenine nucleotide stimulation of $\mathrm{Ca}^{2+}$-induced $\mathrm{Ca}^{2+}$ release in sarcoplasmic reticulum. Journal of Biological Chemistry, 259(4):2365-2374, February 1984.

[73] G. Meissner, E. Darling, and J. Eveleth. Kinetics of rapid $\mathrm{Ca}^{2+}$ release by sarcoplasmic reticulum. effects of $\mathrm{Ca}^{2+}, \mathrm{Mg}^{2+}$, and adenine nucleotides. Biochemistry, 25(1):236-244, January 1986.

[74] Gerhard Meissner. Ryanodine receptor $/ \mathrm{Ca}^{2+}$ release channels and their regulation by endogenous effectors. Annual Review of Physiology, 56:485-508, 1994.

[75] F. M. Muggia. Cytoprotection: concepts and challenges. Supportive Care in Cancer, 2(6):377-379, November 1994.

[76] J. Nakai, T. Imagawa, Y. Hakamat, M. Shigekawa, H. Takeshima, and S. Numa. Primary structure and functional expression from cdna of the cardiac ryanodine receptor/calcium release channel. FEBS Letters, 271(12):169-177, October 1990. 
[77] H.'T. Narahara, V. G. Vogrin, J. D. Green, R.A. Kent, and M. K. Gould. Isolation of plasma membrane vesicles, derived from transverse tubules, by selective homogenization of subcellular fractions of frog skeletal muscle in isotonic media. Biochimica et biophysica acta, 552(2):247-261, April 1979.

[78] M. C. Nowycky, A. P. Fox, and R. W. Tsien. Three types of neuronal calcium channel with different calcium agonist sensitivity. Nature, 316(6027):440-443, August 1985.

[79] M. G. Nunzi and C. Franzini-Armstrong. Trabecular network in adult skeletal muscle. Journal of ultrastructure research, 73(1):21-26, October 1980.

[80] H. M. Olson, D. M. Young, D. J. Prieur, A. F. LeRoy, and R. L. Reagan. Electrolyte and morphologic alterations of myocardium in adriamycintreated rabbits. American Journal of Pathology, 77(3):439-454, December 1974.

[81] R. D. Olson and P. S. Mushlin. Doxorubicin cardiotoxicity: analysis of prevailing hypotheses. FASEB Journal, 4(13):3076-3086, October 1990.

[82] Isaac N. Pessah, Roxanne A. Stambuk, and John E. Casida. Ca ${ }^{2+}$-activated ryanodine binding: Mechanisms of sensitivity and intensity modulation by 
$\mathrm{Mg}^{2+}$, caffeine, and adenine nucleotides. Molecular Pharmacology, 31:232$238,1987$.

[83] C. Praga et al. Adriamycin cardiotoxicity: a survey of 1273 patients. Cancer Treatment Reports, 63(5):827-834, May 1979.

[84] M. Radermacher, T. Wagenknecht, R. Grassucci, J. Frank, M. Inui, C. Chadwick, and S. Fleischer. Cryo-em of the native structure of the calcium release channel/ryanodine receptor from sarcoplasmic reticulum. Biophysical Journal, 61(4):936-940, April 1992.

[85] S. Rajagopalan, P. M. Politi, B. K. Sinha, and C. E. Myers. Adriamycininduced free radical formation in the perfused rat heart: implications for cardiotoxicity. Cancer Research, 48(17):4766-4769, September 1988.

[86] E. Rios and G. Brum. Involvement of dihydropyridine receptors in excitationcontraction coupling in skeletal muscle. Nature, 325(6106):717-720, February 1987.

[87] E. Rios, G. Pizarro, and E. Stefani. Charge movement and the nature of signal transduction in skeletal muscle excitation-contraction coupling. Annual Review of Physiology, 54:109-133, 1992. 
[88] R. A. Sabbadini and A. S. Dahm. Biochemical properties of isolated transverse tubular membranes. Journal of bioenergetics and biomembranes, 21(2):163-213, April 1989.

[89] M. F. Schneider and W. K. Chandler. Voltage dependent charge movement of skeletal muscle: a possible step in excitation-contraction coupling. Nature, 242(5395):244-246, March 1973.

[90] Martin F. Schneider. Control of calcium release in functioning skeletal muscle fibers. Annu. Rev. Physiol., 56:463-484, 1994.

[91] L. M. Schwartz, E. W. McCleskey, and W. Almers. Dihydropyridine receptors in muscle are voltage-dependent but most are not functional calcium channels. Nature, 314(6013):747-751, April 1985.

[92] C. F. Seifert, M. E. Nesser, and Thompson D. F. Dexrazoxane in the prevention of doxorubicin-induced carditoxicity. The Annals of Pharmacotherapy, 28:1063-1072, September 1994.

[93] K. Shan, A. M. Lincoff, and J. B. Young. Anthracycline-induced cardiotoxicity. Annals of Internal Medicine, 125(1):47-58, July 1996.

[94] L. G. Sillen and A. E. Martell. Stability Constants of Metal-Ion Complexes. Chemical Society, London, 1964. 
[95] David S. Smith. Muscle. Academic Press, Inc., New York, 1972.

[96] J. S. Smith, R. Coronado, and G. Meissner. Single channel measurements of the calcium release channel from skeletal muscle sarcoplasmic reticulum. activation by $\mathrm{Ca}^{2+}$ and ATP and modulation by $\mathrm{Mg}^{2+}$. Journal of General Physiology, 88(5):573-588, November 1986.

[97] J. S. Smith, T. Imagawa, J. Ma, M. Fill, and K. P. Campbell. Purified ryanodine receptor from rabbit skeletal muscle is the calcium-release channel of sarcoplasmic reticulum. Journal of General Physiology, 92(1):1-26, July 1988.

[98] M. M. Sobol, R. G. Amiet, and M. D. Green. In vitro evidence for direct complexation of ADR-529/ICRF-187 [(+)-1,2-bis-(3,5-dioxo-piperazin1-yl)propane] onto an existing ferric-anthracycline complex. Molecular Pharmacology, 41(1):8-17, January 1992.

[99] E. Stefani and D. J. Chiarandini. Ionic channels in skeletal muscle. Annual Review of Physiology, 44:357-372, 1982.

[100] H. Takekura, L. Bennet, T. Tanabe, K. G. Beam, and C. Franzini-Armstrong. Restoration of junctional tetrads in dysgenic myotubes by dihydropyridine receptor cdna. Biophysical Journal, 67(2):793-803, August 1994. 
[101] H. Takeshima, S. Nishimura, T. Matsumoto, H. Ishida, K. Kangawa, N. Minamino, H. Matsuo, M. Ueda, M. Hanaoka, T. Hirose, and et al. Primary structure and expression from complementary dna of skeletal muscle ryanodine receptor. Nature, 339:439-445, June 1989.

[102] T. Tanabe, K. G. Beam, B. A. Adams, T. Niidome, and S. Numa. Regions of the skeletal muscle dihydropyridine receptor critical for excitationcontraction coupling. Letters to Nature, 346:567-569, August 1990.

[103] T. Tanabe, K. G. Beam, J. A. Powell, and S. Numa. Restoration of excitation-contraction coupling and slow calcium current in dysgenic muscle by dihydropyridine receptor complementary dna. Nature, 336(6195):134-139, November 1988.

[104] T. Tanabe, H. Takeshima, A. Mikami, V. Flockerzi, H. Takahashi, K. Kangawa, M. Kojima, H. Matsuo, T. Hirose, and S. Numa. Primary structure of the receptor for calcium channel blockers from skeletal muscle. Nature, 328(6128):313-318, July 1987.

[105] Thomas scientific catalog, 1996.

[106] C. Thomas, G. F. Vile, and C. C. Winterbourn. The hydrolysis product of ICRF-187 promotes iron-catalysed hydroxyl radical production via the 
fenton reaction. Biochemical Pharmacology, 45(10):1967-1972, May 1993.

[107] J. L. Trimm, G. Salama, and J. J. Abramson. Sulfhydryl oxidation induces rapid calcium release from sarcoplasmic reticulum vesicles. Journal of Biological Chemistry, 261(34):16092-16098, December 1986.

[108] M. Valdeolmillos, S. C. O'Neill, G. L. Smith, and D. A. Eisner. Calciuminduced calcium release activates contraction in intact cardiac cells. Pflugers Archiv. European Journal of Physilogy, 413(6):676-678, April 1989.

[109] J. F. Van Vleet, V. J. Ferrans, and W. E. Weirich. Cardiac disease induced by chronic adriamycin administration in dogs and an evaluation of vitamin $\mathrm{E}$ and selenium as cardioprotectants. American Journal of Pathology, 99(1):1342, April 1980.

[110] R. A. Venosa and P. Horowicz. Density and apparent location of the sodium pump in frog sartorius muscle. Journal of Membrane Biology, 59:225-232, 1981.

[111] J. Vergara, R. Y. Tsien, and M. Delay. Inositol 1,4,5-trisphosphate: a possible chemical link in excitation-contraction coupling in muscle. Proceedings of the National Academy of Sciences of the United States of America, 82(18):62526256, September 1985. 
[112] G. F. Vile and C. C. Winterbourn. dl-N, $\mathrm{N}^{\prime}$-dicarboxamidomethyl$\mathrm{N}, \mathrm{N}^{\prime}$-dicarboxymethyl-1,2-diaminopropane (ICRF-198) and d-1,2-bis(3,5dioxopiperazine-1-yl)propane (ICRF-187) inhibition of $\mathrm{Fe}^{3+}$ reduction, lipid peroxidation, and CaATPase inactivation in heart microsomes exposed to adriamycin. Cancer Research, 50(8):2307-2310, April 1990.

[113] M. Villaz, M. Robert, L. Carrier, T. Beeler, B. Rouot, M. Toutant, and Y. Dupont. G-protein dependent potentiation of calcium release from sarcoplasmic reticulum of skeletal muscle. Cellular Signalling, 1(5):493-506, 1989.

[114] P. Volpe, G. Salviati, F. Di-Virgilio, and T. Pozzan. Inositol 1,4,5trisphosphate induces calcium release from sarcoplasmic reticulum of skeletal muscle. Nature, 316(6026):347-349, July 1985.

[115] T. Wagenknecht, R. Grassucci, J. Frank, A. Saito, M. Inui, and S. Fleischer. Three-dimensional architecture of the calcium channel/foot structure of sarcoplasmic reticulum. Nature, 338(6211):167-170, March 1989.

[116] Raymond B. Weiss. The anthracyclines: Will we ever find a better doxorubicin? Seminars in Oncology, 19:670-686, 1992.

[117] World Precision Instruments, Inc. IE Series Liquid Ion Exchangers. 
[118] K. Yano and A. Zarain-Herzger. Sarcoplasmic reticulum calsequestrins: structural and functional properties. Molecular and Cellular Biochemistry, 135(1):61-70, June 1994.

[119] N. F. Zaidi, C. F. Lagenaur, R. J. Hilkert, Xiong-H., J. J. Abramson, and G. Salama. Disulfide linkage of biotin identifies a $106-\mathrm{kDa} \mathrm{Ca}^{2+}$ release channel in sarcoplasmic reticulum. Journal of Biological Chemistry, 264(36):21737-21747, December 1989.

[120] F. Zorzato, G. Salviati, T. Facchinetti, and P. Volpe. Doxorubicin induces calcium release from terminal cisternae of skeletal muscle. a study on isolated sarcoplasmic reticulum and chemically skinned fibers. Journal of Biological Chemistry, 260(12):7349-7355, June 1985.

[121] J. L. Zweier, L. Gianni, J. Muindi, and C. E. Myers. Differences in $\mathrm{O}_{2}$ reduction by the iron complexes of adriamycin and daunomycin: the importance of the sidechain hydroxyl group. Biochimica et Biophysica Acta, 884(2):326-336, 1986. 